\title{
City Minimum Wages and Spatial Equilibrium Effects
}

\author{
Jorge Pérez Pérez* \\ This draft: May 18th, 2022
}

\begin{abstract}
This paper studies the effect of minimum wage changes on spatial equilibriums in local labor markets. Using data for the U.S. and minimum wage variation across state borders, I analyze how commuting, residence, and employment locations change in response to local minimum wage changes. I find that areas where the minimum wage increases receive fewer low-wage commuters. I formulate a spatial equilibrium model and calculate counterfactuals with a higher minimum wage for U.S. cities considering an increase. For small minimum wage increases, most counties would receive higher low-wage commuting and have fewer low-wage residents. As minimum wage increases are larger, there are higher low-wage commuting reductions driven by employment relocation.
\end{abstract}

\section{Introduction}

Local minimum wage laws are becoming common across cities in the United States. The federal minimum wage has remained constant at $\$ 7.25$ an hour since 2009, leading city governments to raise the minimum wage themselves. Recently, Seattle and New York City increased their minimum wage to an unprecedented $\$ 15$ an hour. Political movements are pushing for rises in several other cities and an increase in the federal minimum wage.

*Banco de México. Email: jorgepp@banxico.org.mx. A previous version of this paper was circulated as "City Minimum Wages". This paper is part of my Ph.D. dissertation at Brown University. I am grateful to my advisors John Friedman, Pascal Michaillat and, especially, Matthew Turner for their guidance. I also thank Nathaniel Baum-Snow, Kenneth Chay, Andrew Foster, Nathaniel Hilger, Brian Knight, Guy Michaels, Emily Oster, Alejandrina Salcedo, and anonymous referees at Banco de México for their feedback. I also benefited from conversations with Lorenzo Aldeco, Guillermo Alves, Juan Pablo Chauvin, Emilson Caputo Delfino Silva, David Glancy, Guy Michaels, Joan Monras, Heitor Pellegrina, Nickolai Riabov, Lucas Scottini, Nate Schiff, and seminar participants at the American Association of Geographers, Banco de México, Brown University, CIDE, EALE-SOLE-AASLE, IAB-LASER, LAMES 2019, Universidad del Rosario, Universidad Javeriana, and the Urban Economics Association. I thank Jonathan Meer and Jesús Otero for providing data. David Bernal, Carolina Crispín and Diego Mayorga provided great research assistance. I acknowledge support from Fulbright-Colciencias and S4 at Brown. All errors are my own. 
A key feature of cities is the interaction of labor markets between the city and its surroundings. Cities attract migrants and commuters from surrounding areas. From a policy perspective, the effects of a higher city minimum wage may differ from state- or countrywide policy effects because the former may alter the spatial equilibrium between the city and its surroundings. From the labor supply side, a higher minimum wage may induce additional workers to search for a job in the area, thereby expanding commuting, migration, and labor force participation. However, higher minimum wages may become exclusionary because they may make places less attractive to live in by translating into higher housing rents. From the labor demand side, a higher minimum wage makes workers more expensive for firms, possibly reducing labor demand and inducing firms to relocate towards lower-minimum-wage areas.

This paper studies the reaction of city labor markets to minimum wage changes in a spatial equilibrium context. Through a reduced-form analysis and a structural model of location choice, I look at how employment, commuting, and migration into cities change if the city's minimum wage changes and how these changes relate to each local labor market's features. With the model, I build counterfactual equilibriums for U.S. cities considering minimum wage increases, thus highlighting commuting and migration responses.

In the first part of the paper, I undertake a reduced-form analysis to examine how commuting, migration, and employment change if the minimum wage changes. Because of the recent nature of city minimum wage policies, there is a limited sample of city policies to evaluate. I focus instead on borders between states in which labor markets are as well connected as they are in cities and in which the minimum wage has evolved differently on either side of the border because of state policy. I employ two identification strategies relying on different comparisons. In a first strategy, I compare commuting flows and employment differences in adjacent cross-state-border areas where the minimum wage has diverged across border sides with other cross-border areas where minimum wage differences have remained constant. In a second strategy, I compare cross-border commuting flows and cross-border employment differences that have been affected by minimum wage changes with the corresponding flows and differences in within-state counterparts that have not been so affected.

I show that a higher minimum wage is associated with reductions in commuting. A 10 percent higher minimum wage is associated with a 1.9 to 2.5 percent reduction in commuting by low-wage workers to the side of the border that increased the minimum wage. An examination of the drivers behind this effect reveals that low-wage employment shifts from the higher-minimum wage side of the border toward the lower-minimum wage side. My estimates for migration responses are imprecise but do not rule out emigration from higher minimum wage areas.

The reduced-form analysis highlights that the effect of the minimum wage in cities in- 
volves labor supply and demand responses. To disentangle these effects and study the mechanisms through which higher minimum wages affect the city equilibrium, I formulate a quantitative urban model of cities with a minimum wage in the second part of the paper. The model's distinctive feature is the presence of unemployment in labor markets, which has been absent in recent urban economics models. I consider labor markets with employment rationing and matching frictions. By introducing this framework, I can analyze differences in employment probabilities across areas and how they react to the minimum wage. Higher minimum wages change expected wages, employment, and housing prices. In the model, although higher minimum wages attract more low-skill job-seekers to an area, they may reduce labor demand and reduce the number of vacancies. Therefore, the higher minimum wage may reduce the employment probability in equilibrium. The overall effect on commuting and migration depends on the relative strength of these effects. Through the model's lens, I relate my empirical findings to the magnitude of these adjustment margins. The model allows me to study minimum wage effects beyond an average across cities and allows extrapolation to future minimum wage increases larger than past increases.

In the last part of the paper, I fit the model to commuting data for cities in 26 counties currently considering minimum wage increases. ${ }^{1}$ To fit the model, I estimate the parameters that drive the relative strength of wage and employment effects. I use two different estimation strategies for these parameters: first, maximum likelihood estimation using the variation in commuting over time and wage groups across areas in the same city. Second, methodof-moments estimation using an orthogonality condition between model fundamentals and changes in cross-border differences in the minimum wage over time. I then calculate how labor markets would react to a higher minimum wage. I borrow estimates from the literature for another set of parameters and calibrate the remaining parameters to match local labor market data. The counterfactual scenarios complement the reduced form analysis by highlighting the role of employment and migration responses. Most counties would experience increases in low-wage commuting and losses in low-wage residents. As the minimum wage increases are larger, low-wage commuting elasticities become more negative. Differences in search and employment probabilities drive the heterogeneity in the response across cities. Some cities experience increases in job-seeking and reductions in employment probabilities, translating into lower commuting and low-skill employment.

This paper contributes to the literature on the minimum wage and quantitative urban models in three ways. First, it estimates the elasticities of commuting and migration to

\footnotetext{
${ }^{1}$ Specifically, I consider counties that have cities considering minimum wage increases starting in 2018, after the final period of my data. I use data on local minimum wage policies from National Employment Law Project (2016) and Dube and Lindner (2021).
} 
minimum wages at the local level and relates them to the minimum wage's employment effects. It joins a broad literature on the effects of minimum wages on employment. Belman and Wolfson (2014) survey this literature and conclude that minimum wages do not have a substantial negative effect on employment. Cengiz et al. (2019) do not find evidence of disemployment effects from higher minimum wages in the U.S., except for some limited effects in tradeable sectors. Among the papers that find negative effects, employment elasticity to the minimum wage is around -0.1. The estimates of the elasticity of commuting to minimum wages shown here are larger, suggesting that employment effects may be more significant for commuters or larger in cities.

Within the broad minimum wage literature, this paper joins a recent research branch that examines minimum wage effects in a spatial equilibrium. This literature tends to find larger negative employment effects and large negative elasticities of labor demand. Cadena (2014) shows that immigrants to the United States tend to migrate to states with a lower minimum wage. Monras (2019) builds a spatial equilibrium model with the minimum wage and shows how traditional state panel designs that ignore spatial equilibrium may understate a minimum wage's employment effects. Kuehn (2016) shows that border designs may misstate the effects of minimum wages when there are commuting spillovers. McKinnish (2017) shows that workers are more likely to commute out of state when the minimum wage in their state increases. In contrast, Shirley (2018) finds that higher minimum wage differentials increase commuting probabilities modestly. Unlike McKinnish (2017) and Shirley (2018), this paper examines commuting flows explicitly and models the reaction of other groups of workers beyond low-wage workers.

The paper's second contribution is to provide evidence of local minimum wages' effects beyond case studies and analyze upcoming minimum wage increases. Dube et al. (2007) find positive wage effects and negligible employment effects associated with San Francisco's 2003 minimum wage increase. Regarding recent increases, Jardim et al. (Forthcoming) find large reductions in hours of work associated with Seattle's 2016 minimum wage increase, and Jardim et al. (2018) find that workers made up lost hours by working outside of the city. Leamer et al. (2018) provide preliminary evidence of a large employment decrease in limited-service restaurants in California following the minimum wage increase starting in 2016. Dube and Lindner (2021) argue that the evidence on local minimum wages suggests their effects are similar to the effects of their state and national counterparts but do not analyze commuting explicitly. By using borders between states with labor markets that are as connected as cities, I provide evidence on a large sample. This paper explicitly models the migration and commuting responses to the minimum wage, which are more likely to be relevant in cities. 
This paper's last contribution is to introduce unemployment into a quantitative spatial equilibrium urban model with discrete choice (Redding and Rossi-Hansberg 2017). The paper is closely related to Monte et al. (2018) and Ahlfeldt et al. (2015). Monte et al. (2018) show how employment elasticities to productivity shocks may vary across locations depending on how commuting and migration respond. They also show how traditional designs for estimating the impact of productivity shocks that ignore this heterogeneity may be biased. However, these papers work in an environment of full employment wherein extra productivity fully translates into employment. Here, I use a search framework to model the response of employment and commuting to wage shocks in an unemployment environment. Ahlfeldt et al. (2015) formulate a spatial equilibrium model of city structure and use the fall of the Berlin Wall as a natural experiment to estimate agglomeration effects. The present paper uses the variation in the minimum wage in an analogous fashion. Zhang (2018) formulates a spatial job search model to analyze local minimum wage hikes' distributional effects. This paper focuses on the effects of cities that are in the process of increasing their minimum wage. Bilal (2020) proposes a theory of spatial equilibrium with unemployment and job search, where workers only search for jobs where they live.

This paper has seven sections. Section 2 outlines the reduced form analysis to estimate the minimum wage effect on commuting and employment locally. Section 3 formulates an urban model with unemployment to highlight the effects of a minimum wage in spatial equilibrium. Section 4 shows how a minimum wage alters commuting, migration, and employment in the model's context. Section 5 shows how to fit the model to commuting and employment data. Section 6 calculates counterfactuals for cities considering minimum wage increases. Section 7 concludes. Five appendixes illustrate details on data, the calculation of equilibriums and counterfactuals of the model, and additional results.

\section{Reduced-Form Evidence}

This section provides evidence on the effects of the minimum wage on worker locations. I look at how commuting flows, resident shares, and employment shares change in state border areas if the minimum wage changes on either side of the border. The analysis suggests that the minimum wage significantly affects local labor supply and demand and motivates the quantitative model that follows. 


\subsection{Data and Sample Construction}

Commuting data. The main data source is the Longitudinal Employer-Household Dynamics Program's Local Origin and Destination Employment Statistics (LODES) version 7.4 (2002-17). ${ }^{2}$ For each pair of census blocks in the United States, the data count the number of workers who live in the first census block and work in the second census block. I refer to these as origin-destination pairs. The data come from administrative sources such as unemployment insurance claims, firm data from the Quarterly Census of Employment and Wages, and additional surveys.

An ideal empirical design would be comparing cities that experience a change in the local minimum wage and cities that do not experience such a change. However, relatively few cities have implemented local minimum wage laws, and most of these have only done so very recently. As of 2020, 42 localities had local minimum wage laws, and more than half of these laws were implemented after 2013. To overcome this sample limitation, I focus on areas close to state borders for the empirical analysis instead of looking at cities. This extended geographical focus gives a large number of locations and minimum wage changes.

I use the minimum wage variation in adjacent areas on either side of the borders to estimate the minimum wage change effects. The use of state borders minimizes the impact of local labor market shocks in explaining shifts in commuting and migration. Any observed change in these variables must be due to policy changes that affect only one side of the border, such as the minimum wage.

This local approach has advantages over previous analyses of minimum wage effects in spatial equilibrium. McKinnish (2017) and Shirley (2018) study cross-state commuting and the minimum wage using public use microdata areas (PUMAs). Because PUMAs are generally larger than counties, this analysis may miss effects that emerge only in smaller local areas. Manning and Petrongolo (2017) show that local labor markets are relatively local in extent, so that job attractiveness substantially diminishes if jobs are more than one kilometer away.

Here, to examine effects on commuting, I calculate flows within and across states for all state borders in the United States. ${ }^{3}$ Specifically, I look at a band that stretches 11 kilometers on each side of state borders. I choose this bandwidth because the average commute length in the United States is about 22 kilometers (Kneebone and Holmes 2015). However, for robustness, I also use larger bandwidths in some of the analyses. I then sum the flows in

\footnotetext{
${ }^{2}$ For details on LODES data, see U.S. Census Bureau (2016) and U.S. Census Bureau (2019). The public release contains some noise to avoid confidentiality issues because of the fine geographical level. Appendix A.2 provides details on the imputation process.

${ }^{3}$ I exclude counties from AK, AZ, AR, DC, MA, MS, NH, or WY because of missing commuting data. I also exclude counties where the local minimum wage is higher than the state's wage.
} 
county pairs. This aggregation mitigates the workers' residential locations imputation in census blocks in the LODES data and allows county covariates in the regression analysis. It also mitigates concerns about zero commuting between county-pairs and granularity (Dingel and Tintelnot 2021) that may affect both the reduced-form analysis and the model in section 3.

Extent of cross-border commuting. There are many low-wage cross-border commuters every year. From 2002 to 2017, around 200,000 people commuted across state borders on trips shorter than 11 kilometers. By 2017, cross-border commuting accounted for around 10 percent of total commuting by low-wage workers in these areas every year. ${ }^{4}$

Sample selection. There are some potential issues involved in extrapolating from evidence on state borders to an analysis of future city policy. I select the sample to make state borders comparable with city borders and mitigate the differences between them. City borders may be more populated than state borders. Also, it may be easier for workers to commute or migrate across city borders. I choose a sample of border county pairs that exhibits high total cross-state commuting across the sample. This choice excludes borders with low population and borders across which workers do not commute (for example, the Nevada-Utah border). I divide the county pairs into five clusters according to total crossborder commuting using k-means cluster analysis. Then, I exclude the cluster with the lowest commuting from the sample. The exclusion amounts to omitting county pairs that have fewer than 150 commuters a year. ${ }^{5}$

Figure 1 shows the counties included in the sample. Most of these counties locate in cross-border metropolitan statistical areas or in densely populated borders. Figures J.4 and J.5 on appendix J show the amount of cross-border commuters these counties send and receive.

I focus on private-sector workers who commute for their primary jobs. The LODES data counts workers over three wage categories: below $\$ 1,250$ a month, between $\$ 1,250$ and $\$ 3,333$ a month, and over $\$ 3,333$ a month. I label these categories as low, middle, and highwage workers, respectively. Most minimum-wage workers fall among the low-wage category, although the minimum wage is sufficiently high in some states for the later years that they could fall in the middle category. ${ }^{6}$

\footnotetext{
${ }^{4}$ Figure $\mathrm{J} .2$ in appendix $\mathrm{J}$ shows how commuting varies across time at different distances from state borders.

${ }^{5}$ The commuting and migration responses may be different in connected areas compared to non-connected areas. For example, workers may be more responsive to wage differences across space in connected areas. Differences in commuting costs should account for this heterogeneity.

${ }^{6}$ Table J.1 of appendix J lists the states and years in which minimum wage workers would be in the second category. The results in section 2.3 are robust to excluding these observations or to a redefinition of minimum wage workers to include the second category in these states for all years.
} 
Figure 1: Included counties in sample

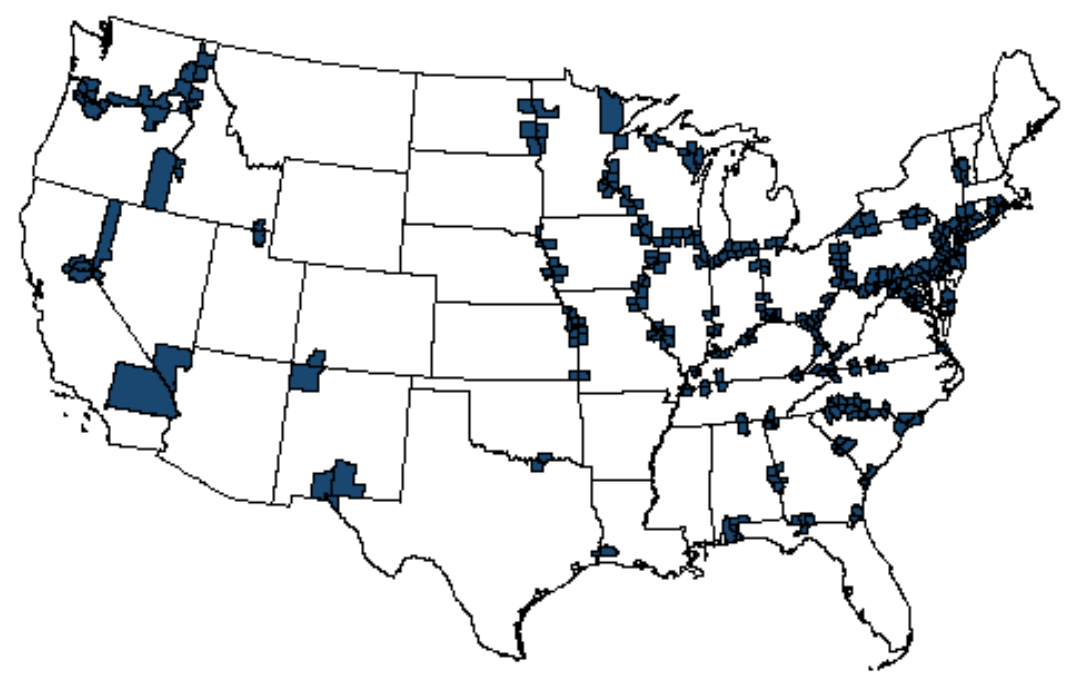

Highlighted counties are included in the reduced form analysis sample.

To examine migration and employment relocation effects, I use LODES data to compute residents' and employees' shares in each wage category for each location. Then, I focus on low-wage employees and residents.

Minimum wage data. For minimum wages, I use the average monthly U.S. state minimum wage from data compiled by Neumark et al. (2014) and Clemens et al. (2018). ${ }^{7}$

Figure 2 shows differences in the minimum wage between neighboring states. If these differences were nonexistent because neighboring states always kept the minimum wage equal, it would be hard to attribute commuting changes to minimum wage policy. It turns out that the differences are substantial. Although the median difference is 0 for most of the time frame, it increases to about $\$ 0.50$ an hour in 2007 before slightly decreasing through 2012. Then, the median difference increases again, to reach about $\$ 0.80$ an hour in 2017. There is substantial heterogeneity in these differences across state pairs every year. ${ }^{8}$

Additional data. I also compile a series of county-level controls that vary over time and may influence commuting behavior. These variables are total population across different age profiles, lags in county unemployment rates, county labor force, establishment counts, corporate taxes, tax credits, and gas prices. Details on the sources are in appendix A.1.

\footnotetext{
${ }^{7}$ For robustness, I also use the data of Vaghul and Zipperer (2016). The main results of section 2.3 are robust to this change.

${ }^{8}$ Figure J.3 of appendix J plots the average minimum wage across states during the sample period. There has been a steady increase in the minimum wage across states. Most of the increase occurred between 2006 and 2010. The median minimum wage across states is equal to the federal minimum wage through most of the decade.
} 
Figure 2: Differences in minimum wages between neighbor U.S. states

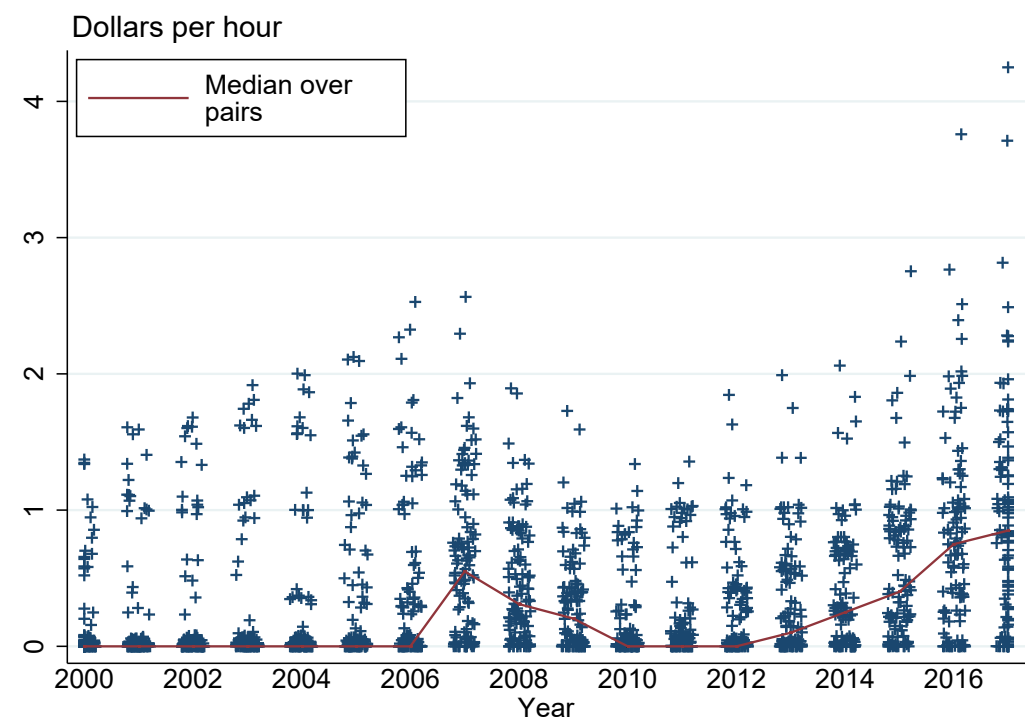

Source: Author's calculations based on data from Neumark et al. (2014) and Clemens et al. (2018). Points have been jittered to show that many state pairs have the same difference in minimum wages.

\section{$2.2 \quad$ Empirical strategy}

This subsection describes the regression strategy. The focus is on three local labor market outcomes. First is how commuting flows change if the minimum wage changes on either side of the border. Second is the difference in employment shares by wage categories across the border. Last is the difference in resident shares by wage categories.

These three outcomes provide a comprehensive view of how worker locations react to a minimum wage. Commuting shifts away from minimum wage increases so cross-border flows into higher minimum wage areas decrease. This commuting reduction could occur for several reasons. If employment decreases in the area that has raised the minimum wage, one would see fewer commuters into that area. In this case, low-wage employment shares should decrease. However, employment may also be unaffected, and workers may be moving into the area that increased the minimum wage. In that case, employment shares should be unaffected, while low-wage resident shares should increase.

Effects on commuting, panel design. The first step is the estimation of the effects on commuting. The unit of analysis is the county pair. I use $n$ to index residence counties, $i$ to index workplace counties, and $C_{n i t}$ to denote commuting from county $n$ to county $i$ at time $t$. Because commuting goes in both directions, there are initially two observations in the sample for every pair of counties each year. I restrict these to the parts of the counties 
that are in a narrow distance band from the border. For the main analysis, I focus on places 11 kilometers from the border, but later I calculate coefficients for alternative bandwidths.

I examine how cross-border commuting flows change if the minimum wage changes on either side. I compare these flows with different counterfactuals using a difference-in-differences strategy. Figure 3a shows the first design, labeled the panel design. I compare flows between areas $\mathrm{A}$ and $\mathrm{B}$ with flows between $\mathrm{C}$ and $\mathrm{D}$ before and after a minimum wage change occurs in area B. This design is analogous to the state-panel design traditionally used in the minimum wage and employment literature (Neumark et al. 2014).

For this panel design, I estimate the following regression:

$$
C_{n i t}=\beta_{0}+\beta_{n} \ln \left(\text { minwage }_{n t}\right)+\beta_{i} \ln \left(\text { minwage }_{i t}\right)+\gamma_{n i}+\delta_{t}+\Phi_{r e s} X_{n t}+\Phi_{w o r k} X_{i t}+\epsilon_{n i t}
$$

The coefficients of interest are $\beta_{n}$ and $\beta_{i}$, the effects of a minimum wage at the residence and the workplace. The residence-workplace pair effects, $\gamma_{n i}$, control for time-invariant differences in commuting between the pairs, while the time effects, $\delta_{t}$, control for national changes in cross-border commuting over time. There is one fixed effect for every pair, so residence fixed effects and workplace fixed effects would be collinear with the pair effects.

Coefficients $\beta_{n}$ and $\beta_{i}$ are identified from changes in the minimum wage at residence and workplace locations. Using the data on both commuting directions allows identifying $\beta_{n}$ and $\beta_{i}$ separately. $^{9}$

I include several control variables to address heterogeneity across local labor markets. $X_{n t}$ and $X_{i t}$ are time-varying variables at the residence and workplace that may influence commuting across borders. I include state-specific linear time trends and pair-specific linear time trends in some specifications. In other specifications, I include census division effects interacted with year effects to compare only residence-workplace pairs within census divisions. In this case, identification requires multiple county pairs per state border and state border within a census division. ${ }^{10}$

The effects of minimum wages $\beta_{n}$ and $\beta_{i}$ are identified here if

$$
E\left(\epsilon_{n i t} \times \ln \left(\text { minwage }_{n t}\right)\right)=E\left(\epsilon_{n i t} \times \ln \left(\text { minwage }_{i t}\right)\right)=0
$$

that is if minimum wage differences are uncorrelated with residual commuting. This condition requires that any unobservable differences in commuting across pairs evolve in parallel

\footnotetext{
${ }^{9}$ I use gross flows in both directions instead of net flows. The gross flows allow me to identify the effect of minimum wages in the workplace and the residence. In Appendix B, I show that regression with net flows would only allow me to identify the difference in these coefficients.

${ }^{10}$ Dube et al. (2010) show that these coarse time-varying trends are sufficient to dampen negative point estimates of the employment effect of minimum wages, and they attribute this to spatial heterogeneity.
} 
Figure 3: Empirical strategy

(a) Panel design

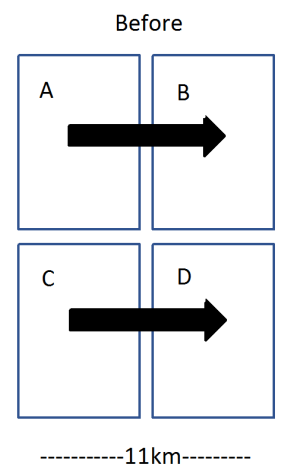

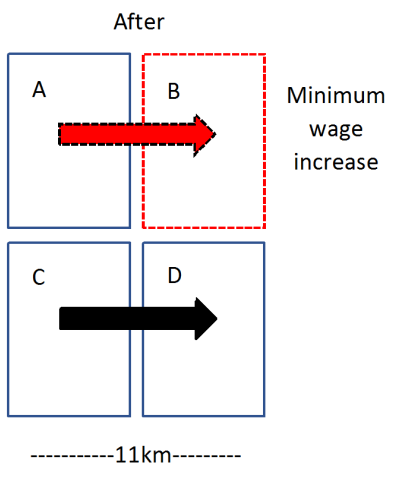

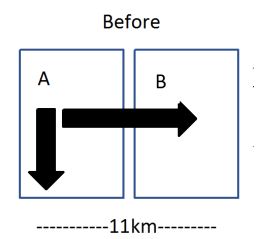

(b) Within design

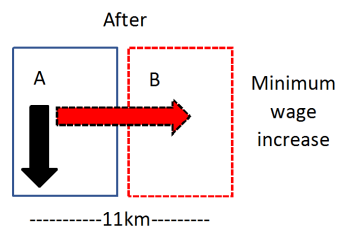

(c) Corner design
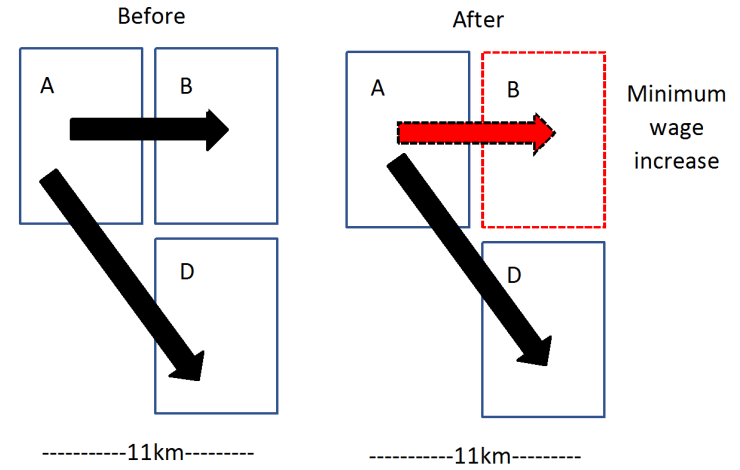

This graph depicts the empirical strategies of section 2.2. Each rectangle represents an area in a state. The gap between the rectangles represents the state border, and the areas are in a bandwidth of $11 \mathrm{~km}$ from the border. The minimum wage increases in area B. The top arrow represents the commuting flow from A to B. This flow is "treated" after the minimum wage increases in B. The treated flow is depicted with a red dashed arrow.

Panel (a) depicts the "panel" design. The flow from C to D, and the flow from A to B before the minimum wage change, are not treated and are represented by black arrows. This design compares the change in the flow from $\mathrm{A}$ to $\mathrm{B}$ when the minimum wage changes, to the change in the flow from $\mathrm{C}$ to $\mathrm{D}$ when the minimum wage changes.

Panel (b) depicts the "within" design. This flow within A is not treated and is represented by a black vertical arrow. This design compares the change in the flow from A to B when the minimum wage changes, to the change in the flow within $\mathrm{A}$ when the minimum wage changes.

Panel (c) depicts the "corner" design. The flows from A to B and A to D are not treated and are represented by black arrows. This design compares the change in the flow from A to $\mathrm{B}$ when the minimum wage changes, to the change in the flow from $\mathrm{A}$ to $\mathrm{D}$ when the minimum wage changes. 
over time. My estimation approach allows unobservables to exhibit different linear trends across states or vary systematically across census divisions by including state trends or census division-year effects. However, the estimates will be biased if these trends do not capture time-varying differences in commuting across pairs.

The usage of areas close to state borders controls for differences in covariates across counties. Dube et al. (2010, 2016) show that neighboring counties are similar in covariates' levels and trends. Dube et al. (2010) estimate the effects of minimum wages on employment using differences in neighboring counties across state borders. Hagedorn et al. (2016) highlight some limitations of using border designs in the context of evaluating the effects of unemployment insurance. First, they argue that border designs may fail to identify effects if policy differences across counties are not large and persistent. As shown in figure 2, cross-border differences in minimum wages can be as high as 50 percent of the federal minimum wage. These differences may not persist if states set minimum wages in response to their neighbor's policy. The lack of persistence in the differences may bias the estimates toward 0 .

Dieterle et al. (2020) argue that border designs need to explicitly account for distance to the border when working with county-level data. My approach looks at pieces of counties usually closer to the border than county centroids, limiting the role of distance. In subsection 2.4, I show that commuting effects vary as I consider larger distances from the border.

Effects on commuting, within design. The second design, shown in figure $3 \mathrm{~b}$, is a within design. It involves comparing cross-border commuting flows from $\mathrm{A}$ to $\mathrm{B}$ and flows within county A before and after the minimum wage changes in B. All the identifying variation derives from workers who reside in the same area. The regression specification is as follows:

$$
C_{n i t}=\beta_{0}+\beta_{d}\left(\ln \left(\text { minwage }_{i t}\right)-\ln \left(\text { minwage }_{n t}\right)\right)+\gamma_{n t}+\tau_{i}+\Phi_{\text {work }} X_{i t}+\tilde{\epsilon}_{n i t},
$$

where I include residence-time fixed effects, $\gamma_{n t}$, instead of the pair fixed effects of equation (1). Alternatively, I also compare commuting flows that end in the same workplace from residences with a different minimum wage. I implement this by including workplace-time fixed effects, $\gamma_{n t}$, as follows:

$$
C_{n i t}=\beta_{0}+\beta_{d}\left(\ln \left(\text { minwage }_{i t}\right)-\ln \left(\text { minwage }_{n t}\right)\right)+\gamma_{i t}+\tau_{n}+\Phi_{r e s} X_{n t}+e_{n i t}
$$

These specifications no longer identify the minimum wage effect at the origin or the destination separately but identify the elasticity of low-wage commuting, $\beta_{d}$, to the minimum wage difference. 
Effects on commuting, corner design. The final design, depicted in figure $3 \mathrm{c}$, is a corner design, where I compare cross-border commuting flows to destinations with different minimum wages for counties that send workers to at least two states. The identifying variation is still derived only from workers who live in the same place. This approach combines the previous two by comparing cross-border flows that have the same origin or destination. Its main drawback is the reduced sample size. For this comparison, I use equation (3), but I restrict the sample to residence counties with commuting flows to more than one state.

Effects on employment and migration. To look at employment responses and migration, I calculate the share of low-wage residents and the share of low-wage workers in each of the areas. I sort the pairs such that the "workplace" is the side that receives the most commuters. I then calculate the difference in shares by subtracting the "residence" share from the "workplace" share. Each county pair only enters the sample once every year. These differences then enter as dependent variables in specification (1). This design is analogous to a difference-in-differences design wherein the control counties are the neighboring counties, as in Dube et al. (2010).

Inference. To conduct inference, I use multi-way clustering (Cameron et al. 2011). Because county pairs that share an origin or a destination are correlated by construction, the error terms can be correlated if different county pairs share an origin or a destination. I also cluster at the state border to address spatial correlation and allow all pairs to be correlated over time. ${ }^{11}$

\subsection{Main Results}

Commuting. Table 1 shows estimates of the elasticity of low-wage commuting to the minimum wage using different panel specifications. Once the estimation includes location fixed effects, the elasticity of flows to the residence minimum wage is small and insignificant. However, the elasticity to the minimum wage in the workplace is significantly negative and stable across specifications, ranging from -0.19 to -0.25 .

To put this elasticity into perspective, most studies that find negative employment effects of the minimum wage find an elasticity of about -0.1 (Neumark et al. 2014; Belman and Wolfson 2014). Most of these studies are panel designs, while border design studies tend to find insignificant effects. I find a negative commuting elasticity in a border design study. In principle, the commuting elasticity should be higher than the employment elasticity if flows

\footnotetext{
${ }^{11}$ An alternative to correct the mechanical correlation of both commuting directions across pairs is to use dyadic clustering (Aronow et al. 2015). However, such a clustering strategy would not account for spatial correlation over the border segments. To estimate the models allowing for multidimensional clustering, I use the software provided by Correia (2017). In cases when the covariance matrix of the coefficients is not positive semi-definite, I apply the adjustment by Cameron et al. (2011).
} 
Table 1: Effect of minimum wages on low wage commuting: Panel design.

Log Low Wage Commuters - $11 \mathrm{Km}$ to Border

\begin{tabular}{|c|c|c|c|c|c|c|}
\hline & (1) & $(2)$ & $(3)$ & (4) & $(5)$ & (6) \\
\hline \multirow[t]{2}{*}{ Log MW Residence } & 0.44 & 0.00 & 0.02 & -0.02 & 0.02 & -0.00 \\
\hline & $(0.35)$ & $(0.11)$ & $(0.10)$ & $(0.11)$ & $(0.12)$ & $(0.12)$ \\
\hline \multirow{2}{*}{ Log MW Workplace } & $-0.78^{*}$ & $-0.25^{* *}$ & $-0.25^{* *}$ & $-0.22 * *$ & $-0.19 *$ & $-0.25 * *$ \\
\hline & $(0.40)$ & $(0.11)$ & $(0.10)$ & $(0.10)$ & $(0.11)$ & $(0.10)$ \\
\hline Adj R sq. & 0.002 & 0.965 & 0.967 & 0.969 & 0.968 & 0.976 \\
\hline $\mathrm{N}$ & 7,610 & 7,603 & 7,603 & 7,603 & 7,603 & 7,603 \\
\hline Work counties & 260 & 259 & 259 & 259 & 259 & 259 \\
\hline Res counties & 295 & 290 & 290 & 290 & 290 & 290 \\
\hline Work, res effects & & Yes & Yes & Yes & Yes & Yes \\
\hline Year effects & & Yes & Yes & Yes & & Yes \\
\hline Controls & & & Yes & Yes & Yes & Yes \\
\hline State trends & & & & Yes & & \\
\hline Census div $\mathrm{x}$ year effects & & & & & Yes & \\
\hline Work, res trends & & & & & & Yes \\
\hline Mean dep. var. & 395.2 & 395.5 & 395.5 & 395.5 & 395.5 & 395.5 \\
\hline
\end{tabular}

The sample excludes 1 . Residence-workplace pairs with average low-wage commuting below 150 a year; 2 . Counties from AK, AZ, AR, DC, MA, MS, NH, or WY because of missing commuting data; 3. Counties where the local minimum wage is higher than the state's minimum wage. Robust standard errors, in parentheses, are calculated with multidimensional clustering at border segment, county of work, county of residence and county pair level. Column 2 includes year effects and fixed effects at the workplace-residence county pair level. Column 3 also includes controls for total county population and population by age groups, lags of yearly state employment, gas prices, average percentage refund from state EITCs and average corporate tax rates. Columns 4 to 6 also include controls for spatial heterogeneity. Column 4 includes linear time trends interacted with state of residence and state of workplace dummies. Column 5 includes residence and work census division dummies interacted with year dummies. Column 6 includes pair-specific linear time trends.

toward low-minimum wage areas replace flows toward high-minimum wage areas. Therefore, the higher elasticity of commuting that I find indicates the presence of spillovers of the minimum wage. These findings stand in contrast with those in Dube et al. (2010), who do not find significant county spillover effects. In narrow bands to state borders, these effects are much larger in magnitude.

Also, using a smaller sample and looking at commuting among PUMAs, McKinnish (2017) finds that a higher minimum wage is associated with lower commuting inflows in the PUMAs, with an elasticity of -0.02 to -0.04 . The estimates here are significantly larger, suggesting that most of the decrease in commuting occurs at distances close to state borders.

The large magnitude of this elasticity compared with the negligible employment elasticity to a minimum wage is worthy of interest. Kuehn (2016) and McKinnish (2017) analyze the 
existence of spillover effects of the minimum wage and how these bias employment elasticity estimates. These results confirm that estimates based on employment by residence may have a bias toward zero.

Table 2 shows estimates of the commuting elasticity using only variations within residence counties. The elasticity remains negative and significant, with a value of -0.26 after including controls. Since these estimates are not affected by heterogeneous shocks in the residence counties, they suggest that heterogeneous trends are not driving the findings.

Table 2: Effect of minimum wages on low wage commuting: Within design, same residence.

Log Low Wage Commuters - $11 \mathrm{Km}$ to Border

\begin{tabular}{|c|c|c|c|}
\hline & \multicolumn{3}{|c|}{$\underline{\text { Same Residence }}$} \\
\hline & $(1)$ & $(2)$ & $(3)$ \\
\hline Log MW Workplace - Log MW Residence & $\begin{array}{l}-0.40 \\
(0.93)\end{array}$ & $\begin{array}{c}-0.24^{* *} \\
(0.10)\end{array}$ & $\begin{array}{c}-0.26^{* * *} \\
(0.09)\end{array}$ \\
\hline Adj R sq. & 0.000 & 0.304 & 0.303 \\
\hline $\mathrm{N}$ & 12,416 & 12,136 & 12,136 \\
\hline Work counties & 362 & 344 & 344 \\
\hline Res counties & 316 & 288 & 288 \\
\hline $\begin{array}{l}\text { Res effects x Year effects } \\
\text { Work effects x Year effects } \\
\text { Res Effects }\end{array}$ & & Yes & Yes \\
\hline Work effects & & Yes & Yes \\
\hline Controls & & & Yes \\
\hline Mean dep. var. & 2309.5 & 2273.6 & 2273.6 \\
\hline
\end{tabular}

The sample excludes 1. Residence-workplace pairs with average low-wage commuting below 150 a year; 2 . Counties from AK, AZ, AR, DC, MA, MS, NH, or WY because of missing commuting data; 3. Counties where the local minimum wage is higher than the state's minimum wage. Robust standard errors, in parentheses, are calculated with multidimensional clustering at border segment, county of work, and county of residence level. Column 2 includes residence-year effects and workplace effects. Column 3 also includes controls for total county population and population by age groups, lags of yearly state employment, gas prices, average percentage refund from state EITCs and average corporate tax rates.

The regression specification makes two implicit assumptions about the way the minimum wage affects low-wage commuting. For the panel design, I allow commuting to be influenced by the minimum wage at the residence and the workplace. From the residence county, the coefficient $\beta_{i}$ captures changes in cross-border commuting if wages change on the other side of the border. The coefficient $\beta_{n}$ captures substitution from cross-border commuting to within-state commuting if the minimum wage changes in the residence location.

If only the difference in wages determined commuting, these coefficients would be equal in absolute value but have opposite signs, but this does not seem to be the case. With controls, 
the coefficient on the residence wage is close to zero. The coefficient on the difference of wages in the within design is similar to the panel design's coefficient, consistent with negligible residence wage effects.

Tables J.2 and J.3 in appendix J also estimate this elasticity using only variation within workplace counties and using only counties in state corners, after comparing cross-border flows originating in the same county. The within-workplace estimates are small and unprecise. If the minimum wage reduces employment among employees commuting from within and across the state in a similar magnitude, these estimates should be small. The corner estimates are still negative, although imprecise, because of the small sample used.

Employment and resident shares. Table 3 shows results on the difference of low-wage employment shares across neighboring county pairs. The results show a significant decrease in low-skill employment shares if the minimum wage goes up at the workplace relative to the neighboring county. A ten percent higher minimum wage reduces the low wage employment share by around thirty percentage points, relative to the adjacent county in the neighboring state. This finding reinforces the view that lower employment plays a significant part in decreasing commuting because of the higher minimum wage.

Table 4 shows analogous results for residence shares. If workers migrate away from minimum wage increases, one should see negative coefficients in this regression. There is also potential heterogeneity in the effects across counties arising from the link between areas and their surroundings. However, all the estimates are imprecise and do not allow inference about migration effects. The finding here contrasts with Cadena (2014), who finds that workers migrate away from minimum wage increases in states. However, the incentive for migrating instead of commuting in response to the wage change is much smaller in this sample because commuting costs are much lower. Nevertheless, the estimates do not rule out negative migration responses.

\subsection{Robustness Tests}

This subsection describes an array of robustness tests to the results above. These tests suggest that neither preexisting trends in commuting, a shift of employment to other categories, or biases in the two-way fixed effects estimate drive the results. They also show that the results vary little if one looks at areas farther away from state borders.

Pre-trends and dynamics. To test for preexisting trends and lagged effects, I follow Schmidheiny and Siegloch (2020) and Freyaldenhoven et al. (2019) and estimate a panelevent study analogs of equations (1) and (3), including leads and lags of up to three years of minimum wages in the workplace and residence (panel design), or their difference (within 
Table 3: Effect of minimum wages on low wage employment shares.

Difference in low wage employment shares: Workplace - residence

\begin{tabular}{|c|c|c|c|}
\hline & $\begin{array}{c}(1) \\
11 \mathrm{Km}\end{array}$ & $\begin{array}{c}(2) \\
11 \mathrm{Km}\end{array}$ & $\begin{array}{c}(3) \\
11 \mathrm{Km}\end{array}$ \\
\hline Log MW Residence & $\begin{array}{c}0.02 \\
(0.01)\end{array}$ & $\begin{array}{l}0.03^{*} \\
(0.01)\end{array}$ & $\begin{array}{l}-0.00 \\
(0.02)\end{array}$ \\
\hline Log MW Workplace & $\begin{array}{l}-0.02^{*} \\
(0.01)\end{array}$ & $\begin{array}{l}-0.03^{*} \\
(0.01)\end{array}$ & $\begin{array}{l}-0.03^{*} \\
(0.02)\end{array}$ \\
\hline Adj R sq. & 0.838 & 0.846 & 0.864 \\
\hline $\mathrm{N}$ & 4,973 & 4,660 & 4,660 \\
\hline Work counties & 189 & 188 & 188 \\
\hline Res counties & 208 & 207 & 207 \\
\hline Work, res effects & Yes & Yes & Yes \\
\hline Year effects & Yes & Yes & Yes \\
\hline Controls & & Yes & Yes \\
\hline Census div x year effects & & & Yes \\
\hline Mean dep. var. & -0.01 & -0.01 & -0.01 \\
\hline
\end{tabular}

The sample excludes 1. Residence-workplace pairs with average low-wage commuting below 150 a year; 2 . Counties from AK, AZ, AR, DC, MA, MS, NH, or WY because of missing commuting data; 3. Counties where the local minimum wage is higher than the state's minimum wage. Robust standard errors, in parentheses, are calculated with multidimensional clustering at border segment, county of work, and county of residence level. Column 1 includes year effects and fixed effects at the workplace-residence county pair level. Column 2 also includes controls for total county population and population by age groups, lags of yearly state employment, gas prices, average percentage refund from state EITCs and average corporate tax rates. Column 3 also includes residence and work census division dummies interacted with year dummies.

design).

The results from these analyses indicate that the elasticity of commuting to either the minimum wage at the workplace or the difference in minimum wages only becomes negative and significant after they increase. For the within design the coefficients grow over time, and the point estimate for the low-wage commuting elasticity is around - 0.5 after two years. The results are in figure C.1 in the Appendix.

Stacked difference-in-differences analysis. A recent literature has highlighted than in settings with staggered variation in the treatment variables and/or heterogeneous treatment effects, two-way fixed effects estimates may fail to recover a properly weighted average of treatment effects across units (de Chaisemartin and D'Haultfouille 2020; GoodmanBacon 2021; Sun and Abraham 2021). Cengiz et al. (2019) propose a "stacked differencein-differences" approach to evaluate minimum wage effects, accounting for the staggered nature of minimum wage increases and the heterogeneity in the minimum wage changes 
Table 4: Effect of minimum wages on low wage residence shares.

Dependent variable: Difference in low wage resident shares: Workplace - residence

\begin{tabular}{|c|c|c|c|}
\hline & $\begin{array}{c}(1) \\
11 \mathrm{Km}\end{array}$ & $\begin{array}{c}(2) \\
11 \mathrm{Km}\end{array}$ & $\begin{array}{c}(3) \\
11 \mathrm{Km}\end{array}$ \\
\hline Log MW Residence & $\begin{array}{c}0.00 \\
(0.01)\end{array}$ & $\begin{array}{c}0.01 \\
(0.02)\end{array}$ & $\begin{array}{l}-0.02 \\
(0.02)\end{array}$ \\
\hline Log MW Workplace & $\begin{array}{c}0.04 \\
(0.04)\end{array}$ & $\begin{array}{c}0.03 \\
(0.04)\end{array}$ & $\begin{array}{c}0.03 \\
(0.04)\end{array}$ \\
\hline Adj R sq. & 0.797 & 0.796 & 0.836 \\
\hline $\mathrm{N}$ & 4,978 & 4,664 & 4,664 \\
\hline Work counties & 189 & 188 & 188 \\
\hline Res counties & 208 & 207 & 207 \\
\hline Work, res effects & Yes & Yes & Yes \\
\hline Year effects & Yes & Yes & Yes \\
\hline Controls & & Yes & Yes \\
\hline Census div $\mathrm{x}$ year effects & & & Yes \\
\hline Mean dep. var. & -0.00 & -0.00 & -0.00 \\
\hline
\end{tabular}

The sample excludes 1. Residence-workplace pairs with average low-wage commuting below 150 a year; 2 . Counties from AK, AZ, AR, DC, MA, MS, NH, or WY because of missing commuting data; 3. Counties where the local minimum wage is higher than the state's minimum wage. Column 1 includes year effects and fixed effects at the workplace-residence county pair level. Column 2 also includes controls for total county population and population by age groups, lags of yearly state employment, gas prices, average percentage refund from state EITCs and average corporate tax rates. Column 3 also includes residence and work census division dummies interacted with year dummies.

across states and over time. I follow their approach and isolate events for county pairs where there is a change in the difference in minimum wages between two years, and then compare these county pairs to a group of pairs that do not experience these changes around the time of the event (panel design) or to within county commuting flows (within design). I do these comparisons for each event and the average the effect across events weighting for the average total number of commuters in each county pair. The details are in Appendix C.1. The results are similar to those from the two-way fixed effects estimation. The preferred estimates for events with changes in the difference of minimum wages of 50 cents or larger, yield a low-wage commuting elasticity of -0.25 , similar to the two-way fixed effects estimates.

Other wage categories. Workers may be keeping their jobs but switching to a higher wage category because of their wage increase. I test this hypothesis by estimating the same regressions for mid-wage and high-wage commuters. The results are in Appendix table J.4. The lack of a positive effect in the mid and high-wage categories indicates a change in categories is not the driver behind the commuting and employment results. 
Distance from state borders. Appendix Figure J.1 shows commuting elasticities at different distances from the state border. The effect remains similar as one looks farther away from the state boundaries, suggesting that differences in commuting flows remain even when considering wider control groups.

Overall, the reduced-form analysis suggests that a larger minimum wage would reduce low-wage commuting to cities and induce employment relocation toward areas that did not increase the minimum wage. However, the reduced-form analysis has a few limitations. First, it only considers state borders where there is a history of minimum wage changes. To the extent that state borders differ from the cities considering minimum wage increases, cities' effects may differ. Cities are also considering wage changes that are larger than those observed in the sample.

The following section describes a new model that allows an extrapolation to cities.

\section{A Quantitative Model of the Minimum Wage and Local Commuting and Migration}

This section specifies a location choice model to study how the minimum wage alters commuting and migration in general equilibrium. The reduced-form results suggest that a higher minimum wage reduces commuting inflows and induces some employment sorting. The model enriches this analysis in several directions. First, it sheds light on the different margins of adjustment behind the reduced form results. Reductions in commuting may arise from employment, migration, or labor supply responses (see above). Second, the model allows me to elicit expectations on how future local minimum wage increases could affect cities by producing counterfactual changes in employment, commuting, and migration.

I build a quantitative urban model in the spirit of Ahlfeldt et al. (2015) and Monte et al. (2018). I consider an economy with $N$ locations indexed by $n$ and $i$. $n$ indexes residence locations, while $i$ indexes work locations. The economy can be a metropolitan area that straddles city or state borders. Each location can be thought of as a county in the crossborder area. There are three types of workers with different skill levels, $s=\ell, m, h$ with measures $L^{\ell}, L^{m}, L^{h}$. The metropolitan area is a closed city, and the city's total measures of workers are exogenous. Each worker decides on a location to live and to search for work. After making location decisions, a proportion of workers ends up employed in each work location, and utilities are realized according to the employment outcome. 


\subsection{Consumers and Firms}

Preferences. Workers have heterogeneous preferences over locations and choose their locations and consumption optimally given the choices of other agents. Workers are indexed by $\omega$. They may live and work in any location. I use $n$ to index the residence location and $i$ to index the job search location. Following Ahlfeldt et al. (2015) and Redding and RossiHansberg (2017), I assume a Cobb-Douglas utility function on consumption and housing:

$$
U_{n i \omega}^{s}=\frac{z_{n i \omega}^{s}}{1+\rho_{i}^{s} \kappa_{n i}}\left(\frac{C_{n \omega}^{s}}{\beta}\right)^{\beta}\left(\frac{H_{n \omega}^{s}}{1-\beta}\right)^{1-\beta} .
$$

Here, $C_{n w}^{s}$ denotes consumption of a numéraire good, and $H_{n \omega}^{s}$ denotes housing. The parameter $\beta$ is the consumption share of income. The variable $\kappa_{n i}$ is the commuting cost from $n$ to $i$. The variable $\rho_{i}^{s}$ is the probability of finding a job in location $i$ for a worker of type $s$, so $\left(1+\rho_{i}^{s} \kappa_{n i}\right)$ is the expected commuting cost.

The variable $z_{n i w}^{s}$ is a preference heterogeneity parameter that reflects the taste for living and working in particular locations. ${ }^{12}$ Each worker $\omega$ gets a draw for each residence workplace pair ni. Following Eaton and Kortum (2002) and Ahlfeldt et al. (2015), I assume these preference heterogeneity parameters follow a Fréchet distribution:

$$
G_{n i}^{s}(z)=e^{-T_{n}^{s} X_{i}^{s}} z^{-\epsilon} \quad T_{n}>0, X_{i}>0, \epsilon>1 .
$$

The variables $T_{n}^{s}$ and $X_{i}^{s}$ are scale parameters that reflect the average taste that each worker type has for living in $n$ and working in $i$, respectively. The parameter $\epsilon$ is common to all locations. A larger $\epsilon$ implies less dispersion of preferences and lower gains from commuting.

Workers maximize utility subject to a budget constraint in terms of expected income $\tilde{w}_{n i}^{s}$. The expected income equals the wage in $i, w_{i}^{s}$, times the probability of employment $\rho_{i}^{s}$, plus a residence-based unemployment benefit, $R_{n}^{s}$, multiplied by the probability of unemployment. Unemployment benefits are funded nationally and are exogenous: ${ }^{13}$

\footnotetext{
${ }^{12}$ Since these parameters multiply the wage; they also have an interpretation as worker-specific productivity measures for every residence workplace pair.

${ }^{13}$ Monras (2019) shows how the effect of increasing the minimum wage on migration varies if the funding of unemployment benefits is local or national. With locally-funded benefits, one mechanism through which a location may become more attractive is through increased unemployment benefits. The increased attractiveness and a negative effect on labor demand yield an ambiguous migration response to higher local minimum wages. With nationally-funded benefits, the effects of higher minimum wages on migration are always negative.

In the current model, the effect of higher minimum wages on commuting and migration is ambiguous even with nationally funded unemployment benefits because of the responses of employment probabilities and housing prices to the minimum wage increases. I explain this ambiguity in section 4.
} 


$$
\tilde{w}_{n i}^{s}=\rho_{i}^{s} w_{i}^{s}+\left(1-\rho_{i}^{s}\right) R_{n}^{s} .
$$

This optimization yields the following indirect utility function: ${ }^{14}$

$$
u_{n i \omega}=\frac{z_{n i \omega}^{s} \tilde{w}_{n i}^{s}}{\left(1+\rho_{i}^{s} \kappa_{n i}\right) Q_{n}^{1-\beta}},
$$

where the variable $Q_{n}$ is the price of housing in $n$.

Production. Each region has a representative firm that uses workers of all types to produce a single, numéraire consumption good that is homogeneous across locations. This good is consumed locally and is costlessly traded across locations, so its price is the same everywhere. The firm's production function is CES with constant returns to scale (Card and Lemieux 2001; Ottaviano and Peri 2012): ${ }^{15}$

$$
Y_{i}=\left[A_{i}^{\ell}\left(L_{M i}^{\ell}\right)^{\sigma}+A_{i}^{m}\left(L_{M i}^{m}\right)^{\sigma}+A_{i}^{h}\left(L_{M i}^{h}\right)^{\sigma}\right]^{\frac{1}{\sigma}},
$$

where $L_{M i}^{s}$ is the total number of workers of type $s$ in location $i$. Denoting $L_{n i}^{s}$ as the number of workers of type $s$ who live in $n$ and are employed in $i$, then employment by workplace is the sum of employees across residence locations. Similarly, $L_{R n}^{s}$ denotes employment by residence and is the sum of employees across workplace locations:

$$
L_{M i}^{s} \equiv \sum_{n} L_{n i}^{s} ; \quad L_{R n}^{s} \equiv \sum_{i} L_{n i}^{s} .
$$

The parameter $\sigma$ governs the elasticity of substitution between different types of labor. The $A_{i}^{s}$ terms are productivity terms specific to each type of labor and each location. ${ }^{16}$

\footnotetext{
${ }^{14}$ This form for the utility function has a particular implication in terms of risk preferences. It implies that the worker values income and commuting costs separately in a risk-neutral fashion. Income enters as an expectation in the numerator, and commuting costs enter as an expectation in the denominator. These expectations also have an interpretation as beliefs about income and commuting costs (Dingel and Tintelnot 2021).

This utility function may be odd compared to a utility function where the probability of employment multiplies employment value, and the probability of unemployment multiplies the value of unemployment. I use this specification to have utility be a product of fundamentals and the Fréchet heterogeneity parameter, such that utility for each residence-place of search pair distributes Fréchet, which allows me to use the results from Monte et al. (2018).

${ }^{15}$ Here, I focus on substitution between labor at different skill levels and treat the capital stock as fixed. This focus assumes that the effects of wage changes are short-term or that capital stocks adjust slowly.

${ }^{16}$ I drop the upper limits of the summations in the remainder of the text for convenience
} 


\subsection{Labor Markets.}

Labor supply and unemployment. Workers choose where to live and search for work to maximize their utility in (8). Their optimal choice of residence and place of search determines labor supply in each location. Following Monte et al. (2018), utility is Fréchet distributed and the residence-place of search probabilities are given by: ${ }^{17}$

$$
\begin{aligned}
o_{n i}^{s} & =\frac{\psi_{n i}^{s}}{\sum_{n, i} \psi_{n i}^{s}}, \\
\psi_{n i}^{s} & \equiv T_{n}^{s} X_{i}^{s}\left[\left(1+\rho_{i}^{s} \kappa_{n i}\right) Q_{n}^{1-\beta}\right]^{-\epsilon}\left(\tilde{w}_{n i}^{s}\right)^{\epsilon} .
\end{aligned}
$$

From these bilateral probabilities, one may obtain the marginal probabilities of living in $n$ and searching in $i$, as follows:

$$
o_{R n}^{s}=\sum_{i} o_{n i}^{s} ; \quad o_{M i}^{s}=\sum_{n} o_{n i}^{s} .
$$

These probabilities, multiplied by the exogenous measures of workers of each type, give the number of residents, $O_{R n}^{s}$, and job-seekers, $O_{M i}^{s}$, in each location. ${ }^{18}$

I allow for the possibility of some unemployment in each place of search. Define $U_{M i}^{s}$ as unemployment in each place of search for each skill type and $L_{M i}^{s}$ as employment in each workplace. Unemployment, search, and employment must satisfy:

$$
U_{M i}^{s}=O_{M i}^{s}-L_{M i}^{s}
$$

Labor demand. I model labor demand using the approach of Michaillat (2012) and Michaillat and Saez (2015). At a given wage, firms do not hire all the workers searching for a job in each area for two reasons. First, there are matching frictions, and not all workers who search for a job are matched. Second, firms may post fewer vacancies in response to higher wages, which induces job rationing. In equilibrium, there is unemployment in every area. The modeling of unemployment contrasts with existing quantitative urban models without unemployment (Redding and Rossi-Hansberg 2017), where productivity shocks fully translate into employment.

Each firm chooses an optimal amount of labor of every type $s \in\{\ell, m, h\}$ to maximize profits according to the production function of equation (9), taking wages as given. Then, they post vacancies, $V_{i}^{s}$, in every region. There is a recruiting mark-up, $\tau_{i}^{s}$, per vacancy filled, so every worker of skill level $s$ costs the firm $w_{i}\left(1+\tau_{i}^{s}\right)$. Following Michaillat (2012), I

\footnotetext{
${ }^{17}$ Details are in appendix E.

${ }^{18}$ The model does not feature a decision to search or not search for a job. I use the term "job-seekers" in location $i$ to refer to everybody who chooses location $i$ to search fro a job.
} 
assume that recruiting mark-ups are wages paid to recruiters. Filling each vacancy requires $r^{s}$ recruiters, and recruiters have the same skills as the employees who fill the vacancies. The number of recruiters required does not vary by location, and recruiters are employed outside the city.

Vacancies are randomly matched to unemployed workers, $U_{i}^{s}$, with a matching function $\mu^{s}\left(U_{i}^{s}, V_{i}^{s}\right)$ that is increasing in both arguments, homogeneous of degree 1 , and concave (Petrongolo and Pissarides 2001). There is a matching market for every type of labor $s$. Define labor market tightness as $\theta_{i}^{s} \equiv \frac{V_{i}^{s}}{U_{i}^{s}}$. The probability of finding a job in each region is $f^{s}\left(\theta_{i}^{s}\right)=\mu^{s}\left(U_{i}^{s}, V_{i}^{s}\right) / U_{i}^{s}$, and the probability of filling a vacancy is $q^{s}\left(\theta_{i}^{s}\right)=\mu^{s}\left(U_{i}^{s}, V_{i}^{s}\right) / V_{i}^{s}$.

The number of filled vacancies is $q^{s}\left(\theta_{i}^{s}\right) V_{i}^{s}$, which requires $r^{s} V_{i}^{s}$ recruiters. Therefore, each vacancy has a mark-up of:

$$
\tau^{s}\left(\theta_{i}^{s}\right)=\frac{r^{s}}{q^{s}\left(\theta_{i}^{s}\right)}
$$

Firms take wages and recruiting mark-ups as given; then they choose employment, $L_{M i}^{s}$, to maximize profits. The first-order conditions are:

$$
Y^{1-\sigma} A_{i}^{s}\left(L_{M i}^{s}\right)^{\sigma-1}=w_{i}^{s}\left(1+\tau_{i}^{s}\left(\theta_{i}^{s}\right)\right), \quad s=\ell, m, h .
$$

These equations implicitly define labor demand functions $L_{i}^{s}\left(\theta_{i}^{s}, w_{i}^{s}\right)$.

To make the matching model operational, I choose specific functional forms for the matching function and the recruiting mark-up. I adopt a standard Cobb-Douglas matching function

$$
\mu^{s}\left(U_{i}^{s}, V_{i}^{s}\right)=\Omega^{s}\left(U_{i}^{s}\right)^{\eta}\left(V_{i}^{s}\right)^{1-\eta}
$$

where I allow matching efficiency, $\Omega^{s}$, to vary by skill, but not by location. ${ }^{19}$ The parameter $\eta$ is the elasticity of the matching function, which is assumed constant across skills and locations. With this functional form, the job finding probability is $f^{s}\left(\theta_{i}^{s}\right)=\Omega^{s}\left(\theta_{i}^{s}\right)^{1-\eta}$ and the vacancy filling probability is $q^{s}\left(\theta_{i}^{s}\right)=\Omega^{s}\left(\theta_{i}^{s}\right)^{-\eta}$. Because $q^{s}\left(\theta_{i}^{s}\right)$ is decreasing in tightness $\theta_{i}^{s}$, recruiting mark-ups $\tau^{s}\left(\theta_{i}^{s}\right)$ in equation (14) are increasing in $\theta_{i}^{s}$, implying that vacancies are harder to fill if there are fewer individuals searching for a job in location $i$.

Dube et al. (2016) show that minimum wage jobs have high turnover. To allow for the possibility of differences in turnover across low- and high-wage jobs, I allow for the possibility of different separation rates. I assume that workers may be dismissed from their jobs but always search in the same location. Jobs are lost according to an exogenous separation rate

\footnotetext{
${ }^{19}$ The Cobb-Douglas matching function has constant returns to scale, homogeneous of degree 1 , and its value equals 0 if either of its arguments is 0 . See Petrongolo and Pissarides (2001) for details on assumptions behind matching functions.
} 
$\xi^{s}$ that varies by job type.

Minimum wages and wages for other skill levels. There is a binding minimum wage, $w_{i}$, in each location. This minimum wage applies to workers of the lowest skill level $\ell$. With a binding minimum wage, firms reduce their hiring if the minimum wage rises and jobs become rationed in each region, reducing the number of matches. Simultaneously, the minimum wage alters the number of people who search for a job in the region, changing $O_{M i}$.

I do not specify a wage-setting process for the wages of the other skill levels and assume them exogenous for the counterfactual exercises in sections 5 and (6). There are two reasons for not specifying such a wage-setting mechanism. First, there is limited evidence of spillovers of higher minimum wages to other wages higher up in the wage distribution in the U.S. (Autor et al. 2016). Second, even with fixed wages in the other categories, minimum wage increases change equilibrium in these markets. As the minimum wage changes in one market, the equilibrium market tightness $\theta_{i}^{\ell}$ in the low-skill labor market changes. Both changes in market tightness and the minimum wage change the equilibrium demand of labor for mid and high-skill workers according to equation 15 . Together with the migration of mid and highskill workers and changes in housing prices, these changes change employment probabilities and recruiting mark-ups in these markets.

\subsection{Housing Markets}

Absentee landlords provide housing. Land supply is inelastic and given by $D_{n}$. Because of the Cobb-Douglas specification in (8), workers spend a fraction, $1-\beta$, of their income on housing. Therefore, the total income spent on housing at each location is a fraction $1-\beta$ of expected income in each residential location. For each level of skill, expected income in each residential location is:

$$
v_{n}^{s}=\sum_{i} o_{n i \mid n}^{s} \tilde{w}_{n i}^{s}
$$

where $o_{n i \mid n}^{s}$ is the conditional probability of searching for a job in location $i$ when living in $n$,

i.e. $o_{n i \mid n}^{s}=\frac{o_{n i}^{s}}{\sum_{i} o_{n i}^{s}}$. Expected residential income is the average of these skill-specific expected residential incomes across skills:

$$
v_{n}=\sum_{s}\left(\frac{O_{R n}^{s}}{\sum_{s^{\prime}} O_{R n}^{s^{\prime}}} v_{n}^{s}\right) .
$$




\subsection{Equilibrium}

Labor market equilibrium. The amount of job seekers in each location is given by equation (12). Allowing for turnover, the number of separated employed workers needs to equal the number of unmatched job-seekers for each skill level in each location:

$$
\xi^{s} L_{M i}^{s}=f\left(\theta_{i}^{s}\right)\left(O_{M i}^{s}-L_{M i}^{s}\right),
$$

The previous labor supply in each location, together with labor demand from equation (15), determine equilibrium values of labor market tightness $\theta_{i}^{s}$, job search $O_{M i}^{s}$ employment $L_{M i}^{s}$, and unemployment $U_{M i}^{s}$ in each location, given a number of searchers, $O M_{i}^{s}$, and a wage. In equilibrium, labor demand equals employment in each location, so $L_{i}^{s}\left(\theta_{i}^{s}, w_{i}^{s}\right)=L_{M i}^{s}$.

The employment probabilities that workers perceive must be consistent with the ratios of employment to job-seekers at each location:

$$
\rho_{i}^{s}=\frac{L_{M i}^{s}}{O_{M i}^{s}}=\frac{f^{s}\left(\theta_{i}^{s}\right)}{\xi^{s}+f^{s}\left(\theta_{i}^{s}\right)} .
$$

To determine employment at the residence level and commuting flows, I assume that the employment probabilities at each workplace do not depend on where the job-seekers reside. This assumption implies that the number of people employed in location $i$ coming from $n$ is proportional to the number of job-seekers from $n .^{20}$

$$
L_{n i}^{s}=O_{n i}^{s} \rho_{i}^{s} .
$$

Define global commuting probabilities as $l_{n i}^{s} \equiv \frac{L_{n i}^{s}}{L^{s}}$. Equation (21) implies that

$$
l_{n i}^{s}=o_{n i}^{s} \rho_{i}^{s}=o_{n i}^{s} \frac{L_{M i}^{s}}{O_{M i}^{s}} .
$$

The probability of living in $n$ while employed and the probability of being employed in $i$ are then given by:

$$
l_{R n}^{s}=\sum_{i} l_{n i}^{s} ; \quad l_{M i}^{s}=\sum_{n} l_{n i}^{s} .
$$

Housing market equilibrium. The price of housing equals the amount spent on it in each location $v_{n}$ from equation 18 , divided by the inelastic supply of housing, as follows:

\footnotetext{
${ }^{20}$ While tractable, this assumption may fail to hold if employers care about commuting distance and its effects on productivity. For example, Diaz and Salas (2020) show that firms discriminate against workers that live further away from firms.
} 


$$
Q_{n}=\frac{(1-\beta) v_{n} O_{R n}}{D_{n}}
$$

General equilibrium. An equilibrium in the model is a vector of housing prices, $Q_{n}$, income, $v_{n}$, residents, $O_{R n}^{s}$, workers, $L_{M i}^{s}$, and job-seekers, $O_{M i}^{s}$, of each worker type at each location such that:

1. Residence-search probabilities satisfy equation (11).

2. Equations (15) and (19) are satisfied so the labor market is in equilibrium.

3. Employment probabilities are consistent with ratios of search to employment and satisfy equation (20).

4. Equation (24) is satisfied so the housing market clears.

Appendix G.1 describes an algorithm to compute equilibriums in the model, allowing for turnover. In equilibrium, employment probabilities must be consistent with commuting patterns. The algorithm starts from an initial value of employment probabilities and housing prices and updates commuting patterns and employment probabilities until they are mutually consistent.

\subsection{Welfare}

Because of spatial equilibrium and the Fréchet distributional assumption, for a given skill group, the utility of search conditional on choosing a residence-workplace to search pair has the same distribution across areas (Monte et al. 2018). The expected utility conditional on a residence-workplace to search pair is equal across areas and equal to the expected utility of the economy as a whole. This utility is given by:

$$
\bar{U}^{s}=\Gamma\left(\frac{\epsilon-1}{\epsilon}\right)\left[\sum_{n, i} \psi_{n i}^{s}\right]^{1 / \epsilon}
$$

where $\Gamma$ is the Gamma function and $\psi_{n i}^{s}$ is defined as in equation (11).

Nevertheless, utility can vary across skill groups and by employment status within each skill group. If an agent ends up employed, they receive wage $w_{i}^{s}$ and pay commuting cost $\left(1+\kappa_{n i}\right)$. If they end up unemployed, they receive the unemployment benefit $R_{n}$ and do not pay a commuting cost. In Appendix F I show that expected utilities of employment and unemployment for each residence - workplace pair are: 


$$
\begin{aligned}
\bar{U}_{n i, \text { employed }}^{s} & =\Gamma\left(\frac{\epsilon-1}{\epsilon}\right)\left[\sum_{n, i} \psi_{n i}^{s}\right]^{1 / \epsilon} \frac{1+\rho_{i}^{s} \kappa_{n i}}{1+\kappa_{n i}} \frac{w_{i}^{s}}{\tilde{w}_{n i}^{s}} \\
\bar{U}_{n i, \text { unemployed }}^{s} & =\Gamma\left(\frac{\epsilon-1}{\epsilon}\right)\left[\sum_{n, i} \psi_{n i}^{s}\right]^{1 / \epsilon} \frac{R^{n}}{\tilde{w}_{n i}^{s}}\left(1+\rho_{i}^{s} \kappa_{n i}\right)
\end{aligned}
$$

\section{Effects of the Minimum Wage}

This section examines the effects of changes in the minimum wage on low-wage commuting, migration, and employment in the model. I show that the effects depend on the relative strength of wage effects, employment effects, and housing price changes. I relate the effects found in the model to the elasticities estimated in the reduced form analysis.

A simple illustration of the minimum wage effects. I illustrate the minimum wage effects in a model of two regions and a single labor type. Figure 4 shows an initial equilibrium of the model. Job-seekers in each region, $O_{M 1}$ and $O_{M 2}$, are determined by wages, $w$, employment probabilities, $\rho$, and housing prices, $Q$, in each region. The number of job-seekers and the equilibrium conditions of each labor market in equation (19) determine labor supply curves, $L_{M 1}$ and $L_{M 2}$. Firms in each location have labor demand curves, $L_{1}$ and $L_{2}$, that depend on tightness and wages. The intersection of labor supply and demand curves determines equilibrium employment, $L_{M 1}^{*}$ and $L_{M 2}^{*}$, and unemployment, $U_{M 1}^{*}$ and $U_{M 2}^{*}$.

Consider an increase in the wage in market 1 . This increase changes equilibriums in these locations through three effects.

1. A positive wage effect on the number of job-seekers, since larger wages make location 1 more attractive.

2. A negative employment effect: larger wages reduce labor demand by firms in location 1 , reducing employment probabilities and making location 1 less attractive for searchers.

3. A housing prices effect: larger wages increase expected income and housing prices unless the wage change causes a large share of workers to become unemployed, in which case average income and housing prices decrease.

The overall change in employment in these locations depends on the relative strength

of these effects. Figure 5 a shows a new equilibrium with increased employment. Dashed 
Figure 4: Labor market equilibrium for a model with two locations

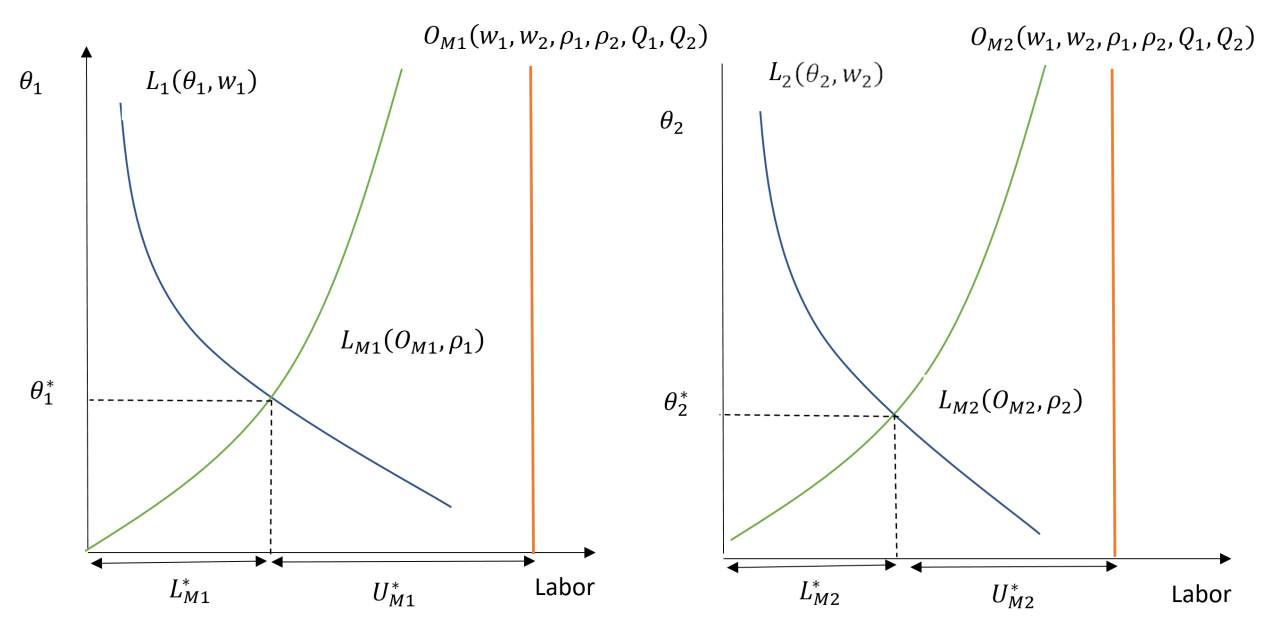

The figure depicts an equilibrium in labor markets for a model with two locations $i, n=1,2$, and a single labor type. The variables $O_{M 1}$ and $O_{M 2}$ are the supply of searchers in each market, which depend on wages $w_{i}$, employment probabilities $\rho_{i}$, and housing prices $Q_{n}$. The curves $L_{M 1}$ and $L_{M 2}$ are labor supply curves that are upward sloping in market tightness $\theta_{i}$ since more workers are hired as tightness increases. The curves $L_{1}$ and $L_{2}$ are labor demand functions decreasing in market tightness since higher tightness implies higher recruiting costs. The quantities $L_{M 1}^{*}$ and $L_{M 2}^{*}$ are equilibrium employment levels. The quantities $U_{M 1}^{*}$ and $U_{M 2}^{*}$ are equilibrium unemployment levels. The values $\theta_{1}^{*}$ and $\theta_{2}^{*}$ are equilibrium market tightness levels.

lines depict new labor supply and demand curves. In this equilibrium, the increase in wages increases the search in location 1 and reduces the search in location 2. Employment and unemployment are now greater in location 1 and lower in location 2, although labor demand has decreased in location 1.

Figure 5b shows a new equilibrium with lower employment. In this equilibrium, the increase in wages reduces the search in location 1 and increases the search in location 2. The search reduction in location 1 occurs because the employment effect is large and negative, overcoming the positive wage effect. Employment is now lower in location 1 and higher in location 2. Unemployment in location 2 increases, but the effect on unemployment in location 1 is ambiguous.

The effects on commuting and migration depend on how the search changes in location 1 are distributed between commuters and migrants. As location 1 becomes more attractive, some residents from location 2 may decide to search for a job in location 1, increasing commuting. In contrast, other individuals may migrate to location 1, increasing the search but decreasing commuting from 2 to 1.

Elasticity of low-wage commuting to the minimum wage. The model allows me to examine the determinants of the commuting and migration elasticities to minimum wage increases estimated in the reduced-form analysis. 
Figure 5: Changes in labor market equilibrium when the minimum wage increases in location 1

(a) Increase in employment in location 1

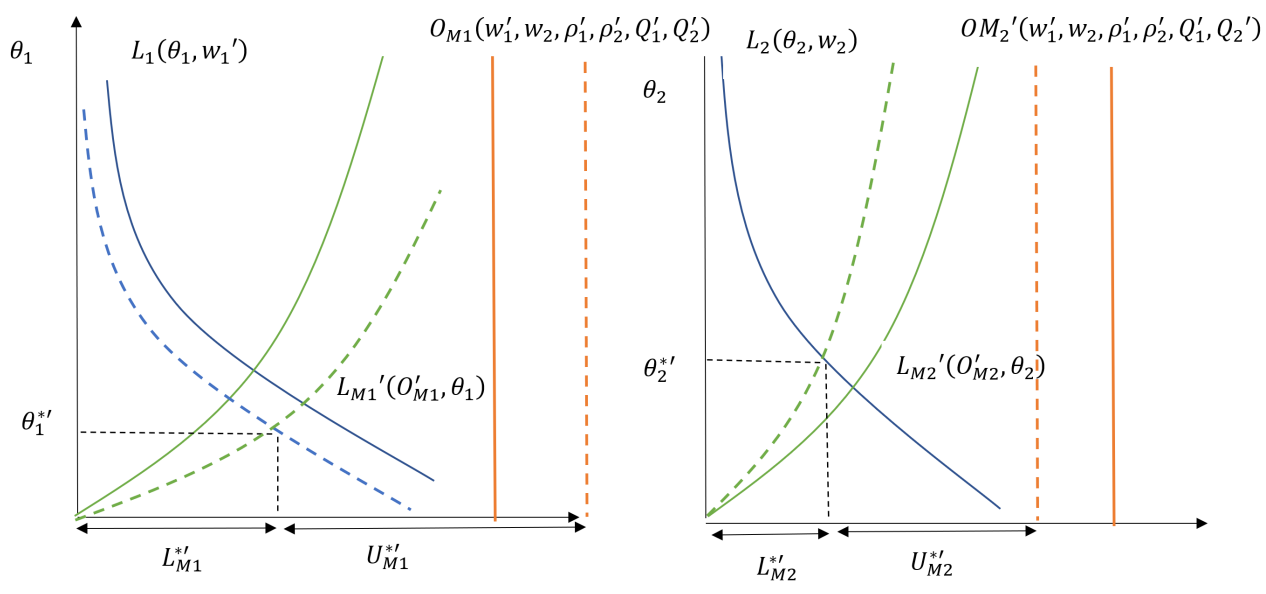

(b) Decrease in employment in location 1
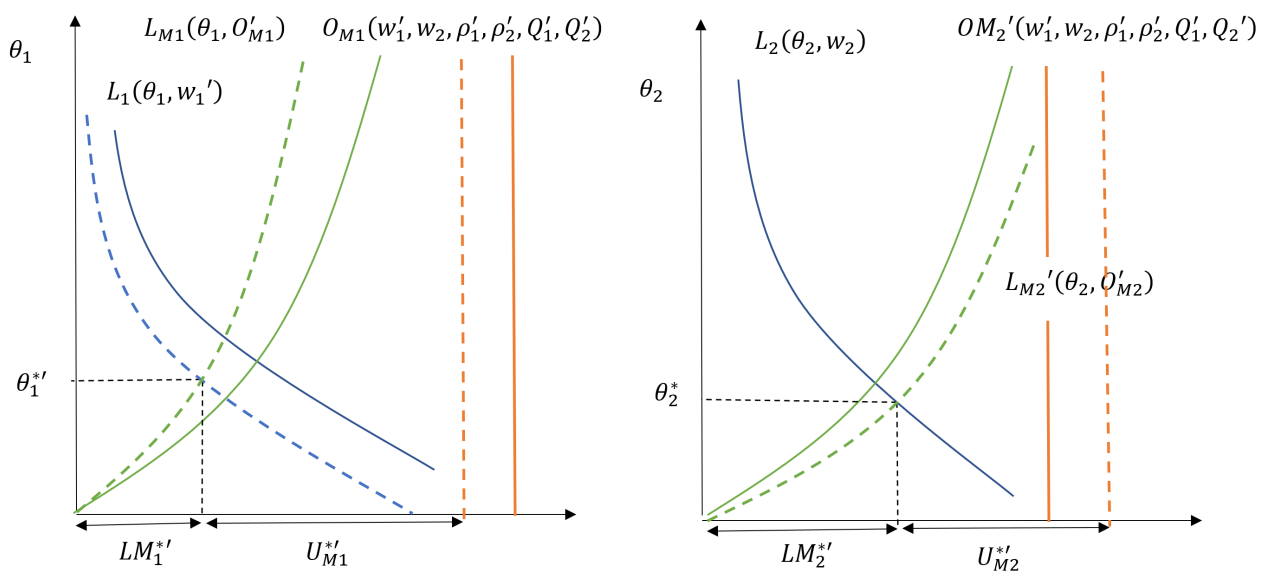

The figure depicts how equilibrium changes after a wage increase in a single market, for a model with two locations $i, n=1,2$ and a single labor type. Solid lines depict the initial equilibrium and dashed lines depict the new equilibrium. The wage increases in location 1 from $w_{1}$ to $w_{1}^{\prime}$.

Panel (a) depicts a case where employment increases in location 1. The number of searchers in location 1 increases to $O_{M 1}\left(w_{1}^{\prime}, w_{2}, \rho_{1}^{\prime}, \rho_{2}^{\prime}, Q_{1}^{\prime}, Q_{2}^{\prime}\right)$, and decreases search in location 2. Employment in location 1 increases to $L_{M 1}^{* \prime}$, and unemployment increases to $U_{M 1}^{* \prime}$. Employment and unemployment in location 2 decrease.

Panel (b) depicts a case where employment decreases in location 1. The number of searchers in location 1 decreases to $O_{M 1}\left(w_{1}^{\prime}, w_{2}, \rho_{1}^{\prime}, \rho_{2}^{\prime}, Q_{1}^{\prime}, Q_{2}^{\prime}\right)$, and increases in location 2. Employment in location 1 decreases to $L_{M 1}^{* \prime}$, and unemployment decreases to $U_{M 1}^{* \prime}$. Employment and unemployment in location 2 increase. 
Consider the probability of commuting from $n$ to $i$ among low-wage workers from equation $(22)$ :

$$
l_{n i}^{\ell}=o_{n i}^{\ell} \rho_{i}^{\ell}
$$

The change in this probability depends on how search probabilities and employment probabilities change. Define the partial equilibrium elasticity of low-wage commuting to the minimum wage, $\eta_{w_{i}^{e}}^{l_{n i}^{e}}$, as the log change in commuting over the log change in the minimum wage keeping endogenous variables constant in locations that are not analyzed. That is, for the commutes from $n$ to $i$, commuting across other residence-workplace pairs remain fixed. From equation (22), this elasticity is:

$$
\eta_{w_{i}^{\ell}}^{l_{n i}^{e}}=\eta_{w_{i}^{e}}^{\rho_{i}^{\ell}}+\eta_{w_{i}^{\ell}}^{o_{n i}^{e}}
$$

The first term, $\eta_{w_{i}^{\ell}}^{\rho_{i}^{\ell}}$, summarizes how the employment probability changes as the minimum wage changes. The second term, $\eta_{w_{i}^{\ell}}^{o_{n i}^{\ell}}$, summarizes how the search probability changes with the change in wages. This second term may depend on how the employment probability changes, since $o_{n i}^{\ell}$ is a function of $\rho_{i}^{\ell}$.

In Appendix H, I derive the elasticities of search probabilities to changes in the minimum wage and obtain the following decomposition for the partial equilibrium commuting elasticity:

$$
\eta_{w_{i}^{\ell}}^{o_{n i}^{\ell}}=\underbrace{\left(\epsilon-\epsilon O_{n i}^{\ell}\right)\left[\theta_{n i}^{\ell}-\left(1-\theta_{n i}^{\ell}\right)-\frac{1}{\tilde{w}_{n i}^{\ell}}-\boldsymbol{\kappa}_{a b}^{s}\right] \eta_{w_{i}^{\ell}}^{\rho_{i}^{\ell}}}_{\text {Employment effect }}+\underbrace{\left(\epsilon-\epsilon O_{n i}^{\ell}\right) \theta_{n i}^{\ell}}_{\text {Wage effect }}-\underbrace{\left(\epsilon-\epsilon O_{n i}^{\ell}\right)(1-\beta) \eta_{w_{i}^{\ell}}^{Q_{n}}}_{\text {Housing prices effect }} .
$$

where $\theta_{n i}^{\ell} \equiv \frac{\rho_{i}^{\ell} w_{i}^{\ell}}{\rho_{i}^{s} w_{i}^{\ell}+\left(1-\rho_{i}\right) R_{n}^{\ell}}$ is the fraction of wages in expected income, and $\boldsymbol{\kappa}_{n i}^{s}=\frac{\kappa_{n i}^{s}}{1+\rho_{i} \kappa_{n i}^{s}}$.

The wage effect is positive and increases with the share of wages in expected income. The housing price effect grows with the housing share of expenditure. In partial equilibrium, this effect is negative because it increases $v_{n}$ and leaves $L R_{n}$ unchanged. The sign of the employment effect is ambiguous. If the elasticity of the search probabilities to the wage is negative, and the wage share in income is sufficiently large, this effect is negative.

The dispersion parameter $\epsilon$ plays a crucial role in determining the value of this elasticity. As $\epsilon$ grows, wage effects are larger. Larger $\epsilon$ implies lower gains from commuting and lower initial commuting in equilibrium. If commuting is lower in an initial equilibrium, then commuting is more sensitive to higher expected wages. Larger $\epsilon$ also increases the magnitude of the other effects. 
Based on equation (29), the commuting elasticity becomes

$$
\eta_{w_{i}^{\ell}}^{l_{n i}^{\ell}}=\underbrace{\left(\epsilon-\epsilon O_{n i}^{\ell}\right)\left[\theta_{n i}^{\ell}-\left(1-\theta_{n i}^{\ell}\right)-\frac{1}{\tilde{w}_{n i}^{\ell}}-\boldsymbol{\kappa}_{a b}^{s}\right] \eta_{w_{i}^{\ell}}^{\rho_{i}^{\ell}}+\eta_{w_{i}^{\ell}}^{\rho_{i}^{\ell}}}_{\text {Employment effect }}+\underbrace{\left(\epsilon-\epsilon O_{n i}^{\ell}\right) \theta_{n i}^{\ell}}_{\text {Wage effect }}-\underbrace{\left(\epsilon-\epsilon O_{n i}^{\ell}\right)(1-\beta) \eta_{w_{i}^{\ell}}^{Q_{n}}}_{\text {Housing prices effect }},
$$

which is similar to the effect on search probabilities except for an extra term $\eta_{w_{i}^{\ell}}^{\rho_{i}^{\ell}}$ in the employment effect. If $\eta_{w_{i}^{e}}^{\rho_{i}^{\ell}}<0$ then the employment effect becomes more negative overall.

The reduced-form analysis in section 2 above showed an average negative effect of minimum wages on commuting and employment relocation toward the side that did not increase the minimum wage. The average negative effect implies that employment effects are negative and larger in absolute value than the sum of wage and housing price effects for the average county pair in the sample.

Elasticities of low-wage residents to the minimum wage. I now examine the effects on the share of low-wage residents, which reflects migration. Define the share of low-skill residents as

$$
\Lambda_{R n}^{\ell}=\frac{l_{R n}^{\ell}}{l_{R n}^{\ell}+l_{R n}^{m}+l_{R n}^{h}}
$$

The semi-elasticity of the share of low-skill residents is given by $\varepsilon_{w_{n}^{\ell}}^{\Lambda_{R n}^{\ell}} \Lambda_{R n}^{\ell}$. This elasticity equals

$$
\varepsilon_{w_{n}^{\ell}}^{\Lambda_{R n}^{\ell}} \Lambda_{R n}^{\ell}=\Lambda_{R n}^{\ell}\left(\varepsilon_{w_{n}^{\ell}}^{l_{R n}^{\ell}}-\Lambda_{R n}^{\ell} \varepsilon_{w_{n}^{\ell}}^{l_{R n}^{\ell}}-\Lambda_{R n}^{m} \varepsilon_{w_{n}^{\ell}}^{l_{R n}^{m}}-\Lambda_{R n}^{h} \varepsilon_{w_{n}^{\ell}}^{l_{R n}^{h}}\right)
$$

which is a function of the initial resident shares by skill and the elasticity of residents for each skill level. These total resident elasticities can be written as sums of commuting elasticities over workplaces, as follows:

$$
\varepsilon_{w_{n}^{t}}^{l_{R n}^{s}}=\sum_{b} \varepsilon_{w_{n}^{\ell}}^{l_{n b}^{s}}
$$

In general, the effect on migration is ambiguous because this sum could take any sign. A comparison with the estimated reduced form effect is not informative because these effects have been imprecisely estimated.

Extrapolating to cities considering minimum wage changes. The analysis in this section shows how to analyze the effects of minimum wages in the model and decomposes the elasticities into several effects arising through different channels. It shows that the overall effects are ambiguous and depend on the relative strength of these channels. To suggest how 
minimum wage policies affect cities that increase their minimum wage, one could quantify these channels for each city separately.

One way of achieving this extrapolation would be to quantify the elasticity components in equation (30). The key would be to obtain reduced-form estimates of the elasticities of employment and housing prices to the change in the minimum wage, as well as an estimate of the dispersion parameter $\epsilon$. This exercise would be limited, however. The decomposition of equation (30) is only valid for a partial equilibrium elasticity. Besides, a reduced-form estimate of the effect on housing prices would require detailed rental price data.

Instead, I focus on the policy's general equilibrium effects, which I calculate by fitting the model to data for the cities considering increases and obtaining counterfactuals with a higher minimum wage.

\section{$5 \quad$ Fitting the Model}

This section shows how to implement the model on commuting data and calculate counterfactual equilibriums when exogenous variables such as the minimum wage change. Table 5 shows the parameters of the model grouped into three categories. The section shows how to obtain these parameters and model counterfactuals. First, I show how I obtain observed location-specific parameters. Second, I show how I calibrate parameters that are constant across locations, except the parameter $\epsilon$. Third, I outline two strategies to estimate $\epsilon$ and calculate the remaining location-specific parameters from data and values associated with the other parameters. Last, I describe an algorithm to calculate model counterfactuals.

Table 5: Model parameters

\begin{tabular}{ll}
\hline Type & Parameters \\
\hline Observed location-specific & $w_{i}^{s}, R_{n}^{s}, D_{n}, \kappa_{n i}$ \\
Constant across locations & $L^{s}, \epsilon, \beta, \sigma, \Omega^{s}, \eta, r^{s}, \xi^{s}$ \\
Unobserved location-specific & $\rho_{i}^{s}, T_{n}^{s}, X_{i}^{s}, A_{i}^{s}$ \\
\hline
\end{tabular}

\subsection{Calculation of observed parameters that vary by location}

The first group of parameters that I consider are location-specific but may be observed in the data. To fit the model, I consider the counties together with their commuting zones. The commuting zone acts as a city, and each county in the commuting zone is a location.

The wage among the low-skill group is the minimum wage used in section 2 . Wages for the other skill groups are exogenous, and they are calculated from average wages in the 
American Community Survey (ACS) by location and industry. Unemployment benefits are residence-based and obtained from the Bureau of Labor Statistics. Details on these variables are in appendix A.1.

Unemployment benefits are residence-based and obtained from BLS data. Land areas come from NHGIS data. Details on these variables are in Appendix A.1. ${ }^{21}$

I calculate commuting costs as a function of the distance between county centroids. Using driver data, Couture et al. (2018) calculate average commuting costs as a function of distance as follows:

$$
\ln \left(\text { avgcommutingcost }_{n i}\right)=-0.394 \log \left(\text { distance }_{n i}\right)+\log (1.352)+e_{n i} \text {. }
$$

Here, avgcommutingcost is the cost in minutes per kilometer for a commuting trip, and $e_{n i}$ is an error term. The equation implies a cost of about four minutes per kilometer traveled. Using this relationship, I calculate commuting costs as the loss in hourly wages from commuting:

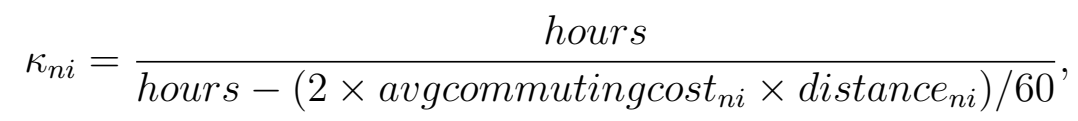

where hours are hours of work per day. For the baseline estimates, I assume 8 hours of work a day.

\subsection{Parameters that do not vary by location}

The second group of parameters needed does not vary by location inside the city. I take values from the literature for the housing share of income, the elasticity of substitution between labor types, and the matching function elasticity. I also calibrate other parameters to match vacancy filling rates and recruiting rates from the literature. Last, I obtain local separation rates from Quarterly Workforce Indicators (QWI) data. Table 6 summarizes the calibrated parameters. The only parameter that $\mathrm{I}$ do not set here is $\epsilon$.

I obtain labor supply by skill $L^{s}$ from the LODES data in section 2.1 for each county and commuting zone. I set $1-\beta$ as the housing share of expenditure from the Consumer Expenditure Survey following Monte et al. (2018). ${ }^{22}$

I set the parameter $\sigma$ at 2, in the lower end of estimates from Ottaviano and Peri (2012).

\footnotetext{
${ }^{21}$ Wages in other categories may react to the minimum wage, in which case they would not be exogenous. The evidence on the extent of these spillovers in the United States is limited. (Autor et al. 2016) finds that, while there are spillovers from increased minimum wages to higher percentiles of the wage distribution, they may be due to measurement error.

${ }^{22}$ Davis and Ortalo-Magne (2011) estimate the parameter at around 0.24 for renters in the United States. Combes et al. (2019) estimate this share at 0.2 to 0.4 from a sample of French cities.
} 
Table 6: Values for parameters that do not vary for location, excluding $\epsilon$

\begin{tabular}{llll}
\hline Parameter & Interpretation & Value & Source \\
\hline $1-\beta$ & Housing share of income & 0.4 & $\begin{array}{l}\text { Monte et al. (2018) match- } \\
\text { ing housing share of expen- } \\
\text { diture from the Consumer } \\
\text { Expenditure Survey }\end{array}$ \\
\hline$\sigma$ & $\begin{array}{lll}\text { Elasticity of substitution } \\
\text { between labor types }\end{array}$ & 2 & $\begin{array}{l}\text { Lower end of estimates from } \\
\text { Ottaviano and Peri (2012) }\end{array}$ \\
\hline$\Omega^{s}$ & Matching function constant & varies by city & $\begin{array}{l}\text { To match a vacancy filling } \\
\text { rate of 1.3 (Landais et al. } \\
\end{array}$ \\
& Matching function elasticity & 0.5 & $\begin{array}{l}\text { Petrongolo and Pissarides } \\
\text { (2001) }\end{array}$ \\
\hline$\eta$ & Separation rate & varies by city & $\begin{array}{l}\text { Separation rates by city and } \\
\text { wage category from Quar- } \\
\text { terly Workforce Indicators } \\
\text { (QWI) }\end{array}$ \\
\hline$\xi^{s}$ & & $\begin{array}{l}\text { To match a recruiting cost } \\
\text { of 2.5 percent of wage } \\
\text { (Landais et al. 2018) }\end{array}$ \\
\hline$r^{s}$ & Recuiters per vacancy & varies by cite & \\
& & &
\end{tabular}

Using a CES production function analogous to (9), they estimate this parameter using U.S. census data on employees by educational attainment and place of birth, among other variables. Here, I use the lower end of their estimates for the substitutability across educational levels. In the counterfactuals, some of the employment losses from an increased minimum wage arise because of substitution for other labor types. If $\sigma$ is higher than this estimate, employment losses in the counterfactuals should be a lower bound.

The parameters $\Omega^{s}$ and $r^{s}$ are set to match a recruiting cost of 2.5 percent of a worker's wage and a vacancy filling rate of 1.3, following Landais et al. (2018). There is relatively little evidence on the extent of recruiting costs or how these costs vary across types of jobs. Landais et al. (2018) estimate the costs based on the size of the recruiting industry. Their vacancy filling rate comes from data from the Job Openings and Labor Turnover Survey.

The matching function's elasticity $\eta$ is set at 0.5 following a survey by Petrongolo and Pissarides (2001) that finds constant returns to scale on matching functions and elasticities close to 0.5 across a wide range of studies. Separation rates, $\xi^{s}$, are set using data on separations by industry from the Quarterly Workforce Indicators and averaged across wage categories. Details are in appendix A.1. 


\subsection{Estimation of $\epsilon$ and unobserved location-specific parameters}

The last group of parameters in table 5 are location-specific but are unobserved and have to be recovered from data. These are employment probabilities, $\rho_{i}^{s}$, residential amenities, $T_{n}^{s}$, workplace amenities, $X_{i}^{s}$, and productivity, $A_{i}^{s}$, by worker type. I describe two strategies to obtain these parameters and the parameter $\epsilon$, which governs the strength of commuting and migration responses to changes in wages. The first strategy is maximum likelihood estimation taking the observed commuting probabilities as realizations of the model. The second strategy is estimation through the generalized method of moments (GMM), assuming that changes in residential and workplace amenities are uncorrelated with changes in wages.

Both strategies rely on the estimation of employment probabilities $\rho_{i}^{s}$. Appendix I.1 describes how to obtain employment probabilities using unemployment data by wage category across counties. Details on the unemployment data are in appendix A.1. Because unemployment is observed only by residence, I obtain unemployment at the workplace level using a random-matching assumption, which implies that unemployment data by residence are weighted averages of unemployment data by the workplace.

Maximum likelihood estimation. The first strategy assumes that the observed commuting flows are a realization of the model and finds the parameters that maximize the likelihood of observing this particular sample. From equations (11) and (22), the probability of commuting from $n$ to $i$ for skill group $s$ is:

$$
l_{n i}^{s}=\rho_{i}^{s} \frac{T_{n}^{s} X_{i}^{s}\left[\left(1+\rho_{i}^{s} \kappa_{n i}\right) Q_{n}^{1-\beta}\right]^{-\epsilon}\left(\tilde{w}_{n i}^{s}\right)^{\epsilon}}{\sum_{n} \sum_{i} T_{n}^{s} X_{i}^{s}\left[\left(1+\rho_{i}^{s} \kappa_{n i}\right) Q_{n}^{1-\beta}\right]^{-\epsilon}\left(\tilde{w}_{n i}^{s}\right)^{\epsilon}}
$$

Let $\mathbf{l}_{\text {nit }}^{s}$ be the observed fractions of commuters from $n$ to $i$ at time $t$ in the LODES data. Following Dingel and Tintelnot (2021), the log of the likelihood of observing these commuting flows is:

$$
\mathscr{L}=\sum_{s, n, i, t} \mathbf{l}_{n i t}^{s} \ln \left\{\rho_{i t}^{s} \frac{T_{n t}^{s} X_{i t}^{s}\left[\left(1+\rho_{i t}^{s} \kappa_{n i}\right) Q_{n t}^{1-\beta}\right]^{-\epsilon}\left(\tilde{w}_{n i t}^{s}\right)^{\epsilon}}{\sum_{n, i} T_{n t}^{s} X_{i t}^{s}\left[\left(1+\rho_{i t}^{s} \kappa_{n i}\right) Q_{n t}^{1-\beta}\right]^{-\epsilon}\left(\tilde{w}_{n i t}^{s}\right)^{\epsilon}}\right\}
$$

From Guimaraes et al. (2003) and Dingel and Tintelnot (2021), maximizing this loglikelihood is equivalent to Poisson regression with fixed effects by residence-skill-time, workplaceskill-time, and skill-time. The regression yields estimates of $\epsilon$, and the values of $T_{n t}^{s}$ and $X_{n t}^{s}$ can be recovered from the fixed effects. I implement this regression using the software in Correia et al. (2020).

GMM estimation. The second strategy is a generalized method of moments (GMM) 
estimation using the minimum wage variation across borders used to estimate the results in section 2. I can only use this estimation strategy for border cities in which the minimum wage varies by location, and I only use low-wage commuting data in the estimation. Following Ahlfeldt et al. (2015), I consider $X_{i}^{\ell}$ and $T_{i}^{\ell}$ to be structural errors of the model. The identifying assumption is that changes over time in these structural errors are uncorrelated with changes over time in the minimum wage, as follows: ${ }^{23}$

$$
\begin{aligned}
\Delta X_{i t}^{\ell} \Delta w_{i t}^{\ell} & =0 \\
\Delta T_{n t}^{\ell} \Delta w_{n t}^{\ell} & =0 .
\end{aligned}
$$

The border design of section 2 makes this identification assumption plausible because it reduces the impact of local shocks that may be correlated with changes in the minimum wage.

The estimation involves an "inner-loop" and an "outer-loop" procedure, following Holmes and Stevens (2014). In the inner-loop procedure, I obtain estimates of the unobserved components $X_{i}^{s}$ and $T_{i}^{s}$ given a value of $\epsilon$. In the outer loop procedure, I find a value of $\epsilon$ consistent with the moment conditions in equations (38) and (39).

For the computation of unobserved amenities and productivity in the inner loop, I assume that the data are a model equilibrium and recover the parameter values that rationalize the data. Given data on commuting, $L_{n i}$, unemployment, $U_{M i}$, and the observed location-specific parameters, there exist unique values of the unobserved parameters $T_{n}^{s}, X_{i}^{s}$, and $A_{i}^{s}$ that are consistent with the data as an equilibrium of the model, up to a normalization (Ahlfeldt et al. 2015; Monte et al. 2018). Appendix sections I.2, I.3 and I.4 show how to calculate these parameters given values of the parameters that are constant across locations and the observed data on commuting and location-specific parameters. Here, I briefly describe how I obtain these parameters.

- Based on employment probabilities, $\rho_{i}^{s}$, and wages, I calculate expected wages, $\tilde{w}_{i}^{s}$. Conditional on the residence and expected wages, places that receive more commuters must have higher workplace amenities. The variation in commuters allows the identification of workplace amenities, $X_{i}^{s}$. Details are in appendix I.2.

- Given these workplace amenities, places that have more residents must have higher residential amenities or lower housing prices. This relationship allows the identification of residential amenities, $T_{n}^{s}$, adjusted by housing prices. Details are in appendix I.3.

\footnotetext{
${ }^{23}$ This assumption is equivalent to assuming that $X_{i}^{\ell}$ and $T_{i}^{\ell}$ have a fixed component and a time-varying shock, as in Ahlfeldt et al. (2015). Also, note that $X_{i}^{s}$ and $T_{i}^{s}$ are measured up to a normalization. Normalizing cancels out components that are constant across locations.
} 
- Given the wages, unemployment, and labor market tightness, the firm's first-order conditions imply productivity values by type, $A_{i}^{s}$. Equilibrium market tightness can be obtained from data on job finding probabilities related to the spatial distribution of employment through equation (20). Details are in appendix I.4.

In the outer loop, using commuting and unemployment data, values of the calibrated parameters, I vary the parameter $\epsilon$ to satisfy the moment conditions in equations (38) and (39). For each value of epsilon, I obtain the values of $X_{i t}^{\ell}$ and $T_{i t}^{\ell}$ with the algorithms of the inner loop, for every city and year in my sample. I then obtain sample analogs of equations (38) and (39) and find the optimal value of $\epsilon$ through the generalized method of moments. The estimated $\epsilon$ solves the following minimization problem:

$$
\hat{\epsilon}=\underset{\epsilon}{\arg \min } \frac{1}{N T} \sum_{i, t}\left[\begin{array}{ll}
\Delta X_{i t}^{\ell} \Delta w_{i t} & \Delta T_{n t}^{\ell} \Delta w_{n t}^{\ell}
\end{array}\right] W\left[\begin{array}{c}
\Delta X_{i t}^{\ell} \Delta w_{i t} \\
\Delta T_{n t}^{\ell} \Delta w_{n t}^{\ell}
\end{array}\right],
$$

where $N$ is the number of locations in a city, $T$ is the number of years, and $W$ is a weighting matrix. I use a two-step efficient GMM estimator and set W equal to the inverse of the variance of each of the moments.

\section{Counterfactuals for City Data}

This section calculates counterfactual scenarios for cities that are considering minimum wage increases. I show some descriptive data on commuting and low-wage employment in these cities. Then I show estimates of $\epsilon$ derived from the methods described in the previous section. With these estimates of $\epsilon$ and other calibrated parameters, I calculate commuting, migration, and employment elasticities by comparing counterfactuals with minimum wage changes against the initial equilibriums. I show that the effects are heterogeneous across cities. Two-fifths of the counties with cities that are considering minimum wage increases would experience reductions in low-wage commuting. Furthermore, there is a nonlinear effect of the minimum wage on low-wage commuting.

\subsection{City-level Minimum Wage Policies}

Figure 6 shows counties with cities that are considering minimum wage increases. I consider all increases that would take place from 2018 onward since the LODES data ends in 2017. There are 50 cities in 28 counties considering increases, ranging from $\$ 9.05$ to $\$ 16.00$ an 
hour. The counties are in 20 commuting zones, 8 of which span state borders. ${ }^{24}$

Figure 6: Counties for cities with proposed minimum wage increases

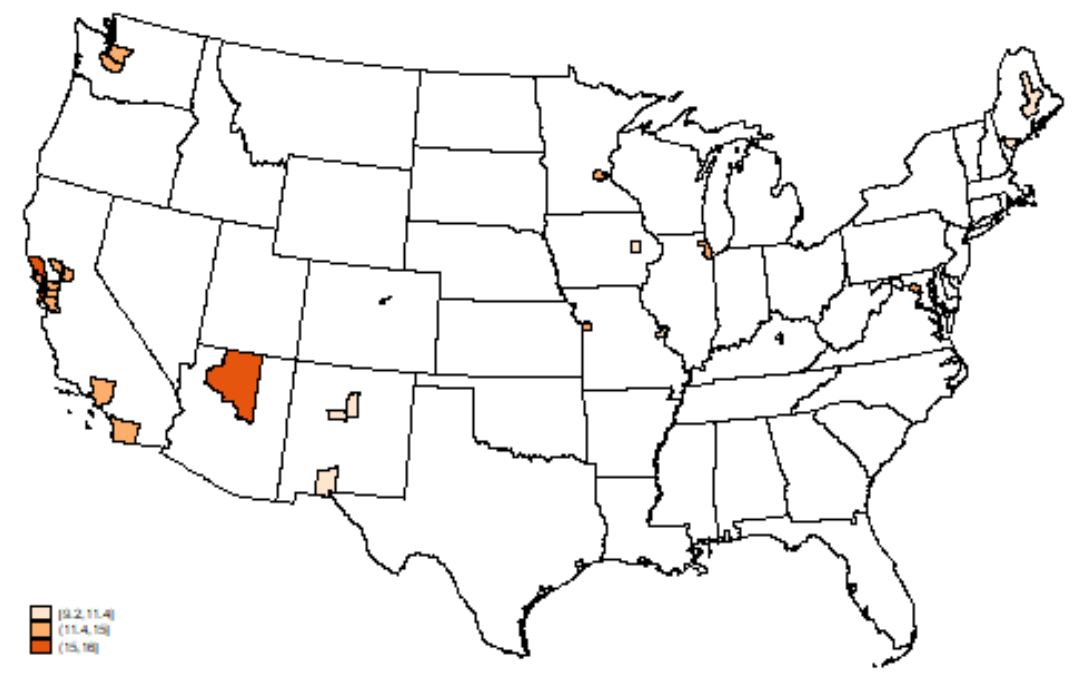

Source: Author's calculations based on National Employment Law Project (2016) and Dube and Lindner (2021). The colors indicate the maximum minimum wage proposed. Target years for minimum wage increases differ across counties.

I show the cross-sectional relationship between commuting, minimum wages, and employment probabilities in Figures $7 \mathrm{a}$ and $7 \mathrm{~b}$. Figure $7 \mathrm{a}$ shows the relationship between commuting and the minimum wage in the associated counties in 2017 , the latest year in the sample. It illustrates a weak positive relationship between higher minimum wages and the fraction of low-wage commuters, which would be expected if the higher wages attract them. The positive association appears even though places with a higher minimum wage tend to have lower shares of low-wage employment, as shown in figure J.7 of appendix J.

Figure $7 \mathrm{~b}$ shows the initial state of low-wage commuting and employment probabilities. A substantial share of low-wage employees in these areas are commuters, ranging from 3 percent to 77 percent. Employment probabilities range from 70 percent to 96 percent. As a share of low-wage employment, low-wage commuting tends to be higher in places with high employment probabilities. Larger employment probabilities (over job-seekers) on the vertical axis do not necessarily imply a large share of low-wage employment (over total employment). In figure J.6 of appendix J, I show that counties with higher low-wage employment tend to have fewer low-wage commuters as a share of employees. This last observation highlights the relevance of considering differences in search when examining commuting.

\footnotetext{
${ }^{24}$ The cross-border commuting zones are: Washington DC-MD-VA, Flagstaff, AZ-Kane City UT, Kansas City KS-MO, Las Cruces NM-El Paso TX, Los Angeles CA-La Paz AZ, Minneapolis-St. Paul MN-WI, Sacramento CA-Douglas City CO, and St. Louis MO - IL.
} 
Figure 7: Low-wage commuting, minimum wages and employment probabilities in 2017

(a) Low wage commuting and minimum wages

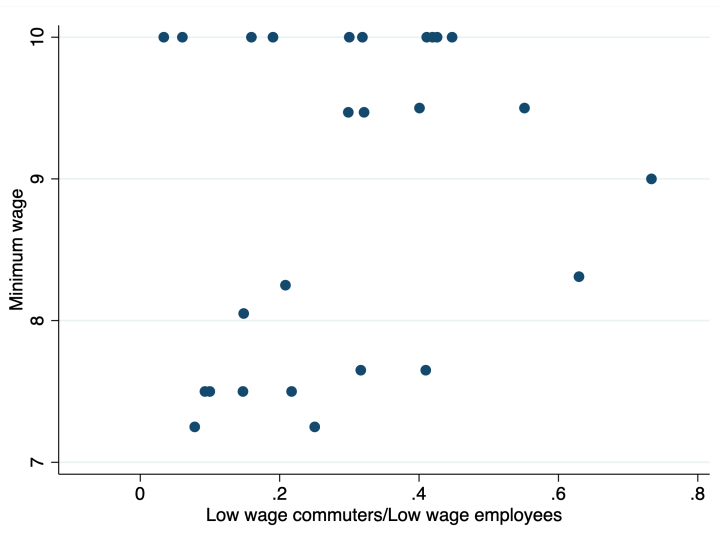

(b) Low wage commuting and employment probabilities

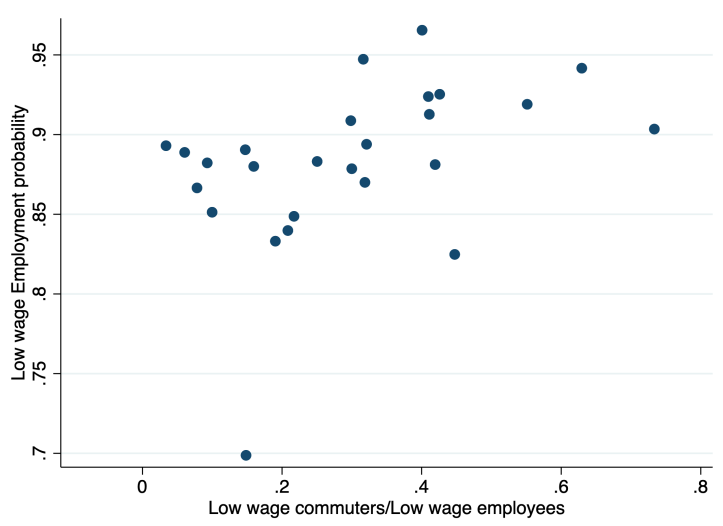

Source: Author's calculations based on LODES. Counties that include cities with approved proposals for minimum wage increases. Panel (a) shows the relationship between low-wage commuting and minimum wages. Panel (b) shows the relationship between low-wage commting and employment probabilities. The employment probabilities are calculated using unemployment data and the algorithm described in section I.1.

\subsection{Estimates of $\epsilon$ and counterfactual calculation}

Estimates of $\epsilon$. Since I fit the model for each commuting zone and counties inside the commuting zone act as locations, I obtain an estimate of $\epsilon$ for each commuting zone. This definition disregards commuting and migration responses that may occur across commuting zones. There are 20 commuting zones in which one or more counties are considering increases in the minimum wage. ${ }^{25}$

I calculate maximum-likelihood estimates of $\epsilon$ for each of the commuting zones using the commuting data described in section 2. Unemployment data from the ACS have only been available since 2005, so the sample runs from 2005 to 2017. Figure 8 shows the estimates for each commuting zone. These estimates range from around 6 to around 20. The lowest estimate corresponds to the Los Angeles, CA commuting zone, while the largest estimate is for Fayette, KY. The estimate of Monte et al. (2018) is around 3.5 based on commuting data for all workers and the entire country. The estimates here are much larger. Ahlfeldt et al. (2015) estimate coefficients between 8 and 12 for blocks in Berlin after the fall of the Berlin Wall. This latter range of estimates is closer to the ones presented here for U.S. cities. The hypothesis of equality of coefficients across commuting zones is rejected at the

\footnotetext{
${ }^{25}$ Figure J.8 of appendix J shows these commuting zones, the counties they include, and the target minimum wage.
} 
$1 \%$ significance level.

Figure 8: Estimated $\epsilon$ for commuting zones with counties considering minimum wage increases: Maximum likelihood estimation
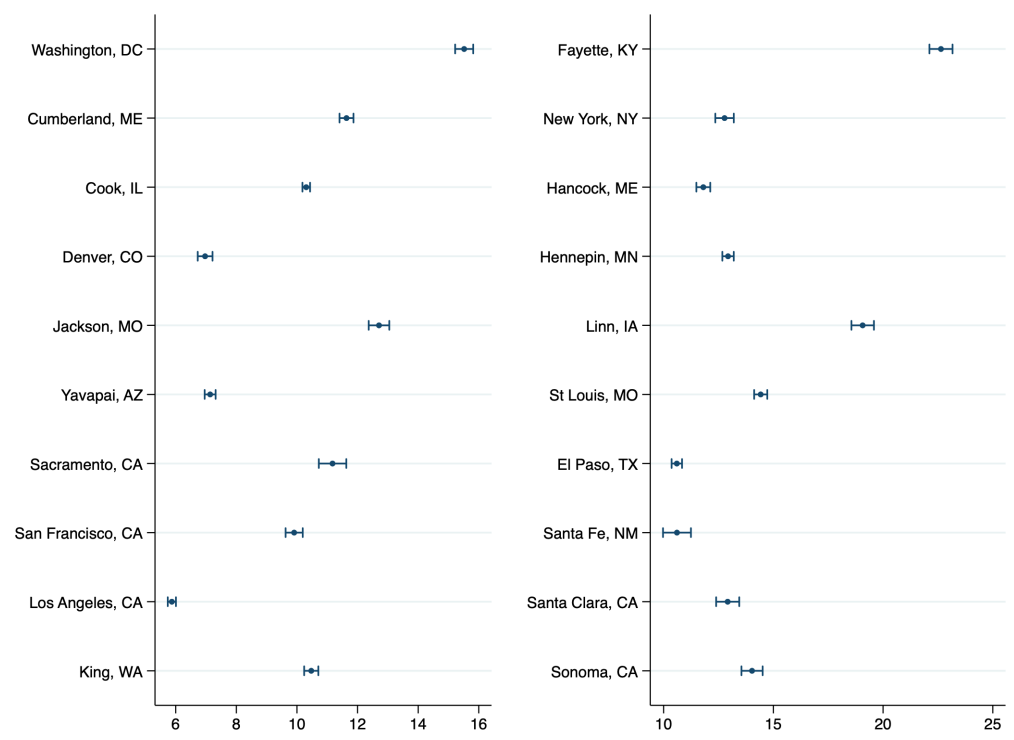

Source: Author's calculations. Observations are 20 commuting zones with cities considering minimum wage increases. Values of $\epsilon$ are estimates using equation (37) with commuting data from LODES described in section 2, and additional data described in Appendix A.1. The horizontal bars are confidence intervals at the $95 \%$ confidence level. Sample goes from 2005 to 2017.

I also estimate $\epsilon$ through GMM for seven commuting zones that span state borders and in which the minimum wage varies. Figure J.9 in the Appendix compares estimates of $\epsilon$ for these commuting zones using both estimation methods. In general, GMM estimates tend to be lower than maximum-likelihood estimates. While the maximum-likelihood estimates rely on commuting information for all labor types, GMM estimates use only data on low-wage commuting and the variation in the minimum wage. This pattern of estimation suggests that low-wage commuting may react less than high-wage commuting to wages. For consistency across cities, I use maximum-likelihood estimates for the analysis across all the cities. Higher values imply larger wage effects.

Computing counterfactuals. With the values of the constant and location-specific parameters, the model can be used to calculate counterfactual equilibriums if the minimum wage has increased in a location. Unlike the reduced-form analysis of section 2 and the partial equilibrium elasticities of section 4 , the counterfactual exercises allow me to obtain commuting and employment in general equilibrium after the minimum wage changes.

Appendix G.2 describes an algorithm to compute counterfactual equilibriums based on Monte et al. (2018). Given the observed data on commuting and employment and the 
values of the parameters, $\epsilon, \beta, \sigma, \Omega^{s}, \eta, r^{s}$ and $\xi^{s}$, the counterfactuals of the employment probabilities, $f\left(\theta_{i}^{s}\right)$ ), and the search probabilities, $o_{n i}^{s}$, can be obtained.

\subsection{Counterfactuals for commuting and migration}

Counterfactual scenarios for all cities. I calculate counterfactuals based on a computation of new equilibriums of the model involving increases in the minimum wage in the areas proposing changes. To compare cities, I increase the minimum wage by the same percentages in all these areas. This way, heterogeneity across areas in terms of responses will be derived from differences across cities and not because of differences in the target minimum wage. For the baseline estimates, I increase the minimum wage by 5 percent. To keep this magnitude in perspective, one of the largest increases in the sample, the Minneapolis minimum wage proposal for 2022, corresponds to an increase of 33 percent. I report elasticities of employment, commuting, and migration to these minimum wage increases. ${ }^{26}$

The first step is to check if the areas that increase the minimum wage become more attractive for low-wage job-seekers in the city. Figure 9 shows the elasticity of low-wage job searchers, $O_{M i}^{\ell}$, to the minimum wage increase. 15 out of 26 counties in the sample experience increases in job searches. The rest of the counties experience modest decreases in the number of job searchers. For the cities that experience job search increases, the model implies that the increase in job searches associated with a higher minimum wage if a job is found offsets the decrease in job searches associated with lower employment probabilities. ${ }^{27}$

After establishing that more than half of the cities would experience higher job search rates and the others would experience decreases in job search, and after showing that the magnitude of the decrease in job search depends on the size of the employment effects, I focus on commuting and migration. The aim is to examine if areas that increase minimum wages attract more commuters from other areas or induce workers to move to the former areas.

Figure 10a shows the estimated elasticities of low-wage commuting, calculated as total low-wage employment, minus low-wage employment among nonresidents. 5 out of 26 counties

\footnotetext{
${ }^{26}$ I exclude Albuquerque, NM from the counterfactual calculations because the ACS data did not report any high-wage unemployment there in 2017; and San Diego, CA, because its commuting zone only has one county. I also exclude the DC metropolitan area because of incomplete commuting data. The final sample for the counterfactuals includes 26 counties.

${ }^{27} \mathrm{I}$ also examine the effects on total employment in the appendix. Figure J.10 of appendix J shows that the places in which employment losses are the largest experience the largest reductions in job searches, as expected in the model. All counties experience reductions in employment probability. For most cities, the low-wage employment probability elasticity to the minimum wage is between -1.3 and -1.5 . Figure J.11 of appendix $\mathrm{J}$ shows how employment probabilities change for other types of labor. Because of substitution away from low-wage employment, these probabilities increase slightly.
} 
Figure 9: Elasticity of low wage searchers $O_{M i}^{\ell}$

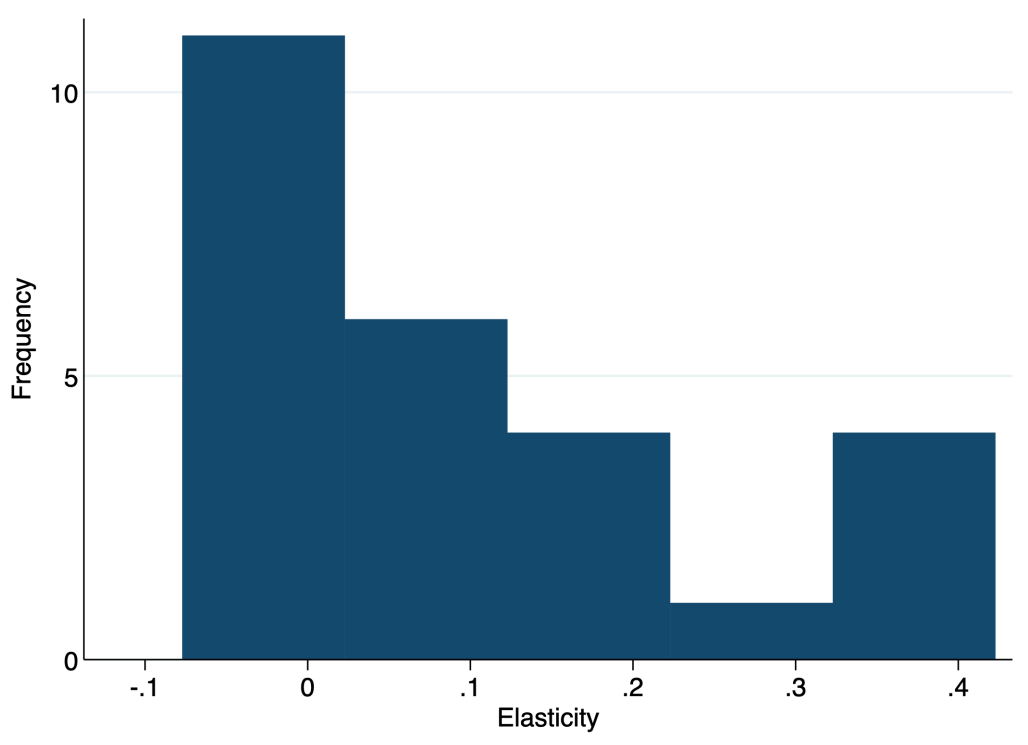

Source: Author's calculations. Observations are 26 counties with cities considering minimum wage increases. Values are elasticities of the number of low wage searchers $O_{M i}^{\ell}$ to an increase in the minimum wage, calculated from comparing an initial equilibrium to a model counterfactual with a minimum wage increase. In the counterfactuals, minimum wages were increased by $5 \%$.

would experience decreases in commuting, with an average elasticity of around -0.5. The rest of the counties would experience commuting increases, with an average elasticity of around 1.

Figure 10b shows that low-wage workers would migrate away from most of the relevant counties. The average elasticity is around -0.5. The negative elasticity shows that the commuting losses are not because of low-wage workers moving to areas with an increased minimum wage. The losses arise, instead, because of employment losses and relocation.

The differences in the magnitude of the wage effects explain a great deal of commuting and migration responses' heterogeneity. I show this relationship in figure 11, which illustrates $\epsilon$ and the elasticities of low-wage commuting and migration. As shown in section $4, \epsilon$ governs the size of the wage effects. As these wage effects increase, areas tend to experience increases in commuting. The relationship between $\epsilon$ and the migration elasticity is negative, with areas with higher values of $\epsilon$ exhibiting more negative migration elasticities, possibly due to housing price effects.

Elasticities and the size of minimum wage increases. One of the concerns about upcoming minimum wage policies is that the proposed increases are more considerable than historical increases of the federal or state minimum wage. Jardim et al. (Forthcoming) argue that Seattle's employment responses are more negative than what might be expected from 
Figure 10: Elasticities of commuting and migration to changes in the minimum wage

(a) Elasticities of low wage commuting

$$
L_{M i}^{\ell}-L_{i i}^{\ell}
$$

(b) Elasticities of low wage residents $O_{R n}^{\ell}$
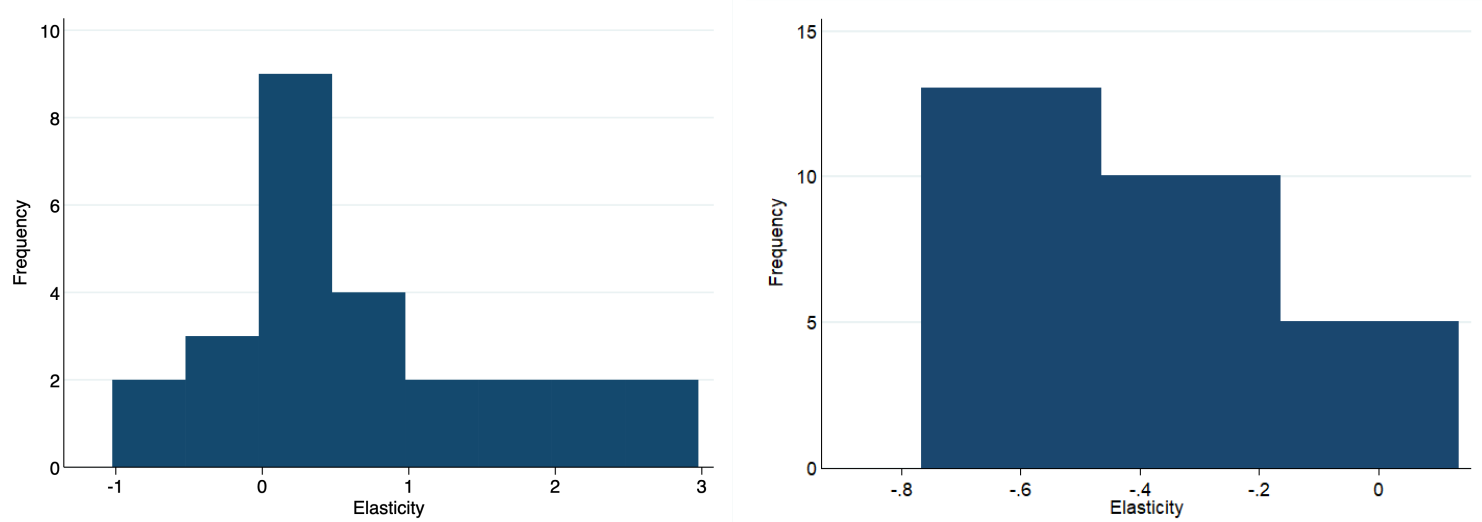

Source: Author's calculations. Observations are 26 counties with cities considering minimum wage increases. Values are elasticities calculated by comparing an initial equilibrium to a model counterfactual with a minimum wage increase. In the counterfactuals, minimum wages were increased by five percent.

Panel (a) shows elasticities of low wage commuting $L_{M i}^{\ell}-L_{i i}^{\ell}$ to an increase in their minimum wage. Low wage commuting is low-wage employment coming from areas different from the area that experiences the minimum wage increase.

Panel (b) shows elasticities of low wage residents $O_{R n}^{\ell}$ to an increase in the minimum wage. 
Figure 11: Low-wage commuting and migration elasticities and value of $\epsilon$
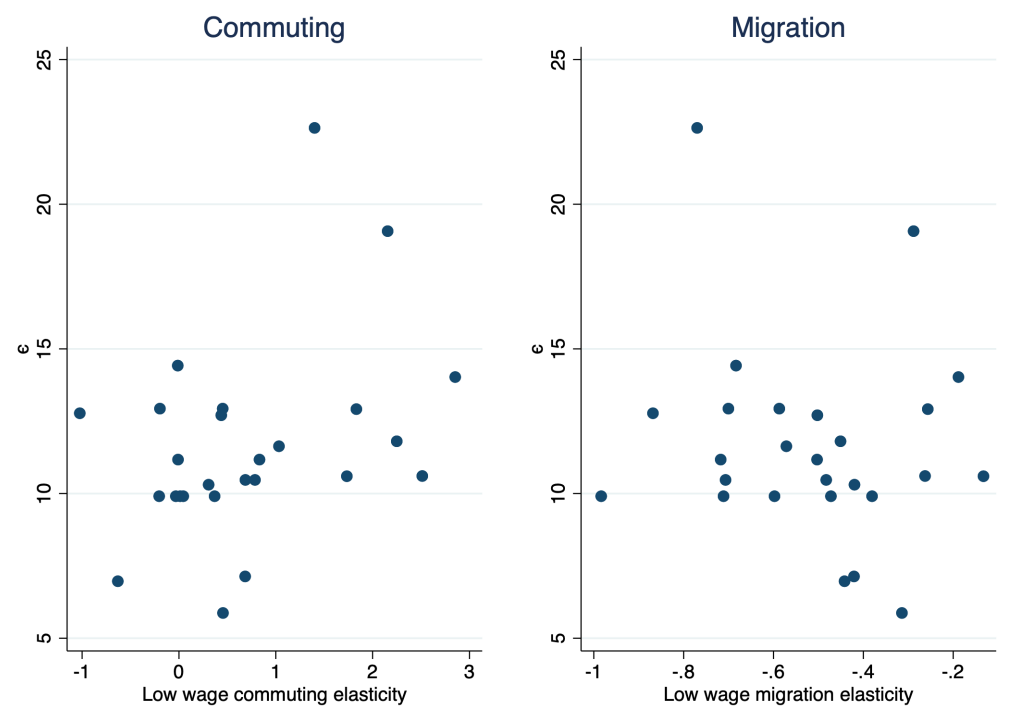

Source: Author's calculations. Observations are 26 counties with cities considering minimum wage increases. The left panel shows values of the elasticity of low wage commuting $L_{M i}^{\ell}-L_{i i}^{\ell}$ to an increase in the minimum wage against values of the dispersion parameter $\epsilon$. The right panel shows values of the elasticity of low wage residents $O_{R n}^{\ell}$ to an increase in the minimum wage against values of the dispersion parameter $\epsilon$. Elasticities are calculated from comparing an initial equilibrium to a model counterfactual with a minimum wage increase. Low wage commuting is low-wage employment coming from areas different from the area that experiences the minimum wage increase. In the counterfactuals, minimum wages were increased by five percent. 
current estimates in the minimum wage literature. Clemens and Strain (2021) also argue that employment elasticities are more negative for large minimum wage changes. The study here indicates the possibility of larger effects on commuting if the minimum wage increases are more extensive than historical. Figure 12 shows the average low-wage commuting elasticity for increases of 1 percent, 5 percent, and 10 percent in the minimum wage across areas. The commuting elasticity becomes more negative as the minimum wage increase becomes larger. Although in the model (from equation 22), commuting probabilities are a nonlinear function of expected wages, they have a constant elasticity to expected wages. The nonlinear response arises from other channels in the model, such as stronger employment responses. The variance in commuting elasticities across cities also grows with the size of the minimum wage increase.

Figure 12: Low wage commuting elasticity and size of the minimum wage increase

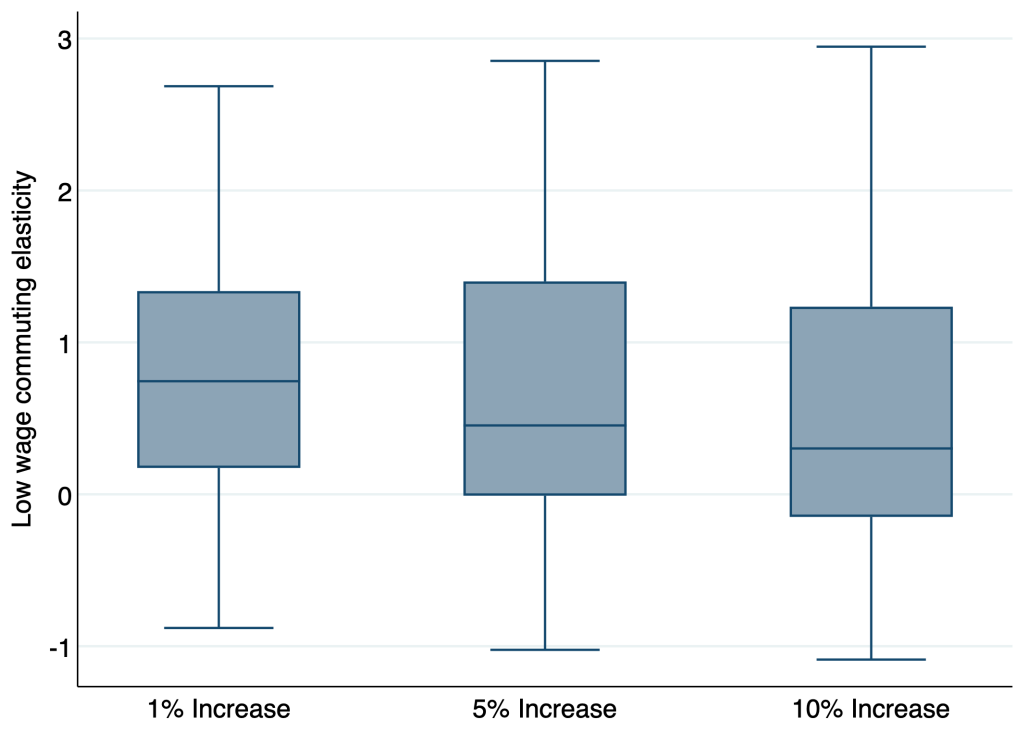

Source: Author's calculations. Observations are low-wage commuting elasticities for minimum wage increases of 1,5 , and $10 \%$ in counties with cities considering minimum wage increases. Elasticities are calculated from comparing an initial equilibrium to a model counterfactual with a minimum wage increase. Low wage commuting is low-wage employment coming from areas different from the area that experiences the minimum wage increase.

Alternative estimates of $\epsilon$ from figure J.9 imply smaller wage effects, which would imply that commuting elasticities would be more negative if we were to use the estimates from this subset of cities. The counterfactual scenarios based on maximum-likelihood estimates of $\epsilon$ should be interpreted as a lower bound on the negative elasticity of commuting to the minimum wage if one prefers the smaller estimates. 


\subsection{Welfare}

Table 7 shows the average effects on expected utility of a $5 \%$ minimum wage increase across the commuting zones with counties considering minimum wage increases. To calculate the change in commuting zone utility, I weight the utility changes in each skill group by the number of residents of each. I also calculate the change in utility by skill group.

The utility of search (before employment outcomes are realized) grows on average $0.07 \%$ across observations, with substantial heterogeneity across commuting zones. In those where the employment probabilities decrease the most, this expected utility can drop as much as $0.3 \%$. The expected utility of search increases the most for the low-wage group due to increased wages. On average, the mid-wage group sees a reduction in their expected utility from increases in housing prices not offset by increases in employment probabilities. On the other hand, the high-wage group sees an average increase in utility from higher employment probabilities.

Conditional on employment, the utility of the low-wage group unambiguously increases. For the other groups, utility may increase or decrease depending on the effect on housing prices. ${ }^{28}$ On average, utility for these groups decreases because of housing price increases. Conditional on unemployment, utility also decreases on average for the same reason. Overall, while the other wage groups may benefit from higher employment probabilities, they lose utility on average.

\footnotetext{
${ }^{28}$ Note that the percentage changes in the expected utility conditional on employment or unemployment need not be the same across wage groups, even if the percentage changes in utility given a workplace-residence pair are the same. Because the utility of search is different across skill groups, the effect of the minimum wage on the location choices of agents is different across skill groups.
} 
Table 7: Average changes in expected utility from a 5\% minimum wage change in counterfactuals

\begin{tabular}{lccc}
\hline \% change in Utility & Search & Employment & Unemployment \\
\hline \multicolumn{1}{c}{ Average across wage groups, weighted by number of residents } \\
Mean & 0.07 & 0.36 & -0.04 \\
Median & 0.07 & 0.25 & -0.04 \\
Range & $(-0.30,0.21)$ & $(-0.02,1.06)$ & $(-0.10,0.03)$ \\
\hline \multicolumn{4}{c}{ Low wage group } \\
Mean & 0.15 & 1.77 & -0.04 \\
Median & 0.13 & 1.24 & -0.05 \\
Range & $(-0.34,0.57)$ & $(0.03,4.90)$ & $(-0.11,0.02)$ \\
\hline & Mid wage group & \\
Mean & -0.03 & -0.04 & -0.04 \\
Median & 0.04 & -0.04 & -0.03 \\
Range & $(-2.28,0.23)$ & $(-0.11,0.03)$ & $(-0.10,0.03)$ \\
\hline & High wage group & \\
Mean & 0.10 & -0.05 & -0.04 \\
Median & 0.06 & -0.05 & -0.04 \\
Range & $(0.00,1.07)$ & $(-0.12,0.01)$ & $(-0.10,0.03)$ \\
\hline
\end{tabular}

Source: Author's calculations. Observations are commuting zones for counties considering minimum wage increases. The average across wage groups, the averages are weighted by the number of residents of each wage group. The expected utility of search comes from equation (25), and the expected utilities of employment and unemployment come from equation (26). See Appendix J for calculations with minimum wage increases of $1 \%$ and $10 \%$. 


\section{Concluding Remarks}

To analyze the effects of a higher city minimum wage, I estimate the reduced form elasticity of low-wage commuting, low-wage employment, and low-wage residents to changes in the minimum wage in cross-state-border areas in the United States. I find a negative association between the minimum wage and commuting in cities adjacent to U.S. state borders. I find that commuting responses can be explained by employment relocation.

To clarify the drivers behind these results and extrapolate to U.S. cities considering an increase in the minimum wage, I propose a structural model of commuting, migration, and employment. The model extends standard quantitative urban models to allow for unemployment. The framework accounts for several mechanisms through which higher minimum wages may change spatial equilibriums in cities: increased job search in places with high minimum wages, reductions in labor demand, and changes in housing prices.

I describe how to obtain equilibriums and counterfactuals for this model, and I fit it to data on U.S. cities. In counterfactual scenarios with higher minimum wages, some areas considering larger minimum wage increases experience commuting and low-wage employment losses. Several other channels beyond the ones included in the model may change this elasticity. Two significant channels are the relocation of firms from high-minimum wage to low-minimum wage areas, which changes labor demand, and the responses in the labor supply of low-skill workers. More research on these topics might explore the spatial variation of these demand and supply responses.

\section{References}

Ahlfeldt, Gabriel M; Redding, Stephen J; Sturm, Daniel M and Wolf, NikoLAUs (2015). "The Economics of Density: Evidence from the Berlin Wall". Econometrica, 83(6), pp. 2127-2189.

Aronow, Peter M; Sami, Cyrus and Assenova, Valentina A (2015). "ClusterRobust Variance Estimation for Dyadic Data". Political Analysis, pp. 564-577.

Autor, David H.; Manning, Alan and Smith, Christopher L. (2016). "The Contribution of the Minimum Wage to US Wage Inequality over Three Decades: A Reassessment". American Economic Journal: Applied Economics, 8(1), pp. 58-99.

Belman, Dale and Wolfson, Paul J. (2014). What Does the Minimum Wage Do? W.E. Upjohn Institute for Employment Research. 
Bilal, Adrien (2020). "The Geography of Unemployment". Working Paper.

Cadena, Brian C. (2014). "Recent Immigrants as Labor Market Arbitrageurs: Evidence From the Minimum Wage". Journal of Urban Economics, 80(C), pp. 1-12.

Cameron, A. Colin; Gelbach, Jonah B. and Miller, Douglas L. (2011). "Robust Inference With Multiway Clustering". Journal of Business 63 Economic Statistics, 29(2), pp. 238-249.

Card, David and Lemieux, Thomas (2001). "Can Falling Supply Explain the Rising Return to College for Younger Men? A Cohort-Based Analysis". The Quarterly Journal of Economics, 116(2), pp. 705-746.

Cengiz, Doruk; Dube, Arindrajit; Lindner, Attila and Zipperer, Ben (2019). "The Effect of Minimum Wages on Low-Wage Jobs". The Quarterly Journal of Economics, 134(3), pp. 1405-1454.

Clemens, Jeffrey; Kahn, Lisa B and Meer, Jonathan (2018). "The Minimum Wage, Fringe Benefits, and Worker Welfare". Working Paper 24635, National Bureau of Economic Research.

Clemens, Jeffrey and Strain, Michael R (2021). "The Heterogeneous Effects of Large and Small Minimum Wage Changes: Evidence over the Short and Medium Run Using a Pre-Analysis Plan". Working Paper 29264, National Bureau of Economic Research.

Combes, Pierre-Philippe; Duranton, Gilles and Gobillon, Laurent (2019). "The Costs of Agglomeration: House and Land Prices in French Cities". The Review of Economic Studies, 86(4), pp. 1556-1589.

Correia, Sergio (2017). "Linear Models with High-Dimensional Fixed Effects: An Efficient and Feasible Estimator". Working Paper.

Correia, Sergio; Guimaraes, Paulo and Zylkin, Tom (2020). "Fast Poisson estimation with high-dimensional fixed effects". The Stata Journal, 20(1), pp. 95-115.

Couture, Victor; Duranton, Gilles and Turner, Matthew A (2018). "Speed". Review of Economics and Statistics, 100(4), pp. 725-739.

Davis, Morris A. and Ortalo-Magne, Francois (2011). "Household Expenditures, Wages, Rents". Review of Economic Dynamics, 14(2), pp. 248-261. 
de Chaisemartin, Clément and D’Haultfaullle, Xavier (2020). "Two-Way Fixed Effects Estimators with Heterogeneous Treatment Effects". American Economic Review, 110(9), pp. 2964-96.

Diaz, Ana Maria and Salas, Luz Magdalena (2020). "Do Firms Redline Workers?" Regional Science and Urban Economics, 83, p. 103541.

Dieterle, Steven; Bartalotti, Otávio and Brummet, Quentin (2020). "Revisiting the Effects of Unemployment Insurance Extensions on Unemployment: A MeasurementError-Corrected Regression Discontinuity Approach". American Economic Journal: Economic Policy, 12(2), pp. 84-114.

Dingel, Jonathan I. and Tintelnot, Felix (2021). "Spatial Economics for Granular Settings". Working paper.

Dube, Arindrajit; Lester, T William and Reich, Michael (2010). "Minimum Wage Effects Across State Borders: Estimates Using Contiguous Counties". The Review of Economics and Statistics, 92(4), pp. 945-964.

Dube, Arindrajit; Lester, T. William and Reich, Michael (2016). "Minimum Wage Shocks, Employment Flows, and Labor Market Frictions". Journal of Labor Economics, 34(3), pp. 663-704.

Dube, Arindrajit and Lindner, Attila (2021). "City Limits: What Do Local-Area Minimum Wages Do?" Journal of Economic Perspectives, 35(1), pp. 27-50.

Dube, Arindrajit; Naidu, Suresh and Reich, Michael (2007). "The Economic Effects of a Citywide Minimum Wage". Industrial and Labor Relations Review, 60(4), pp. 522543.

Eaton, Jonathan and Kortum, Samuel (2002). "Technology, Geography, and Trade". Econometrica, 70(5), pp. 1741-1779.

Ferman, Bruno and Pinto, Cristine (2019). "Inference in Differences-in-Differences with Few Treated Groups and Heteroskedasticity". The Review of Economics and Statistics, 101(3), pp. 452-467.

Freyaldenhoven, Simon; Hansen, Christian and Shapiro, Jesse M. (2019). "Preevent Trends in the Panel Event-Study Design". American Economic Review, 109(9), pp. 3307-38. 
Goodman-Bacon, Andrew (2021). "Difference-in-Differences with Variation in Treatment Timing". Journal of Econometrics, 225(2), pp. 254-277.

Graham, Matthew R.; Kutzbach, Mark J. and McKenzie, Brian (2014). "Design Comparison of LODES and ACS Commuting Data Products". Working Papers 14-38, Center for Economic Studies, U.S. Census Bureau.

Guimaraes, Paulo; Figueirdo, Octávio and Woodward, Douglas (2003). "A Tractable Approach to the Firm Location Decision Problem". Review of Economics and Statistics, 85(1), pp. 201-204.

Hagedorn, Marcus; Karahan, Fatih; Manovskit, Iourit and Mitman, Kurt (2016). "Unemployment Benefits and Unemployment in the Great Recession: The Role of Macro Effects". Working Paper 19499, National Bureau of Economic Research.

Hayward, Heath (2014). "Local Employment Dynamics: Connecting Workers and Jobs". https://lehd.ces.census.gov/doc/learning_guide/LED_Lodes_Intro.pdf

Holmes, Thomas J. and Stevens, John J. (2014). "An Alternative Theory of the Plant Size Distribution, with Geography and Intra- and International Trade". Journal of Political Economy, 122(2), pp. 369 - 421.

Jardim, Ekaterina; Long, Mark C; Plotnick, Robert; van Inwegen, Emma; VigDOR, Jacob and Wething, Hilary (2018). "Minimum Wage Increases and Individual Employment Trajectories". Working Paper 25182, National Bureau of Economic Research.

Jardim, Ekaterina; Long, Mark C.; Plotnick, Robert; van Inwegen, Emma; Vigdor, Jacob and Wething, Hilary (Forthcoming). "Minimum Wage Increases and Low-Wage Employment: Evidence from Seattle". American Economic Journal: Economic Policy.

Kneebone, Elizabeth and Holmes, Natalie (2015). "The Growing Distance Between People and Jobs in Metropolitan America". Working paper, Brookings Institution Metropolitan Policy Program.

Kuehn, Daniel (2016). "Spillover Bias in Cross-Border Minimum Wage Studies: Evidence from a Gravity Model". Journal of Labor Research, 37(4), pp. 441-459.

Landais, Camille; Michaillat, Pascal and Saez, Emmanuel (2018). "A Macroeconomic Approach to Optimal Unemployment Insurance: Applications". American Economic Journal: Economic Policy, 10(2), pp. 182-216. 
Leamer, Edward E.; Nickelsburg, Jerry; von Wachter, Till M. and Zimmerman, Frederic (2018). "Assessing the Differential Impacts of Minimum Wage Increases in Labor Market Areas in California". ASSA Anual Meeting.

Machanavajuhala, Ashwin; Kifer, Daniel; Abowd, John; Gehrke, Johannes and Vilhuber, Lars (2008). "Privacy: Theory Meets Practice on the Map". In: Proceedings of the 2008 IEEE 24th International Conference on Data Engineering, ICDE '08, pp. 277-286. IEEE Computer Society, Washington, DC, USA.

Manning, Alan and Petrongolo, Barbara (2017). "How Local Are Labor Markets? Evidence from a Spatial Job Search Model". American Economic Review, 107(10), pp. $2877-2907$.

Manson, Steven; Schroeder, Jonathan; Riper, David Van; Kugler, Tracy and Ruggles, Steven (2021). "IPUMS National Historical Geographic Information System: Version 16.0".

McKinnish, Terra (2017). "Cross-State Differences in the Minimum Wage and Out-ofState Commuting by Low-Wage workers". Regional Science and Urban Economics, 64, pp. $137-147$.

Michaillat, Pascal (2012). "Do Matching Frictions Explain Unemployment? Not in Bad Times". American Economic Review, 102(4), pp. 1721-50.

Michaillat, Pascal and Saez, Emmanuel (2015). "Aggregate Demand, Idle Time, and Unemployment". Quarterly Journal of Economics, 130(2), pp. 507-569.

Monras, JoAn (2019). "Minimum Wages and Spatial Equilibrium: Theory and Evidence". Journal of Labor Economics, 37(3), pp. 853-904.

Monte, Ferdinando; Redding, Stephen J. and Rossi-Hansberg, Esteban (2018). "Commuting, Migration, and Local Employment Elasticities". American Economic Review, 108(12), pp. 3855-90.

National Employment LaW Project (2016). "City Minimum Wages: Recent Trends and Economic Evidence".

Neumark, David; Salas, J.M. Ian and Wascher, William (2014). "Revisiting the Minimum Wage-Employment Debate: Throwing Out the Baby with the Bathwater?" ILR Review, 67(3_suppl), pp. 608-648. 
Ottaviano, Gianmarco I. P. and Peri, Giovanni (2012). "Rethinking the Effect of Immigration on Wages". Journal of the European Economic Association, 10(1), pp. 152197.

Petrongolo, Barbara and Pissarides, Christopher A. (2001). "Looking into the Black Box: A Survey of the Matching Function". Journal of Economic Literature, 39(2), pp. 390-431.

Redding, Stephen J. and Rossi-Hansberg, Esteban (2017). "Quantitative Spatial Economics". Annual Review of Economics, 9(1), pp. 21-58.

Schmidheiny, Kurt and Siegloch, Sebastian (2020). "On Event Studies and Distributed-Lags in Two-Way Fixed Effects Models: Identification, Equivalence, and Generalization". Working paper.

Shirley, Peter (2018). "The Response of Commuting Patterns to Cross-Border Policy Differentials: Evidence from the American Community Survey". Regional Science and Urban Economics, 73, pp. 1-16. ISSN 0166-0462.

Suárez Serrato, Juan Carlos and Zidar, Owen (2016). "Who Benefits from State Corporate Tax Cuts? A Local Labor Markets Approach with Heterogeneous Firms". American Economic Review, 106(9), pp. 2582-2624.

Sun, Liyang and Abraham, Sarah (2021). "Estimating Dynamic Treatment Effects in Event Studies with Heterogeneous Treatment Effects". Journal of Econometrics, 225(2), pp. 175-199. Themed Issue: Treatment Effect 1.

U.S. Census Bureau (2016). "LODES Data. Longitudinal-Employer Household Dynamics Program.". http://lehd.ces.census.gov/data/lodes/

U.S. Census Bureau (2019). "LEHD Origin-Destination Employment Statistics (LODES) Dataset Structure Format Version 7.4". https://lehd.ces.census.gov/data/lodes/LODES7/LODESTechDoc7.4.pdf

Vaghul, Kavya and Zipperer, Ben (2016). "Historical State and Sub-State Minimum Wage Data". https://equitablegrowth.org/working-papers/historical-state-and-sub-stateminimum-wage-data

Zhang, WeILOng (2018). "Distributional Effects of Local Minimum Wage Hikes: A Spatial Job Search Approach". Available at SSRN 3309362. 


\section{Online Appendix - Not for Publication}

\section{A Data appendix}

\section{A.1 Details on data sources}

This section describes the additional data sources used for the reduced-form analysis and the model in detail.

- Wages for mid and high wage categories: Estimates from ACS data 2005-2017. I assign workers into categories based on their reported monthly income. For unemployed workers, I impute their income category as the modal income category on their PUMA, industry, race, age and education. I calculate their hourly wages by dividing their monthly income over 4 times the reported usual weekly hour of work. I then calculate the average wage across industries and PUMA. To obtain county-level wage data, I use the PUMA - County crosswalks based on the American Fact Finder by the University of Michigan Population Studies Center.

- Population: County-level population estimates from the U.S Census Bureau from 2000 to 2017. I combine information from the 2000-2010 estimates and 2010-2017 estimates. I use the July estimates. I use total population and population younger than 30 grouped in age bins of 4 years.

- Unemployment rate and labor force: For the reduced form analysis, I use data from the Local Area Unemployment Statistics from the BLS. I calculate yearly averages of the monthly non-seasonally adjusted unemployment rate. Then I use lags of these yearly state-level unemployment rate as controls.

For the model I need unemployment rates by wage level for each county. I get unemployment rates for workers in the age and wage categories of the LODES from the yearly ACS at the puma level. I then match these unemployment rates to the county level using the crosswalks provided by the Michigan Population Studies Center.

- Establishment counts: I use Annual Average Establishment counts from the QCEW high level county files.

- Corporate taxes: I use average corporate taxes compiled by Suárez Serrato and Zidar (2016).

- EITC: I use state EITC data from the Center of Budget and Policy Priorities 
- Gas prices: I use data from the State Energy Data System of the US Energy Information Administration

- Unemployment benefits: I use BLS data on the percentage of the wage that can be claimed as unemployment benefits by state.

- Land: I use the sum of low, mid, and high-intensity developed areas from the IPUMS NHGIS files (Manson et al. 2021). I measure areas in square miles.

- Separations: County level separation data from the Quarterly Workforce Indicators (QWI). I use earnings and the separations rate at the beginning of the quarter. I assign wage categories based on industry averages for NAICS industries at the highest level of disaggregation available for every state. Then I average across quarters, earnings categories and locations.

\section{A.2 Details on imputation in LODES data}

This section is heavily based on Hayward (2014) and Graham et al. (2014). LODES employment totals have noise infusion. Job counts are multiplied by random factors specific to each employer and establishment. The LODES dataset does not suppress job counts, as opposed to the QWI. Residential locations of workers are synthesized using a method described in Machanavajjhala et al. (2008). For each workplace cell, residential locations are drawn from a distribution based on the data. This distribution is the posterior distribution produced by combining the data distribution with a prior that is based on the previous year of data. For the initial year in LODES, priors are taken from the CTPP. For later years, the prior is the previous sample of LODES. There is a different distribution for each breakdown of jobs. If the sample taken is not representative of the original data, new samples are redrawn until the data satisfies representability criteria. Each job gets a residential location synthesized at least at the Super-PUMA level, and these are then decoarsened to the census tract and block level using the population distribution from the Census. LODES 7 is based on PUMAs and population from the 2010 Census.

\section{B Regressions with gross flows and regressions with net flows}

In this section I show that a regression with net flows only identifies minimum wage effects if they are symmetric at the workplace and residence levels. Assume that commuting from $n$ to $i$ at time $t$ depends on the differences in minimum wages between $n$ and $i$ in both directions: 


$$
\begin{aligned}
& C_{n i t}=\alpha_{n i}+\beta\left(\text { minwage }_{i t}-\text { minwage }_{n t}\right)+\varepsilon_{n i t} \\
& C_{i n t}=\alpha_{i n}+\beta\left(\text { minwage }_{n t}-\text { minwage }_{i t}\right)+\varepsilon_{i n t}
\end{aligned}
$$

Then a regression of net flows overestimates the coefficient:

$$
C_{n i t}-C_{i n t}=\left(\alpha_{n i}-\alpha_{i n}\right)+2 \beta\left(\text { minwage }_{n t}-\text { minwage }_{i t}\right)+\varepsilon_{n i t}-\varepsilon_{i n t}
$$

Now assume that commuting depends on minimum wages both at the workplace and residence, $\beta_{r}$ is associated with the residence minimum wage, and $\beta_{w}$ is associated with the workplace minimum wage:

$$
\begin{aligned}
& C_{n i t}=\alpha_{n i}+\beta_{r} \text { minwage }_{n t}+\beta_{w} \text { minwage }_{i t}+\varepsilon_{n i t} \\
& C_{\text {int }}=\alpha_{i n}+\beta_{r} \text { minwage }_{i t}+\beta_{w} \text { minwage }_{n t}+\varepsilon_{i n t}
\end{aligned}
$$

Then a regression with net flows as the dependent variable does not identify the coefficients, only their differences :

$$
C_{n i t}-C_{i n t}=\left(\alpha_{n i}-\alpha_{i n}\right)+\left(\beta_{r}-\beta_{w}\right) \text { minwage }_{n t}+\left(\beta_{w}-\beta_{r}\right) \text { minwage }_{i t}+\varepsilon_{n i t}-\varepsilon_{i n t}
$$

A regression with net flows would also fail to identify the coefficients if they are different in each commuting direction, for example, if the flows towards and away from central business district react to minimum wages differently.

\section{Robustness tests on the effect of minimum wages on commuting}

\section{C.1 Panel event-study estimates}

To test for preexisting trends and lagged effects, I follow Schmidheiny and Siegloch (2020) and Freyaldenhoven et al. (2019) and estimate a panel event study analog of equation (3), including leads and lags of up to three years of the difference in minimum wages between workplace and residence.

The specifications for the panel design and the within design are, respectively: 


$$
\begin{aligned}
& C_{n i t}=\beta_{0}+\delta_{-3+}^{r e s}\left[1-\left(\ln \left(\text { minwage }_{n, t-3}\right)\right]+\sum_{k=-2}^{2} \delta_{-k}^{r e s} \ln \left(\text { minwage }_{n, t+k}\right)\right. \\
& +\delta_{3+}^{\text {res }} \ln \left(\text { minwage }_{n, t-3}\right)+\delta_{-3+}^{\text {work }}\left[1-\left(\ln \left(\text { minwage }_{i, t-3}\right)\right]+\sum_{k=-2}^{2} \delta_{-k}^{\text {work }} \ln \left(\text { minwage }_{i, t+k}\right)\right. \\
& +\delta_{3+}^{w o r k} \ln \left(\text { minwage }_{i, t-3}\right)+\tau_{n i}+\gamma_{t}+\Phi_{w o r k} X_{i t}+\Phi_{r e s} X_{n t}+\varepsilon_{n i t} . \\
& C_{n i t}=\beta_{0}+\delta_{-3+}\left[1-\left(\ln \left(\operatorname{minwage}_{i, t-3}\right)-\ln \left(\text { minwage }_{n, t-3}\right)\right]\right. \\
& +\sum_{k=-2}^{2} \delta_{-k}\left[\ln \left(\text { minwage }_{i, t+k}\right)-\ln \left(\text { minwage }_{n, t+k}\right]\right. \\
& +\delta_{3+}\left[\ln \left(\text { minwage }_{i, t-3}\right)-\ln \left(\text { minwage }_{n, t-3}\right)\right]+\gamma_{n t}+\tau_{i}+\Phi_{\text {work }} X_{i t}+\varepsilon_{n i t} .
\end{aligned}
$$

In the panel design,the coefficients $\delta_{k}^{r e s}$ and $\delta_{k}^{\text {work }}, k=-3+,-2, \ldots, 2,3+$ measure lead and lag effects of the increase in minimum wages at the residence and workplace level on the pairwise low-wage commuting flows. For the within design, the coefficients $\delta_{k} k=$ $-3+,-2, \ldots, 2,3+$ measure the effects of the increase in the difference in minimum wages between workplace and residence in these commuting flows. If the coefficients were different from zero for $k<0$, the identification assumptions behind the estimates of equations (1) and (3) would be suspect. This would happen because there would be differences in the flows before the difference in minimum wages changed. The coefficients for $k>0$ measure contemporaneous and lagged effects of minimum wages (or their difference) on commuting.

The results are in figure C.1. These indicate that the elasticity of commuting to either the minimum wage at the workplace or the difference in minimum wages only becomes negative and significant after they increase. The results in panel (a) for the panel design are noisy, but do show a decrease after increments in the minimum wage at the workplace take place. The coefficients in panel (b) show a clearer picture. The coefficients on the leads are not significant and do not display a time pattern, and the coefficient on the contemporaneous effect does not decrease in absolute value. The coefficients grow over time, and the point estimate for the low-wage commuting elasticity is around - 0.5 after two years. However, lagged effects display substantial uncertainty since differences in minimum wages between 
Figure C.1: Effect of minimum wages on low-wage commuting: Panel event study

(a) Panel Design

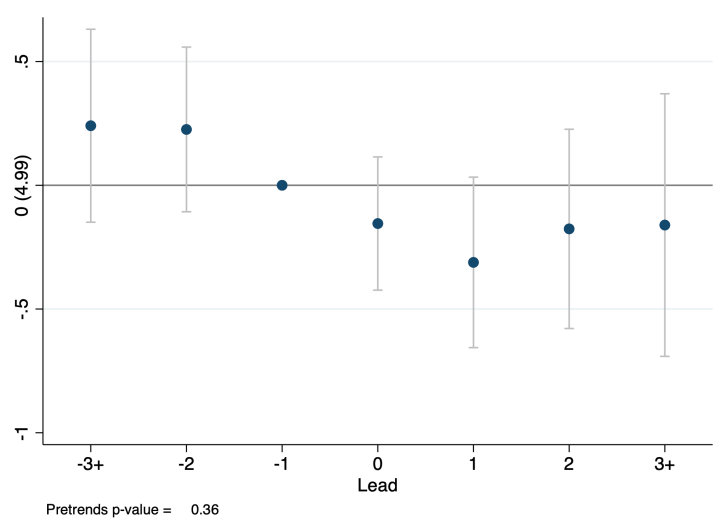

(b) Within Design

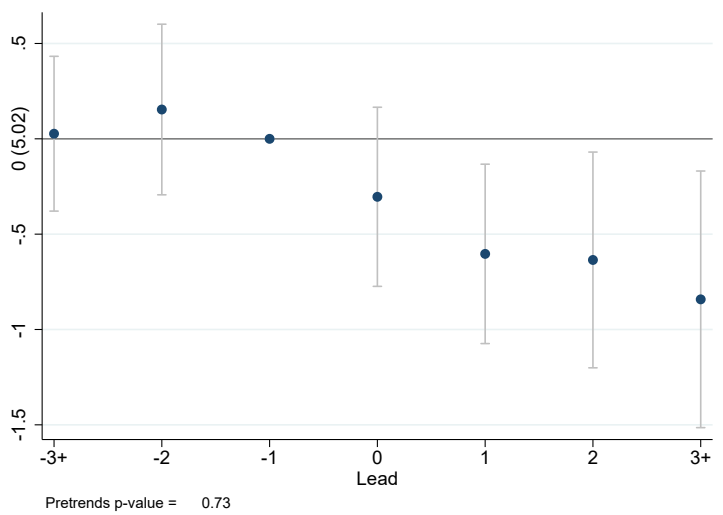

This figure depicts estimates of panel event-study estimations. Panel (a) depicts the coefficients $\delta_{k}^{w o r k}$ from equation (C.1), a panel event-study specification of equation (1). The regression is analogous to that of column 6 of table 1, and includes year fixed effects, workplace-residence county pair fixed effects, pair-specific linear trends. Panel (b) depicts the coefficients $\delta_{k}$ from equation (C.2), a panel event-study specification of equation (3). The regression is analogous to that of column 3 of table 2 , and includes workplace fixed effects and residence-year effects. The regressions for both panels include controls for total county population and population by age groups, lags of yearly state employment, gas prices, average percentage refund from state EITCs, and average corporate tax rates. The vertical bars are $95 \%$ confidence intervals, calculated from a regression with robust standard errors, with multidimensional clustering at border segment, county of work, county of residence. For panel (a), the clustering dimensions also include the county pair. The horizontal axis label at 0 shows the mean of the dependent variable at $k=-1$.. The "pretrends p-value" comes from a test of $\delta_{-3+}=\delta_{-2}=\delta_{-1}=0$.

neighboring counties need not be persistent. ${ }^{29}$

\section{Stacked difference-in-differences}

A recent literature has highlighted than in settings with staggered variation in the treatment variables and/or heterogeneous treatment effects, two-way fixed effects estimates may fail to recover a properly weighted average of treatment effects across units (de Chaisemartin and D'Haultfœuille 2020; Goodman-Bacon 2021; Sun and Abraham 2021). Cengiz et al. (2019) propose a "stacked difference-in-differences" approach to evaluate minimum wage effects, accounting for the staggered nature of minimum wage increases and the heterogeneity in the minimum wage changes across states and over time. I follow their approach to implement stacked difference-in-differences estimates using control groups analogous to those used for the panel design in equation (1) and the within-residence design in equation (3).

\footnotetext{
${ }^{29}$ In the sample, about 15 percent of cross-border differences in minimum wages disappear after one year, and about 60 percent of differences decrease after one year. When the differences decrease, the remaining differences are about 30 percent of the original differences.
} 
For the panel design, I calculate the absolute value of the 1-year change in the difference between the minimum wage at the workplace and the minimum wage at the residence. I then define an "event" as a change in this difference larger than 50 cents. County pairs that do not have any events enter the control group. For robustness, I also consider thresholds for defining an event of 25 and 75 cents.

After defining the events, for each event $e$, I estimate the following equation on a sample with the treated county pair in the event and all the control counties. I weight this regression by the average number of commuters in each county pair:

$$
\begin{aligned}
C_{n i t}^{e} & =\beta_{0}^{e}+\beta_{1}^{e}\left[\ln \left(\text { minwage }_{i t}^{e}\right)-\ln \left(\text { minwage }_{n t}^{e}\right] \times \text { Treated }_{n i}^{e} \times \text { Post }_{t}^{e}\right. \\
& +\gamma_{n i}^{e}+\delta_{t}^{e}+\Phi_{r e s}^{e} X_{n t}^{e}+\Phi_{w o r k}^{e} X_{i t}^{e}+\epsilon_{n i t}^{e}
\end{aligned}
$$

This equation is analogous to equation (1). Treated $_{n i}$ is 1 for the county-pair with the minimum wage difference change in the event, and 0 for the control county pairs. Post $t_{t}$ is 1 after the event takes place, and zero otherwise.

The estimated effect of the difference in minimum wages on low-wage commuting is a weighted average of the $\beta_{1}^{e}$ coefficients across all events, using the average number of commuters in the treated county pair for the event as weights. For inference, I follow Cengiz et al. (2019) and use the bootstrap procedure in Ferman and Pinto (2019).

Table D.1 shows the results for the same specifications as in Table 1, except for specification (5) because there are few control county pairs within each census division for each treated county pair. In panel (A), the estimated commuting elasticity ranges from -0.23 to -0.25 when either state trends or pair trends are included. This estimate is similar to those of table 1. In panels (B) and (C), I consider alternative definitions using events with smaller and larger changes in the minimum wage difference. The estimates for smaller difference changes, in panel (B), are similar to those on panel (A). The estimate in panel (C) is smaller, but it excludes a substantial share of events.

For the within design, I define events in the same fashion and estimate the following equation on a sample that includes the treated county pair and all county pairs where the county of residence and workplace are the same. This way, I use the commuting flows inside the same county as controls. 
Table D.1: Effect of minimum wages on low wage commuting: Stacked difference-in-differences estimates for panel design.

Log Low Wage Commuters - $11 \mathrm{Km}$ to Border

\begin{tabular}{|c|c|c|c|c|c|c|}
\hline & $(1)$ & $(2)$ & $(3)$ & $(4)$ & $(5)$ & $(6)$ \\
\hline \multicolumn{7}{|c|}{ A: Events with change larger than 0.50 - 405 pairs - 837 events } \\
\hline \multicolumn{7}{|l|}{ (Log MW Work - Log MW Res) } \\
\hline$\times$ Post $\times$ Treated Pair & $\begin{array}{c}0.96^{* * *} \\
(0.04)\end{array}$ & $\begin{array}{c}-0.24^{* * *} \\
(0.02)\end{array}$ & $\begin{array}{c}-0.04^{* * *} \\
(0.01)\end{array}$ & $\begin{array}{c}-0.23^{* * *} \\
(0.01)\end{array}$ & . & $\begin{array}{c}-0.25 * * * \\
(0.01)\end{array}$ \\
\hline \multicolumn{7}{|c|}{$\begin{array}{l}\text { B: Events with change larger than } 0.25 \text { - } 442 \text { pairs - 1,879 events } \\
\text { (Log MW Work - Log MW Res) }\end{array}$} \\
\hline$\times$ Post $\times$ Treated Pair & $\begin{array}{c}0.30 * * * \\
(0.03)\end{array}$ & $\begin{array}{c}-0.06^{* * *} \\
(0.01)\end{array}$ & $\begin{array}{c}-0.06^{* * *} \\
(0.01)\end{array}$ & $\begin{array}{c}-0.25^{* * *} \\
(0.01)\end{array}$ & & $\begin{array}{l}-0.25^{* * *} \\
\quad(0.01)\end{array}$ \\
\hline \multicolumn{7}{|c|}{$\begin{array}{l}\text { C: Events with change larger than } 0.75 \text { - } 229 \text { pairs - } 350 \text { events } \\
\text { (Log MW Work - Log MW Res) }\end{array}$} \\
\hline$\times$ Post $\times$ Treated Pair & $\begin{array}{c}-0.09 * * \\
(0.04)\end{array}$ & $\begin{array}{c}-0.10 * * * \\
(0.03)\end{array}$ & $\begin{array}{c}0.02^{*} \\
(0.03)\end{array}$ & $\begin{array}{c}-0.20 * * * \\
(0.02)\end{array}$ & & $\begin{array}{c}-0.07^{* * *} \\
(0.01)\end{array}$ \\
\hline Work, res effects & & Yes & Yes & Yes & Yes & Yes \\
\hline Year effects & & Yes & Yes & Yes & & Yes \\
\hline Controls & & & Yes & Yes & Yes & Yes \\
\hline State trends & & & & Yes & & \\
\hline Census div $\mathrm{x}$ year effects & & & & & Yes & \\
\hline Work, res trends & & & & & & Yes \\
\hline
\end{tabular}

The sample excludes 1 . Residence-workplace pairs with average low-wage commuting below 150 a year; 2 . Counties from AK, AZ, AR, DC, MA, MS, NH, or WY because of missing commuting data; 3. Counties where the local minimum wage is higher than the state's minimum wage. Regressions are weighted by pair aggregated population and coefficients in all columns are average event-by-event estimates. Standard errors are computed using the procedure proposed by Ferman and Pinto (2019). Column 2 includes year effects and fixed effects at the workplace-residence county pair level. Column 3 also includes controls for total county population and population by age groups, lags of yearly state employment, gas prices, average percentage refund from state EITCs and average corporate tax rates. Columns 4 to 6 also include controls for spatial heterogeneity. Column 4 includes linear time trends interacted with state of residence and state of workplace dummies. Column 5 includes residence and work census division dummies interacted with year dummies. Column 6 includes pair-specific linear time trends.

$$
\begin{aligned}
C_{n i t}^{e} & =\beta_{0}^{e}+\beta_{d}^{e}\left[\ln \left(\text { minwage }_{i t}^{e}\right)-\ln \left(\text { minwage }_{n t}^{e}\right)\right] \times \text { Treated }_{n i}^{e} \times \text { Post }_{t}^{e} \\
& +\gamma_{n t}^{e}+\tau_{i}^{e}+\Phi_{\text {work }}^{e} X_{i t}^{e}+\tilde{\epsilon}_{n i t}^{e} .
\end{aligned}
$$


Table D.2 shows the results. In panel (A), with events defined by a change of at least 50 cents in the difference in minimum wages, the low-wage commuting elasticity is between -0.23 and -0.25 when year effects are included. In panels (B) and (C), the estimated commuting elasticity is smaller, either because the events involve smaller minimum wage changes, or because a substantial share of events is excluded.

Table D.2: Effect of minimum wages on low wage commuting: Stacked difference-in-differences estimates for within design.

Log Low Wage Commuters - $11 \mathrm{Km}$ to Border

\begin{tabular}{|c|c|c|}
\hline & \multicolumn{2}{|c|}{$\underline{\text { Same Residence }}$} \\
\hline & (2) & (3) \\
\hline $\begin{array}{l}\text { A: Events with change larger than } 0.50 \text { - } 404 \text { pairs }-837 \text { events } \\
(\text { Log MW Work - Log MW Res }) \times \text { Post } \times \text { Treated Pair }-1.38^{* * *} \\
(0.04)\end{array}$ & $\begin{array}{c}-0.25^{* * *} \\
(0.01)\end{array}$ & $\begin{array}{c}-0.23^{* * *} \\
(0.01)\end{array}$ \\
\hline $\begin{array}{l}\text { B: Events with change larger than } 0.25-441 \text { pairs }-1,879 \text { events } \\
\text { (Log MW Work - Log MW Res) } \times \text { Post } \times \text { Treated Pair }-0.38^{* * *} \\
\end{array}$ & $\begin{array}{c}-0.09 * * * \\
(0.01)\end{array}$ & $\begin{array}{c}-0.08^{* * *} \\
(0.01)\end{array}$ \\
\hline 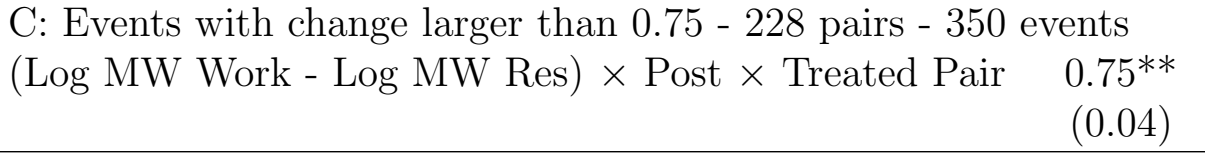 & $\begin{array}{c}-0.14^{* * *} \\
(0.02)\end{array}$ & $\begin{array}{l}-0.09^{*} \\
(0.02)\end{array}$ \\
\hline Pair effects & Yes & Yes \\
\hline Year effects & Yes & Yes \\
\hline Controls & & Yes \\
\hline
\end{tabular}

The sample excludes 1 . Residence-workplace pairs with average low-wage commuting below 150 a year; 2 . Counties from AK, AZ, AR, DC, MA, MS, NH, or WY because of missing commuting data; 3. Counties where the local minimum wage is higher than the state's minimum wage. Regressions are weighted by pair aggregated population and coefficients in all columns are average event-by-event estimates. Standard errors are computed using the procedure proposed by Ferman and Pinto (2019). Column 2 includes pair and year effects. Column 3 also includes controls for total county population and population by age groups, lags of yearly state employment, gas prices, average percentage refund from state EITCs and average corporate tax rates.

\section{E Residence and workplace probabilities}

Here, I derive the expression for the residence and workplace probabilities. Workers choose where to live and search for work to maximize their utility in equation (8). The distribution of utility for a worker of type $s$ that lives in $n$ and searches in $i$ is 


$$
\begin{aligned}
G_{n i}^{s}(u) & =\operatorname{Pr}\left(u_{n i \omega}^{s} \leq u\right) \\
& =\operatorname{Pr}\left(\frac{z_{n i \omega}^{s} \tilde{w}_{n i}^{s}}{\left(1+\rho_{i}^{s} \kappa_{n i}\right) Q_{n}^{1-\beta}} \leq u\right) \\
& =\operatorname{Pr}\left(z_{n i \omega}^{s} \leq \frac{u\left(1+\rho_{i}^{s} \kappa_{n i}\right) Q_{n}^{1-\beta}}{\tilde{w}_{n i}^{s}}\right) \\
& =e^{-\psi_{n i}^{s} u^{-\epsilon}} .
\end{aligned}
$$

So, worker utility is Fréchet distributed with a residence-workplace specific shape parameter given by

$$
\psi_{n i}^{s} \equiv T_{n}^{s} X_{i}^{s}\left[\left(1+\rho_{i}^{s} \kappa_{n i}\right) Q_{n}^{1-\beta}\right]^{-\epsilon}\left(\tilde{w}_{n i}^{s}\right)^{\epsilon} .
$$

From the properties of the Fréchet distribution (Monte et al. 2018)), one may obtain the joint probabilities of living in $n$ and searching in $i$, as follows:

$$
\begin{array}{r}
o_{n i}^{s}=\frac{\psi_{n i}^{s}}{\psi^{s}} \\
\psi^{s}=\sum_{n, i} \psi_{n i} .
\end{array}
$$

These probabilities are the expression in equation (11) in the text.

\section{F Welfare}

Expected utility conditional on a residence-workplace pair is equal across areas and it is equal to the expected utility of the economy as a whole. This utility is given by:

$$
\bar{U}^{s}=\Gamma\left(\frac{\epsilon-1}{\epsilon}\right)\left[\sum_{n, i} \psi_{n i}^{s}\right]^{1 / \epsilon},
$$

where $\Gamma$ is the Gamma function and $\psi_{n i}^{s}$ is defined as in equation (11).

Let $u_{n i}^{s}$ denote the utility of search, and $u_{n i \text {, unemployed }}^{s}$ and $u_{n i \text {, employed }}^{s}$ be the ex-post utilities of unemployment and employment respectively. These utilities are given by: 


$$
\begin{aligned}
u_{n i}^{s} & =\frac{z_{n i}^{s} \tilde{w}_{n i}^{s}}{Q_{n}^{1-\beta}\left(1+\rho_{i}^{s} \kappa_{n i}\right)} \\
u_{n i, \text { unemployed }}^{s} & =\frac{z_{n i}^{s} R_{n}}{Q_{n}^{1-\beta}}=u_{n i}^{s} \frac{R_{n}}{\tilde{w}_{n i}^{s}}\left(1+\rho_{i}^{s} \kappa_{n i}\right) \\
u_{n i, \text { employed }}^{s} & =\frac{z_{n i}^{s} w_{i}^{s}}{Q_{n}^{1-\beta}\left(1+\kappa_{n i}\right)}=u_{n i}^{s} \frac{1+\rho_{i}^{s} \kappa_{n i}}{1+\kappa_{n i}} \frac{w_{i}^{s}}{\tilde{w}_{n i}^{s}}
\end{aligned}
$$

The distribution of $u_{n i}^{s}$ conditional on a residence and a workplace is Fréchet:

$$
\begin{aligned}
& G\left(u_{n i}^{s} \mid \text { choose } n, i\right)=\exp \left(-\psi^{s} u^{-\epsilon}\right) \\
& \psi^{s}=\sum_{n} \sum_{i} \psi_{n i}
\end{aligned}
$$

Therefore, the distribution of the utilities of unemployment and employment conditional on residence and workplace are:

$$
\begin{gathered}
G\left(u_{n i, \text { unemployed }}^{s} \mid \text { choose } n, i\right)=\exp \left[-\psi^{s} \frac{R_{n}}{\tilde{w}_{n i}^{s}}\left(1+\rho_{i}^{s} \kappa_{n i}\right) u^{-\epsilon}\right] \\
G\left(u_{n i, \text { employed }}^{s} \mid \text { choose } n, i\right)=\exp \left[-\psi^{s} \frac{1+\rho_{i}^{s} \kappa_{n i}}{1+\kappa_{n i}} \frac{w_{i}^{s}}{\tilde{w}_{n i}^{s}} u^{-\epsilon}\right]
\end{gathered}
$$

Taking the expected value of these distributions yields the expressions in equation (26) of the main text.

\section{G Algorithms for computing equilibrium and counterfactuals}

\section{G.1 Computing equilibrium}

The following fixed-point algorithm can be used to calculate the equilibrium in the model. Let $X^{t}$ denote the value of variable $X$ at iteration $t$ of the algorithm. Start from conjectured initial values of housing prices $\left(Q_{i}\right)^{t}$ and employment probabilities $\left(\rho_{i}^{s}\right)^{t}$. Then proceed as follows:

1. Compute search probabilities $\left(o_{n i}^{s}\right)^{t}$ according to (E.3).

2. Compute searchers by residence and workplace $\left(O_{M i}^{s}\right)^{t}$ and $\left(O_{R i}^{s}\right)^{t}$ according to (12)

3. Compute equilibrium tightness and recruitment mark-ups with a fixed-point algorithm 
(a) Set the recruiting mark-up $\left(\tau^{s}\left(\theta_{i}^{s}\right)\right)^{t}=0$. Compute equilibrium values of $\theta_{i}^{s}$ using (19) and (15)

(b) Update $\left(\tau^{s}\left(\theta_{i}^{s}\right)\right)^{t}$ using (14)

(c) Iterate until convergence in $\left(\tau^{s}\left(\theta_{i}^{s}\right)\right)^{t}$. Obtain $\left.\left(\theta_{i}^{s}\right)\right)^{t}$

4. Compute equilibrium employment by workplace $\left(L_{M i}\right)^{t}$ using (19) and (15) given the equilibrium mark-ups.

5. Compute unemployment as $\left(U_{M i}^{s}\right)^{t}=\left(O_{M i}^{s}\right)^{t}-\left(L_{M i}^{s}\right)^{t}$

6. Compute employment by residence workplace pair $\left(l_{n i}^{s}\right)^{t}$ using (22)

7. Update employment probabilities $\rho_{i}^{s}$ using (20)

$$
\left(\rho_{i}^{s}\right)^{t+1}=\frac{f^{s}\left(\left(\theta_{i}^{s}\right)^{t}\right)}{\xi^{s}+f^{s}\left(\left(\theta_{i}^{s}\right)^{t}\right)}
$$

8. Calculate expected income $\left(v_{n}\right)^{t}$ using (18)

9. Update housing prices using (24)

$$
\left(Q_{n}\right)^{t+1}=\frac{(1-\beta)\left(v_{n}\right)^{t}\left(L_{R n}\right)^{t}}{D_{n}}
$$

10. Iterate until convergence in $\rho_{i}^{s}$ and $Q_{n}$

\section{G.2 Computing counterfactuals}

Given a cross section of commuting data, wages, unemployment benefits, commuting costs, land supply and unemployment, and values of the parameters $\epsilon, \beta, \sigma, \Omega^{s}, \eta, r^{s}$ and $\xi^{s}$, counterfactuals changes for the job finding probability $\left.f\left(\theta_{i}^{s}\right)\right)$ and the search probabilities $o_{n i}^{s}$ can be obtained. Changes in the other endogenous variables can be obtained from these.

Denote by $x^{\prime}$ the value of a variable on a counterfactual equilibrium and by $\hat{x}=\frac{x^{\prime}}{x}$ the counterfactual change in this variable. From the initial data obtain values of the unobserved location-specific parameters $T_{n}^{s}, X_{i}^{s}, A_{i}^{s}$ and $\rho_{i}^{s}$ using the algorithms of sections I.1, I.2, I.3 and I.4.

Given counterfactual changes in exogenous variables $\left\{\hat{w}_{i}^{s}, \hat{R_{n}}, \hat{T_{n}^{s}}, \hat{X_{i}^{s}}, \hat{\kappa_{n i}}\right\}$, I can solve for counterfactual changes $\left\{\hat{f}_{i}^{s}, o_{n i}\right\}$ using the following fixed-point algorithm. Let $X^{t}$ denote the value of variable $X$ at iteration $t$ of the algorithm. Start from an initial value of these changes, $\left\{\left(\hat{f}_{i}^{s}\right)^{0},\left(\hat{o}_{n i}\right)^{0}\right\}$. Then proceed as follows: 
1. Find the change in employment probabilities using equation (20)

$$
\left(\hat{\rho}_{i}^{s}\right)^{t}=\frac{\left(\hat{f}_{i}^{s}\right)^{t}\left(\xi^{s}+f_{i}^{s}\right)}{\xi^{s}+f_{i}^{s}\left(\hat{f}_{i}^{s}\right)^{t}}
$$

2. Find the new number of searchers by workplace and residence using equation (12)

$$
\begin{aligned}
\left(o_{n i}^{s}\right)^{t} & =o_{n i}^{s}\left(\hat{o}_{n i}^{s}\right)^{t} \\
\left(O_{M i}^{s}\right)^{t} & =\sum_{n} L^{s}\left(o_{n i}^{s}\right)^{t} \\
\left(O_{R n}^{s}\right)^{t} & =\sum_{i} L^{s}\left(o_{n i}^{s}\right)^{t}
\end{aligned}
$$

3. Find counterfactual changes in expected wages using equation (7)

$$
\left(\hat{\tilde{w}}_{n i}^{s}\right)^{t}=\frac{\rho_{i}^{s} \hat{\rho}_{i}^{s} w_{n i}^{s} \hat{w}_{n i}^{s}+\left(1-\rho_{i}^{s} \hat{\rho}_{i}^{s}\right) R_{n} \hat{R}_{n}}{\tilde{w}_{n i}^{s}}
$$

4. Find counterfactual changes in expected income using equation (18)

$$
\begin{aligned}
\left(\hat{v}_{n}^{s}\right)^{t} & =\frac{1}{v_{n}^{s}} \sum_{i} \frac{o_{n i}^{s}\left(1+\rho_{i}^{s} \kappa_{n i}\right)^{\epsilon}\left[1+\rho_{i}^{s}\left(\hat{\rho}_{i}^{s}\right)^{t} \kappa_{n i}\right]^{-\epsilon} \hat{T}_{n}^{s} \hat{X}_{i}^{s}\left(\hat{\tilde{w}}_{n i}^{s}\right)^{t}}{\sum_{b} o_{a b}^{s}\left(1+\rho_{b}^{s} \kappa_{n b}\right)^{\epsilon}\left[1+\rho_{b}^{s}\left(\hat{\rho}_{b}^{s}\right)^{t} \kappa_{n b}\right]^{-\epsilon} \hat{T}_{n}^{s} \hat{X}_{b}^{s}\left(\hat{\tilde{w}}_{n b}^{s}\right)^{t}} \tilde{w}_{n i}^{s}\left(\hat{\tilde{w}}_{n i}^{s}\right)^{t} \\
\left(\hat{v}_{n}\right)^{t} & =\frac{1}{v_{n}} \sum_{s} \frac{\left(O_{R n}^{s}\right)^{t}}{O_{R n}^{s}} \hat{v}_{n}^{s}
\end{aligned}
$$

5. Find counterfactual changes in housing prices using equation (24)

$$
\left(\hat{Q}_{n}\right)^{t}=\left(\hat{v}_{n}\right)^{t} \frac{\sum_{s}\left(O_{R n}^{s}\right)^{t}}{\sum_{s} O_{R n}^{s}}
$$

6. Compute new changes in search probabilities using (E.3)

$$
\left(\hat{o}_{n i}^{s}\right)^{t^{\prime}}=\frac{\left(1+\rho_{i}^{s} \kappa_{n i}\right)^{\epsilon}\left[1+\rho_{i}^{s}\left(\hat{\rho}_{i}^{s}\right)^{t} \kappa_{n i}\right]\left[\left(\hat{Q}_{n}\right)^{t}\right]^{-\epsilon(1-\beta)} \hat{T}_{n}^{s} \hat{X}_{i}^{s}\left[\left(\hat{\tilde{w}}_{n i}^{s}\right)^{t}\right]^{-\epsilon}}{\sum_{a, b}\left(1+\rho_{b}^{s} \kappa_{a b}\right)^{\epsilon}\left[1+\rho_{b}^{s}\left(\hat{\rho}_{b}^{s}\right)^{t} \kappa_{a b}\right]\left[\left(\hat{Q}_{a}\right)^{t}\right]^{-\epsilon(1-\beta)} \hat{T}_{a}^{s} \hat{X}_{b}^{s}\left[\left(\hat{\tilde{w}}_{a b}^{s}\right)^{t}\right]^{-\epsilon}}
$$


7. Compute new searchers by workplace using (12)

$$
\left(O_{M i}^{s}\right)^{t^{\prime}}=\sum_{n} L^{s} O_{n i}^{s}\left(\hat{o}_{n i}^{s}\right)^{t+1}
$$

8. Compute equilibrium tightness, recruitment mark-ups and labor demand with a fixedpoint algorithm

(a) Set the recruiting mark-up $\tau^{s}\left(\theta_{i}^{s}\right)=0$. Compute equilibrium values $\left(\theta_{i}^{s}\right)^{t}$ and $\left(L M_{i}^{s}\right)^{t}$ using (19) and (15)

(b) Update $\tau^{s}\left(\theta_{i}^{s}\right)$ using (14)

(c) Iterate until convergence in $\tau^{s}\left(\theta_{i}^{s}\right)$

9. Compute new counterfactual changes in search probabilities

$$
\left(\hat{f}_{i}^{s}\right)^{t^{\prime}}=\frac{f_{i}^{s} \xi^{s}\left(L M_{i}^{s}\right)^{t}}{\left(O_{M i}^{s}\right)^{t+1}-\left(L M_{i}^{s}\right)^{t}}
$$

10. Update changes in search and employment probabilities with an adjustment factor $\zeta$

$$
\begin{aligned}
& \left(\hat{o}_{n i}^{s}\right)^{t+1}=\zeta\left(\hat{o}_{n i}^{s}\right)^{t^{\prime}}+(1-\zeta)\left(\hat{o}_{n i}^{s}\right)^{t} \\
& \left(\hat{f}_{i}^{s}\right)^{t+1}=\zeta\left(\hat{f}_{i}^{s}\right)^{t^{\prime}}+(1-\zeta)\left(\hat{f}_{i}^{s}\right)^{t}
\end{aligned}
$$

11. Iterate until convergence

\section{H Computing elasticities}

In this appendix I compute general and partial equilibrium elasticities of commuting to minimum wage changes.

I consider two types of elasticities, following Monte et al. (2018). The general equilibrium elasticity $\varepsilon_{x}^{y}$ considers the change in endogenous variable $y$ given a change in $x$ from initial to a final equilibrium of the model where all endogenous variables change. The partial equilibrium elasticity $\eta_{x}^{y}$ considers the change in $y$ keeping other endogenous variables constant.

From equation (22), the elasticity of commuting to a minimum wage change is

$$
\varepsilon_{w_{i}^{\ell}}^{l_{n i}^{\ell}}=\varepsilon_{w_{i}^{\ell}}^{\rho_{i}^{\ell}}+\varepsilon_{w_{i}^{\ell}}^{o_{n i}^{\ell}}
$$


The first term $\varepsilon_{w_{i}^{\ell}}^{\rho_{i}^{\ell}}$ summarizes how the employment probability changes as the minimum wage changes. The second term summarizes how the search probability $\varepsilon_{w_{i}^{\ell}}^{o_{n i}^{\ell}}$ changes with the change in wages.

First, I calculate the general equilibrium elasticity of search $o_{n i}^{s}$ to a change in wages. From equation (E.3), the elasticity of the residence-search probability $o_{n i}^{s}$ to changes in the minimum wage in area $j, w_{j}^{\ell}$ is

$$
\begin{aligned}
\varepsilon_{w_{j}}^{o_{n i}^{s}} & =\varepsilon_{w_{j}}^{\psi_{n i}^{s}}-\varepsilon_{w_{j}^{\ell}}^{\psi} \\
& =\varepsilon_{w_{j}^{\ell}}^{\psi_{n i}^{s}}-\frac{d \psi}{d w_{j}^{\ell}} \frac{w_{j}^{\ell}}{\psi} \\
& =\varepsilon_{w_{j}^{\ell}}^{\psi_{n i}^{s}}-\sum_{a, b} \frac{d \psi_{a b}^{s}}{d w_{j}^{\ell}} \frac{w_{j}^{\ell}}{\psi_{a b}^{s}} \frac{\psi_{a b}^{s}}{w_{j}^{\ell}} \frac{w_{j}^{\ell}}{\psi} \\
& =\varepsilon_{w_{j}}^{\psi_{n i}^{s}}-\sum_{a, b} \varepsilon_{w_{j}^{\ell}}^{\psi_{a b}^{s}} o_{a b}^{s}
\end{aligned}
$$

To solve for $\varepsilon_{w_{j}^{\ell}}^{\psi_{n}^{s}}$, take logs of 11 and differentiate to get

$$
\begin{aligned}
\ln \left(\psi_{n i}^{s}\right) & =\ln \left(T_{n}^{s}\right)+\ln \left(X_{i}^{s}\right)-\epsilon \ln \left(1+\rho_{i}^{s} \kappa_{n i}\right)-\epsilon(1-\beta) \ln \left(Q_{n}\right)+\epsilon \ln \left(\rho_{i}^{s} w_{i}^{\ell}+\left(1-\rho_{i}^{s}\right) R_{n}\right) \\
\varepsilon_{w_{j}^{\ell}}^{\psi^{s}} & =-\frac{\epsilon}{1+\rho_{i}^{s} \kappa_{n i}}\left(\frac{d \rho_{i}^{s}}{d \ln \left(w_{j}^{\ell}\right)} \kappa_{n i}\right)-\epsilon(1-\beta) \varepsilon_{w_{j}^{\ell}}^{Q_{n}} \\
& +\frac{\epsilon}{\rho_{i}^{s} w_{i}^{\ell}+\left(1-\rho_{i}^{s}\right) R_{n}}\left(\frac{d \rho_{i}^{s}}{d \ln \left(w_{j}^{\ell}\right)} w_{i}^{s}+\rho_{i} \frac{d w_{i}^{s}}{d \ln \left(w_{j}^{\ell}\right)}-\frac{d \rho_{i}^{s}}{d \ln \left(w_{j}^{\ell}\right)} R_{n}\right) \\
& =-\frac{\epsilon}{1+\rho_{i}^{s} \kappa_{n i}}\left(\varepsilon_{w_{j}^{\ell}}^{\rho_{i}^{s}} \rho_{i}^{s} \kappa_{n i}\right)-\epsilon(1-\beta) \varepsilon_{w_{j}^{\ell}}^{Q_{n}} \\
& +\frac{\epsilon}{\rho_{i}^{s} w_{i}^{s}+\left(1-\rho_{i}^{s}\right) R_{n}}\left(\varepsilon_{w_{j}^{\ell}}^{\rho_{i}^{s}} \rho_{i}^{s} w_{i}^{s}+\rho_{i}^{s} w_{i} \varepsilon_{w_{j}^{\ell}}^{w_{i}^{s}}-\rho_{i}^{s} \varepsilon_{w_{j}^{\ell}}^{\rho_{i}^{s}} R_{n}\right) \\
& =\varepsilon_{w_{j}^{\ell}}^{\rho_{s}^{s}}\left[\frac{\epsilon \rho_{i}^{s}\left(w_{i}^{s}-R_{n}\right)}{\tilde{w}_{n i}^{s}}-\frac{\epsilon \rho_{i}^{s} \kappa_{n i}}{1+\rho_{i}^{s} \kappa_{n i}}\right]+\frac{\epsilon \rho_{i}^{s} w_{i} \varepsilon_{w_{j}^{\ell}}^{w_{i}^{s}}}{\tilde{w}_{n i}^{s}}-\epsilon(1-\beta) \varepsilon_{w_{j}^{\ell}}^{Q_{n}}
\end{aligned}
$$

Define

$$
\theta_{n i}^{s} \equiv \frac{\rho_{i}^{s} w_{i}^{s}}{\tilde{w}_{n i}^{s}} ; \boldsymbol{\kappa}_{n i}^{s}=\frac{\rho_{i}^{s} \kappa_{n i}}{1+\rho_{i}^{s} \kappa_{n i}}
$$

This is the share of wages in expected income. Rewrite the elasticity as

$$
\frac{\varepsilon_{w_{j}^{\ell}}^{\psi_{n i}^{s}}}{\epsilon}=\varepsilon_{w_{j}^{\ell}}^{\rho_{s}^{s}}\left[\theta_{n i}^{s}-\left(1-\theta_{n i}^{s}\right)-\frac{1}{\tilde{w}_{n i}^{s}}-\kappa_{n i}^{s}\right]+\theta_{n i}^{s} \varepsilon_{w_{j}^{\ell}}^{w_{i}^{s}}-(1-\beta) \varepsilon_{w_{j}^{\ell}}^{Q_{n}}
$$


Plugging in the previous expression and simplifying

$$
\begin{array}{r}
\frac{\varepsilon_{w_{j}^{\ell}}^{o_{0}^{s}}}{\epsilon}= \\
\varepsilon_{w_{j}^{\ell}}^{\rho_{s}^{s}}\left[\theta_{n i}^{s}-\left(1-\theta_{n i}^{s}\right)-\frac{1}{\tilde{w}_{n i}^{s}}-\boldsymbol{\kappa}_{n i}^{s}\right]+\theta_{n i}^{s} \varepsilon_{w_{j}^{\ell}}^{w_{i}^{s}}-(1-\beta) \varepsilon_{w_{j}^{\ell}}^{Q_{n}} \\
-\sum_{a, b} o_{a b}^{s}\left\{\varepsilon_{w_{j}^{\ell}}^{\rho_{b}^{s}}\left[\theta_{a b}^{s}-\left(1-\theta_{a b}^{s}\right)-\frac{1}{\tilde{w}_{a b}^{s}}-\boldsymbol{\kappa}_{a b}^{s}\right]+\theta_{a b}^{s} \varepsilon_{w_{j}^{\ell}}^{w_{s}^{s}}-(1-\beta) \varepsilon_{w_{j}^{\ell}}^{Q_{a}}\right\}
\end{array}
$$

To decompose this elasticity into wage, employment and housing prices effects, it is simpler to focus on a partial equilibrium elasticity, that assumes away effects on employment and prices in other locations. Denote the partial equilibrium elasticity as $\eta_{w_{i}^{s}}^{l_{n}^{\ell}}$. The partial equilibrium elasticity of commuting to the minimum wage is an analog of the general equilibrium elasticity:

$$
\eta_{w_{i}^{\ell}}^{l_{n i}^{\ell}}=\eta_{w_{i}^{\ell}}^{\rho_{i}^{\ell}}+\eta_{w_{i}^{\ell}}^{o_{n i}^{\ell}}
$$

I focus on commuting from a given region $n$ to a given region $i$ and assume that wages, employment probabilities and housing prices do not react in places other than $n$ and $i$. That is, assume $\varepsilon_{w_{j}^{\ell}}^{\rho_{b}^{s}}=0$ for $b \notin(n, i), \varepsilon_{w_{j}^{\ell}}^{w_{b}^{s}}=0$ for $b \neq i$ and $\varepsilon_{w_{j}^{\ell}}^{Q_{a}}=0$ for $a \notin(n, i)$. The partial equilibrium elasticity of the fraction of low wage searchers coming from $n, o_{n i}^{\ell}$ to the minimum wage in $i, w_{i}^{\ell}$, becomes:

$$
\begin{aligned}
\eta_{w_{j}^{\ell}}^{o_{n i}^{s}} & =\eta_{w_{j}^{\ell}}^{\rho_{i}^{\ell}}\left(\epsilon \Theta_{n i}-\sum_{a} \epsilon O_{a i}^{\ell} \Theta_{a i}^{\ell}\right)-\eta_{w_{i}^{\ell}}^{\rho_{n}^{\ell}} \sum_{a} \epsilon h_{a n}^{\ell} \Theta_{a n}^{\ell} \\
& +\epsilon \theta_{n i}^{\ell}-\sum_{a} \epsilon O_{a i}^{\ell} \theta_{a i}^{\ell}-\epsilon\left(1-o_{R_{n}}^{\ell}\right)(1-\beta) \eta_{w_{j}^{\ell}}^{Q_{n}}+\epsilon O_{R i}^{\ell} \eta_{w_{i}^{\ell}}^{Q_{i}}
\end{aligned}
$$

where $\Theta_{a b}^{s}=\left[\theta_{a b}^{s}-\left(1-\theta_{a b}^{s}\right)-\frac{1}{\tilde{w}_{a b}^{s}}-\boldsymbol{\kappa}_{a b}^{s}\right]$. For partial equilibrium, I assume that all search probabilities remain unchanged except for $o_{n i}^{s}$. This is equivalent to assuming $\varepsilon_{w_{i}^{\ell}}^{\rho_{n}^{\ell}}=0, \varepsilon_{w_{i}^{\ell}}^{Q_{i}}=0$ and making all the terms in the summations equal to 0 unless $a=n$. The elasticity becomes

$$
\eta_{w_{j}^{\ell}}^{o_{n i}^{s}}=\left(\epsilon-\epsilon h_{n i}^{\ell}\right)\left[\theta_{n i}^{\ell}-\left(1-\theta_{n i}^{\ell}\right)-\frac{1}{\tilde{w}_{n i}^{\ell}}-\kappa_{a b}^{s}\right] \eta_{w_{i}^{\ell}}^{\rho_{\ell}^{\ell}}+\left(\epsilon-\epsilon h_{n i}^{\ell}\right) \theta_{n i}^{\ell}-\left(\epsilon-\epsilon O_{n i}^{\ell}\right)(1-\beta) \eta_{w_{i}^{\ell}}^{Q_{n}}
$$

Replacing $s=\ell$ for low skilled labor yields equation (30) in the main text.

The search probability elasticity is a combination of three effects: the change in employment probabilities, $\eta_{w_{i}^{\ell}}^{\rho_{i}^{\ell}}$, the change in wages and the change in housing prices $\eta_{w_{j}^{\ell}}^{Q_{n}}$. I call these effects wage effect, employment effect and housing prices effect in the main text. 


\section{Computing unobserved location-specific parameters}

\section{I.1 Computing search and employment probabilities}

We observe data on employment by workplace $l_{M i}^{s}$ and unemployment by workplace $U R_{n}^{s}$. Unemployment at the workplace level $U_{M i}^{s}$ is unobserved, since I do not see how many workers searched in each location. Under random matching, unemployment at the workplace level is an employment-weighted average of employment at the residence level

$$
U_{R n}^{s}=\sum_{b} \frac{L_{n b}^{s}}{L_{M b}^{s}} U_{M b}^{s}
$$

This linear system can be solved for unique values of $U_{M i}^{s}$. Given this data on unemployment by workplace and employment by workplace $L_{M i}^{s}$, the number of searchers in each workplace is

$$
O_{M i}^{s}=U_{M i}^{s}+L_{M i}^{s}
$$

Given this data, under the assumption of random matching, the number of searchers per residence-workplace pair is

$$
O_{n i}^{s}=\frac{L_{n i}^{s} O_{M i}^{s}}{L_{M i}^{s}}
$$

From these we can obtain residents as:

$$
O_{R n}^{s}=\sum_{b} O_{n b}^{s}
$$

Search probabilities are then

$$
o_{n i}^{s}=\frac{O_{n i}^{s}}{\sum_{a} \sum_{b} O_{a b}^{s}}
$$

And employment probabilities are

$$
\rho_{i}^{s}=\frac{O_{M i}^{s}}{L_{M i}^{s}}
$$

\section{I.2 Computing workplace productivities}

Given data on residents per residence location $O_{R n}^{s}$, searchers per workplace $O_{M i}^{s}$, wages $w_{i}^{s}$, employment probabilities $\rho_{i}^{s}$, unemployment benefits $R_{n}^{s}$, a dispersion parameter $\epsilon$ and commuting costs $\kappa_{n i}$, there is a unique (up to a normalization) vector of search costs $X_{i}^{s}$ 
consistent with the data being an equilibrium of the model. From the commuting equilibrium

$$
\begin{aligned}
O_{M i}^{s} & =\sum_{a} o_{a i \mid a} O_{R a} \\
& =\sum_{a} \frac{X_{i}^{s}\left(1+\rho_{i}^{s} \kappa_{n i}\right)^{-\epsilon} \tilde{w}_{n i}^{\epsilon}}{\sum_{b} X_{b}^{s}\left(1+\rho_{b}^{s} \kappa_{n b}\right)^{-\epsilon} \tilde{w}_{n b}^{\epsilon}} O_{R n}^{s}
\end{aligned}
$$

Where $\tilde{w}_{n i}^{s}=\rho_{i}^{s} w_{i}+\left(1-\rho_{i}^{s}\right) R_{n}^{s}$. From Lemmas S.6. and S.7 of Ahlfeldt et al. (2015), this system has a unique solution for $X_{i}^{s}$, up to a normalization,

\section{I.3 Computing residential amenities}

Given productivities $X_{i}^{s}$, data on residents per location $O_{R n}^{s}$, wages $w_{i}^{s}$, employment probabilities $\rho_{i}^{s}$, unemployment benefits $R_{n}^{s}$; and a dispersion parameter $\epsilon$, there is a unique (up to a normalization) vector of amenities $T_{n}^{s}$ that is consistent with the data being an equilibrium of the model. From (12) and (11)

$$
\begin{aligned}
o_{R_{n}}^{s} & =\frac{T_{n}^{s}\left(Q_{n}^{1-\beta}\right)^{-\epsilon} \sum_{b} X_{b}^{s} \tilde{w}_{n s}^{\epsilon}\left(1+\rho_{b}^{s} \kappa_{n s}\right)^{-\epsilon}}{\psi} \\
\frac{\left(T_{n}^{s}\right)^{\frac{1}{\epsilon}} Q_{n}^{-(1-\beta)}}{\psi} & =\frac{\left(o_{R n}^{s}\right)^{\frac{1}{\epsilon}}}{\left(\sum_{b} X_{b}^{s} \tilde{w}_{n s}^{\epsilon}\left(1+\rho_{b}^{s} \kappa_{n s}\right)^{-\epsilon}\right)^{\frac{1}{\epsilon}}}
\end{aligned}
$$

So $T_{n}^{s}$ can be identified up to a normalization by $\psi^{s}$ and housing prices $Q_{n}$. Using (24), housing prices can be identified using data on land $D_{n}$ and expected income $v_{n}$, which can be calculated using equation (18). This allows us to identify $T_{n}^{s}$ up to a normalization.

\section{I.4 Computing productivities}

From the first order conditions of the firm

$$
Y^{\sigma-1} A_{i}^{s}\left(L_{M i}^{s}\right)^{\sigma-1}=w_{i}^{s}\left(1+\tau_{i}^{s}\left(\theta_{i}^{s}\right)\right), \quad s=\ell, m, h
$$

Given values of $\sigma, \tau^{s}\left(\theta_{i}^{s}\right)$ and observed values of $L_{M i}^{s}$, this system can be solved for unique values of $A_{i}^{s}$ if employment $L_{M i}^{s}$ is strictly positive. For the data in section 6, employment is strictly positive in all locations for all wage groups. To obtain $\tau^{s}\left(\theta_{i}^{s}\right)$, I require values of the parameters in the matching process. Given values of separation rates $\xi^{s}$ and employment and unemployment by workplace, job finding probabilities can be obtained from (20) as

$$
f_{i}^{s}=\frac{\xi^{s} L_{M i}^{s}}{U_{M i}^{s}}
$$


Given values of $\Omega^{s}$ and $\eta$, market tightness and vacancy filling probabilities can be obtained as

$$
\begin{aligned}
\theta_{i}^{s} & =\left(\frac{f_{i}^{s}}{\Omega^{s}}\right)^{\frac{1}{1-\eta}} \\
q\left(\theta_{i}^{s}\right) & =\Omega^{s}\left(\theta_{i}^{s}\right)^{-\eta}
\end{aligned}
$$

and given values of recruitment producer ratios $r_{s}, \tau\left(\theta_{i}^{s}\right)$ can be obtained from (14). 


\section{J Additional figures and tables}

Table J.1: State-years where minimum wage workers are in the mid-wage category

\begin{tabular}{ccc} 
State & Since year & Average monthly wage since year \\
\hline Alaska & 2015 & 1400 \\
Arizona & 2014 & 1264 \\
Arkansas & 2016 & 1280 \\
California & 2008 & 1280 \\
Colorado & 2014 & 1298 \\
Connecticut & 2009 & 1345 \\
Delaware & 2015 & 1287 \\
Florida & 2014 & 1278 \\
Hawaii & 2016 & 1360 \\
Illinois & 2009 & 1308 \\
Maryland & 2015 & 1303 \\
Massachusets & 2008 & 1280 \\
Michigan & 2015 & 1304 \\
Minnesota & 2015 & 1347 \\
Montana & 2014 & 1276 \\
Nebraska & 2015 & 1280 \\
Nevada & 2010 & 1310 \\
New Jersey & 2014 & 1330 \\
New York & 2014 & 1340 \\
Ohio & 2013 & 1274 \\
Oregon & 2008 & 1387 \\
Rhode Island & 2014 & 1360 \\
South Dakota & 2015 & 1360 \\
Vermont & 2009 & 1353 \\
Washington & 2007 & 1389 \\
West Virginia & 2015 & 1280 \\
\hline
\end{tabular}

Source: Author's calculations from minimum wage data on Neumark et al. (2014) and Clemens et al. (2018). Calculations are made assuming 40 hours worked per week. The results in section 2 are robust to exclusion of these observations or to a redefinition of minimum wage workers to include the second category in these states. The estimation sample in section 2 excludes: 1 . residence-workplace pairs with average low-wage commuting below 150 a year; 2. Counties from AK, AZ, AR, DC, MA, MS, NH, or WY because of missing commuting data; 3 . Counties where the local minimum wage is higher than the state's minimum wage. 
Table J.2: Effect of minimum wages on low wage commuting: Within design, same workplace.

\begin{tabular}{|c|c|c|c|}
\hline & \multicolumn{3}{|c|}{ Same Workplace } \\
\hline & $(1)$ & $(2)$ & $(3)$ \\
\hline Log MW Workplace - Log MW Residence & $\begin{array}{c}-0.34 \\
(1.16)\end{array}$ & $\begin{array}{c}-0.03 \\
(0.15)\end{array}$ & $\begin{array}{l}-0.02 \\
(0.15)\end{array}$ \\
\hline Adj R sq. & 0.000 & 0.249 & 0.248 \\
\hline Within R sq. & 0.000 & 0.000 & 0.000 \\
\hline $\mathrm{N}$ & 12,290 & 11,672 & 11,672 \\
\hline Work counties & 293 & 260 & 260 \\
\hline Res counties & 377 & 345 & 345 \\
\hline Res effects x Year effects & & Yes & Yes \\
\hline Work effects x Year effects & & & \\
\hline Res Effects & & & \\
\hline Work effects & & Yes & Yes \\
\hline Controls & & & Yes \\
\hline Mean dep. var. & 3349.5 & 3009.5 & 3009.5 \\
\hline
\end{tabular}

The sample excludes 1. Residence-workplace pairs with average low-wage commuting below 150 a year; 2 . Counties from AK, AZ, AR, DC, MA, MS, NH, or WY because of missing commuting data; 3. Counties where the local minimum wage is higher than the state's minimum wage. Robust standard errors, in parentheses, are calculated with multidimensional clustering at border segment, county of work, and county of residence level. Column 2 includes workplace-year effects and residence effects. Column 3 also includes controls for total county population and population by age groups, lags of yearly state employment, gas prices, average percentage refund from state EITCs and average corporate tax rates. 


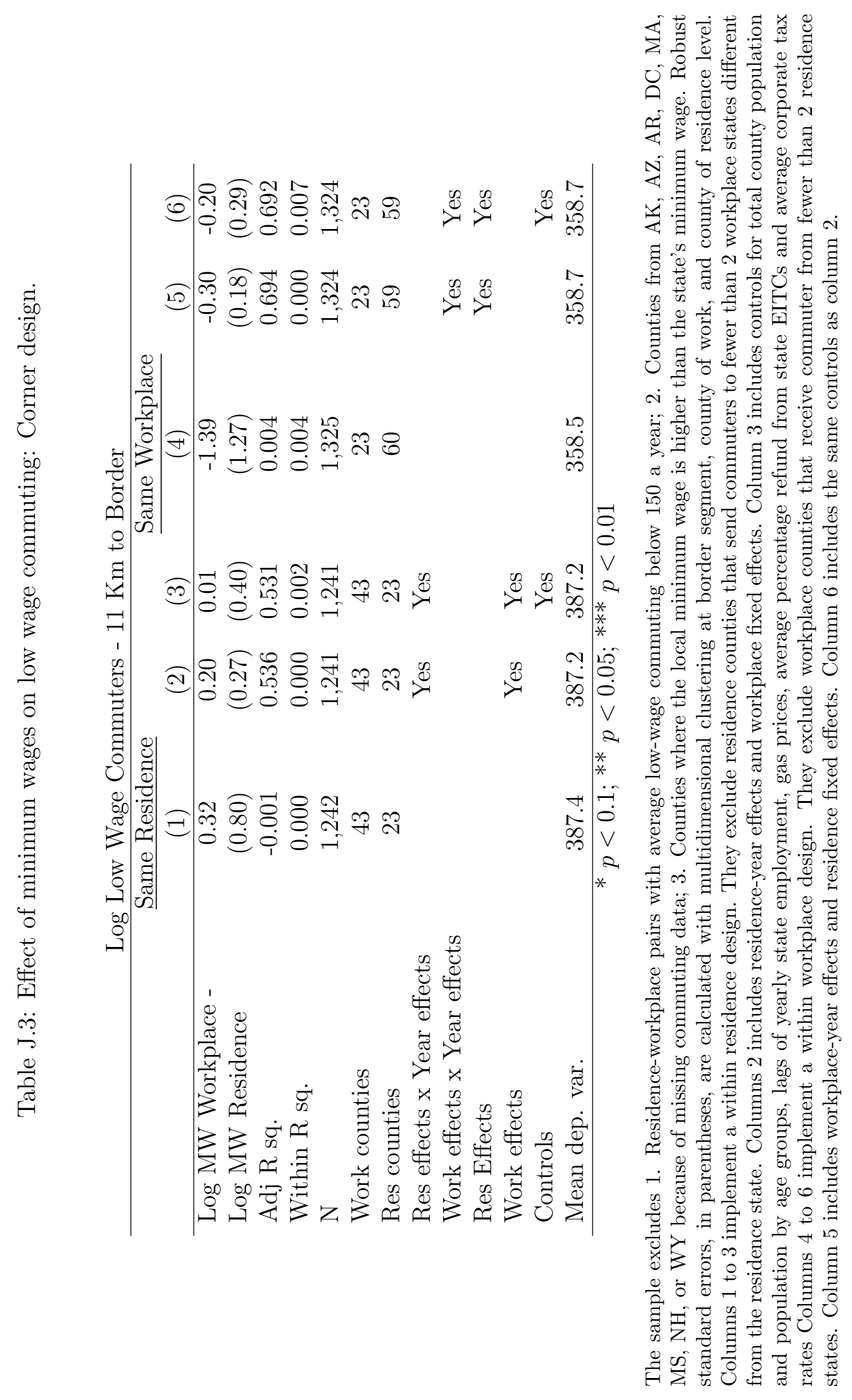


Table J.4: Effect of minimum wages on commuting: other wage categories.

Log Low Wage Commuters - $11 \mathrm{Km}$ to Border

\begin{tabular}{|c|c|c|c|c|c|c|}
\hline & $\begin{array}{c}(1) \\
\text { Low wage } \\
\text { Panel }\end{array}$ & $\begin{array}{c}(2) \\
\text { Mid wage } \\
\text { Panel }\end{array}$ & $\begin{array}{c}(3) \\
\text { High wage } \\
\text { Panel }\end{array}$ & $\begin{array}{c}(4) \\
\text { Low wage } \\
\text { Within }\end{array}$ & $\begin{array}{c}5) \\
\text { Mid wage } \\
\text { Within }\end{array}$ & $\begin{array}{c}(6) \\
\text { High wage } \\
\text { Within }\end{array}$ \\
\hline Log MW Residence & $\begin{array}{l}-0.00 \\
(0.12)\end{array}$ & $\begin{array}{c}-0.11 \\
(0.10)\end{array}$ & $\begin{array}{c}-0.24^{* *} \\
(0.10)\end{array}$ & & & \\
\hline Log MW Workplace & $\begin{array}{c}-0.25^{* *} \\
(0.10)\end{array}$ & $\begin{array}{l}-0.08 \\
(0.12)\end{array}$ & $\begin{array}{l}-0.05 \\
(0.11)\end{array}$ & & & \\
\hline Log MW Difference & & & & $\begin{array}{c}-0.26^{* * *} \\
(0.09)\end{array}$ & $\begin{array}{l}-0.08 \\
(0.11)\end{array}$ & $\begin{array}{l}-0.02 \\
(0.10)\end{array}$ \\
\hline Adj R sq. & 0.976 & 0.982 & 0.986 & 0.303 & 0.216 & 0.334 \\
\hline $\mathrm{N}$ & 7,603 & 7,555 & 7,537 & 12,136 & 12,172 & 12,118 \\
\hline Work counties & 259 & 255 & 254 & 344 & 345 & 341 \\
\hline Res counties & 290 & 288 & 285 & 288 & 291 & 288 \\
\hline Work effects & & & & Yes & Yes & Yes \\
\hline Work, res effects & Yes & Yes & Yes & & & \\
\hline Res effects x Year effects & & & & Yes & Yes & Yes \\
\hline Controls & Yes & Yes & Yes & Yes & Yes & Yes \\
\hline Year effects & Yes & Yes & Yes & & & \\
\hline Work, res trends & Yes & Yes & Yes & & & \\
\hline Mean dep. var. & 395.5 & 693.9 & 1030.3 & 2273.6 & 3858.5 & 3916.4 \\
\hline
\end{tabular}

The sample excludes 1 . Residence-workplace pairs with average low-wage commuting below 150 a year; 2 . Counties from AK, AZ, AR, DC, MA, MS, NH, or WY because of missing commuting data; 3. Counties where the local minimum wage is higher than the state's minimum wage. Robust standard errors, in parentheses, are calculated with multidimensional clustering at border segment, county of work, and county of residence level. Columns 1 to 3 implement a panel design. They include fixed effects at the workplace-residence county pair level, residence and pair-specific linear time trends. Columns 3 to 6 implement a within residence design. They include residence-year effects and workplace effects. All columns include controls for county population and population by age groups, lags of yearly state employment, gas prices, average percentage refund from state EITCs and average corporate tax rates. 
Figure J.1: Elasticities at different distances from the border

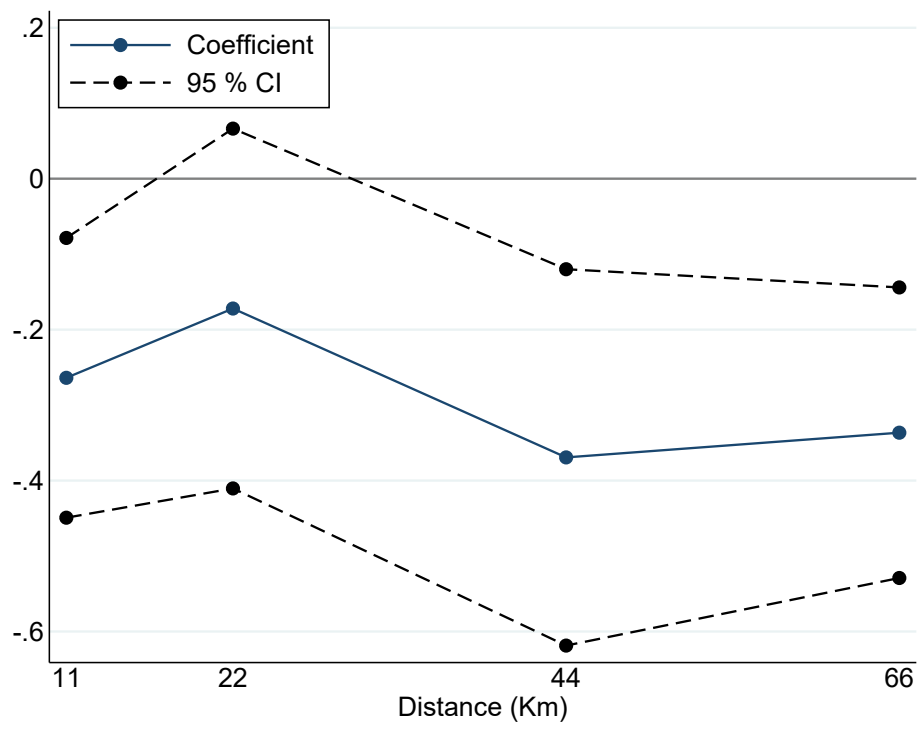

Source: Author's calculations. This graph depicts coefficients on the log minimum wage at the workplace variable from the within design of equation (3). The regressions are analogous to that of column 3 of table 2, and include controls for total county population and population by age groups, lags of yearly state employment, gas prices, average percentage refund from state EITCs and average corporate tax rates.

Figure J.2

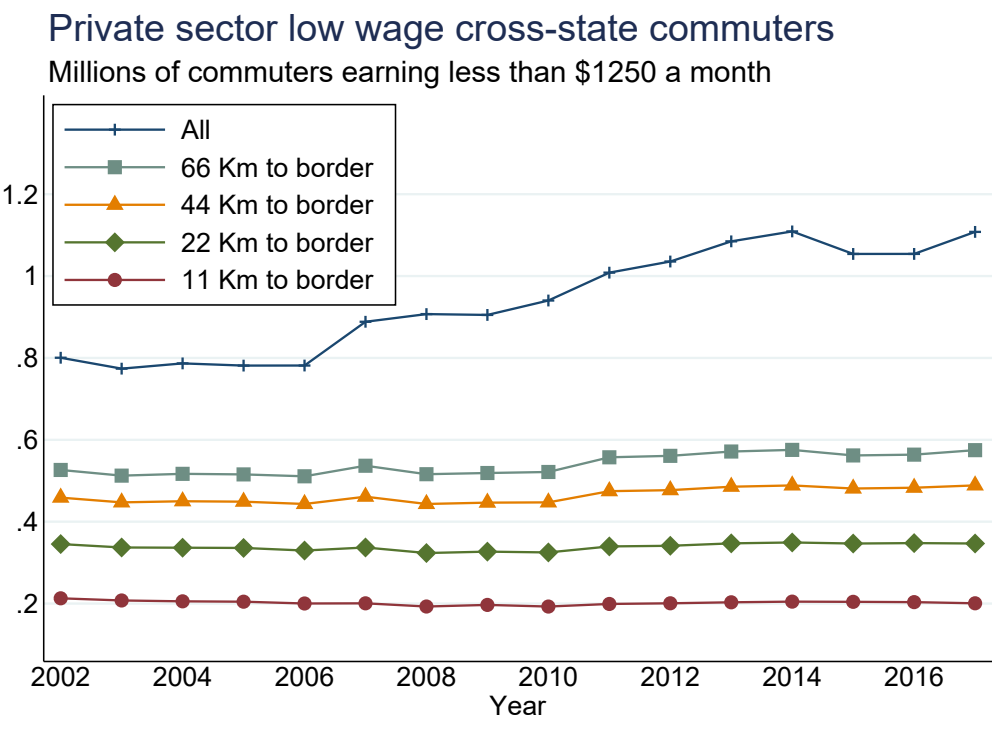

Source: LODES 7.1. Cross state commuters are those who live in one state and work in another state. 
Figure J.3

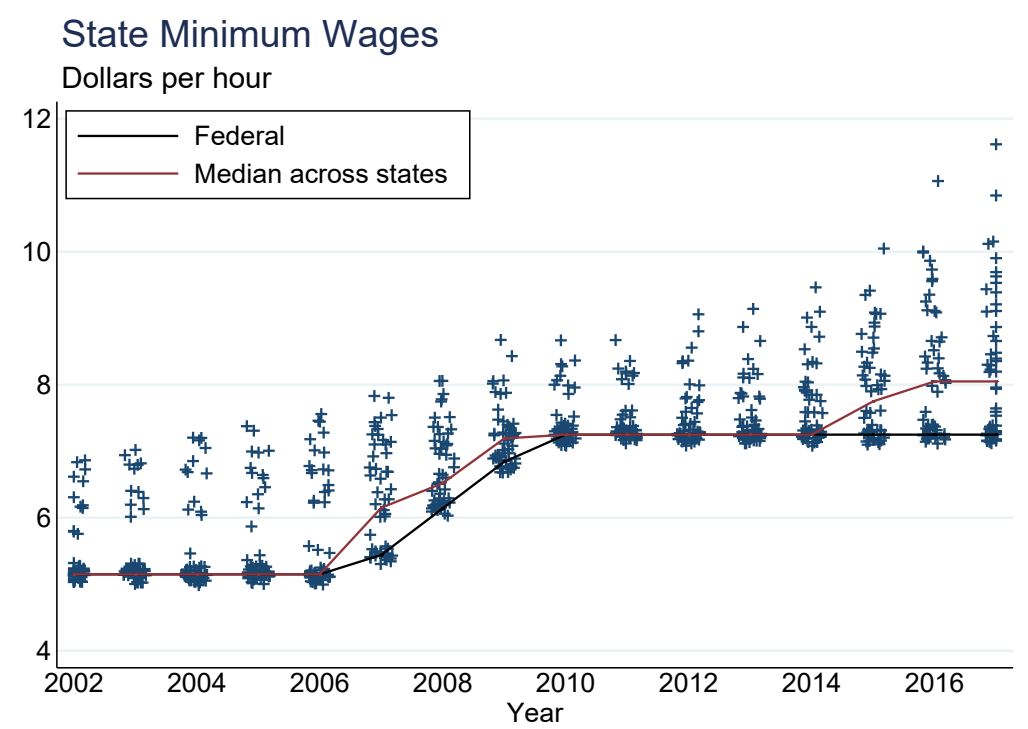

Source: Author's calculations based on data from Neumark et al. (2014) and Clemens et al. (2018). Points have been jittered to show that many states have the same minimum wage.

Figure J.4: Included counties by yearly sent cross border commuting

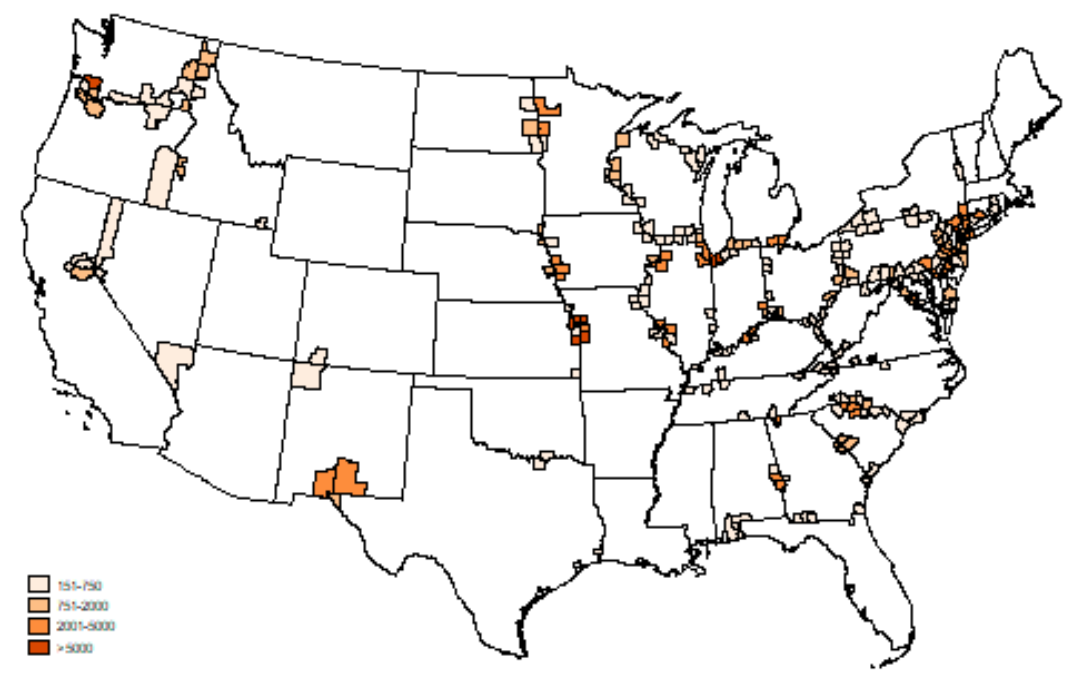

Source: Author's calculations from LODES. Highlighted counties are included in the reduced form analysis sample. Colors represent the amount of commuters they send across the border every year, i.e. the number of workers who live in the county and work in another county across the border. 
Figure J.5: Included counties by yearly received cross border commuting

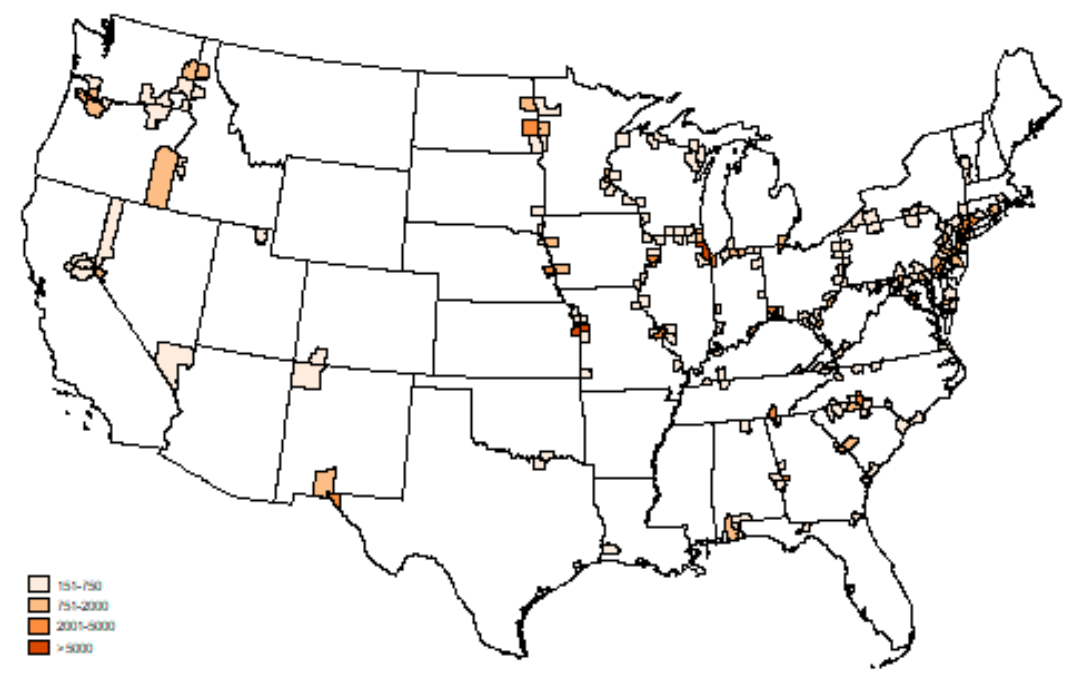

Source: Author's calculations from LODES. Highlighted counties are included in the reduced form analysis sample. Colors represent the amount of commuters they receive from across the border every year, i.e. the number of workers who work in the county and live in another county across the border.

Figure J.6: Low wage commuting and employment, 2017.

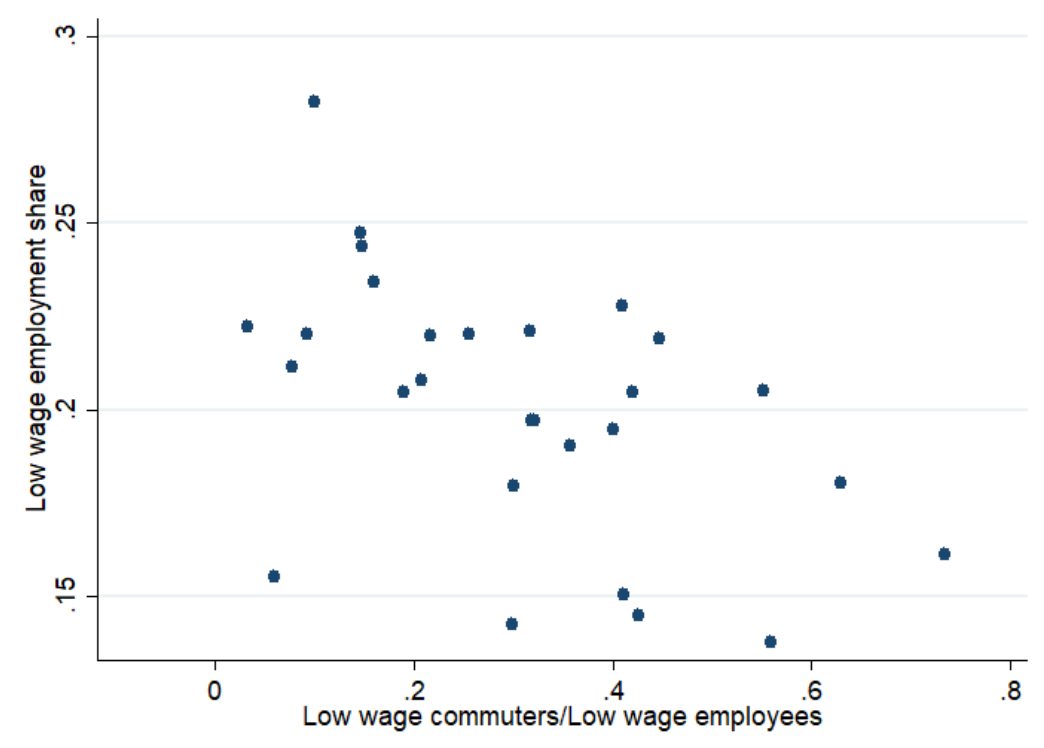

Source: Author's calculations based on LODES. Counties that include cities with approved proposals for minimum wage increases. 
Figure J.7: Low wage employment and minimum wages. 2017.

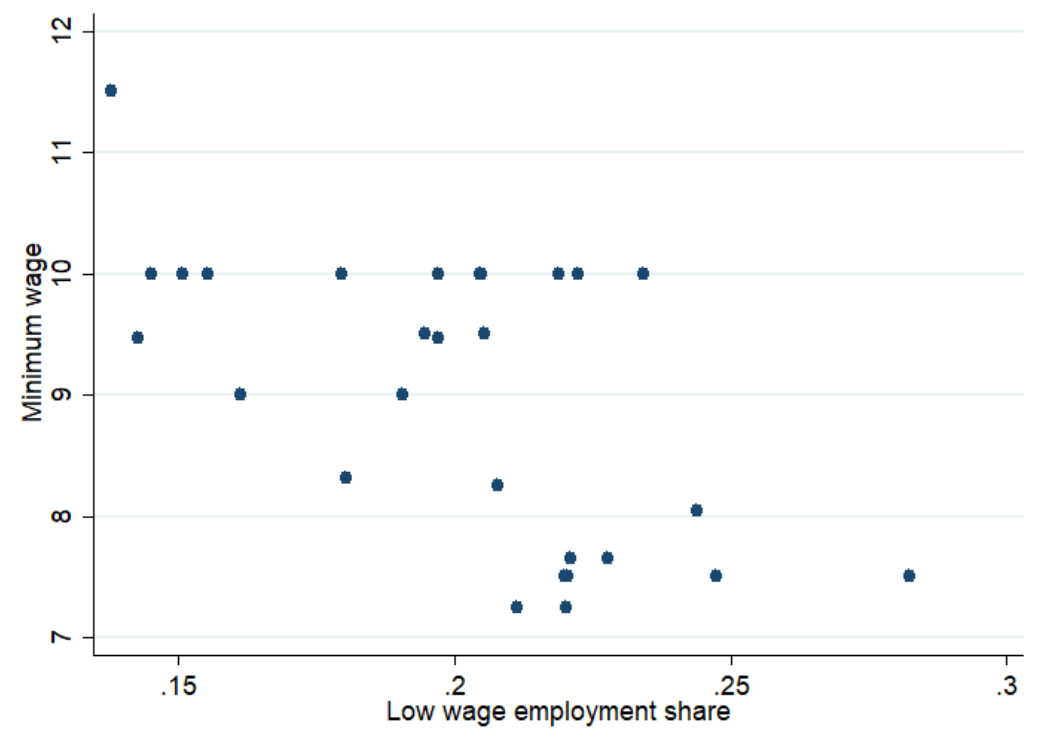

Source: Author's calculations based on LODES. Counties that include cities with approved proposals for minimum wage increases.

Figure J.8: Commuting zones for cities with proposed minimum wage increases

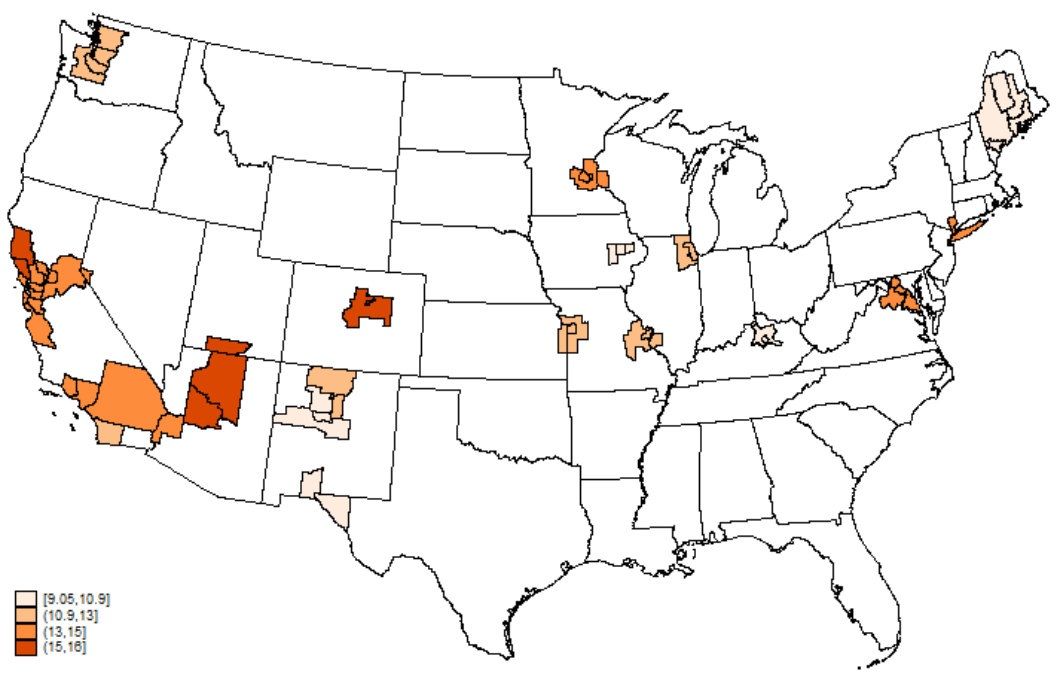

Source: Author's calculations based on National Employment Law Project (2016) and Dube and Lindner (2021). The colors list the maximum minimum wage proposed. Target years for minimum wage increases differ across commuting zones. Thick borders denote commuting zones. Thin borders denote counties. 
Figure J.9: Estimates of $\epsilon$ for border cities.

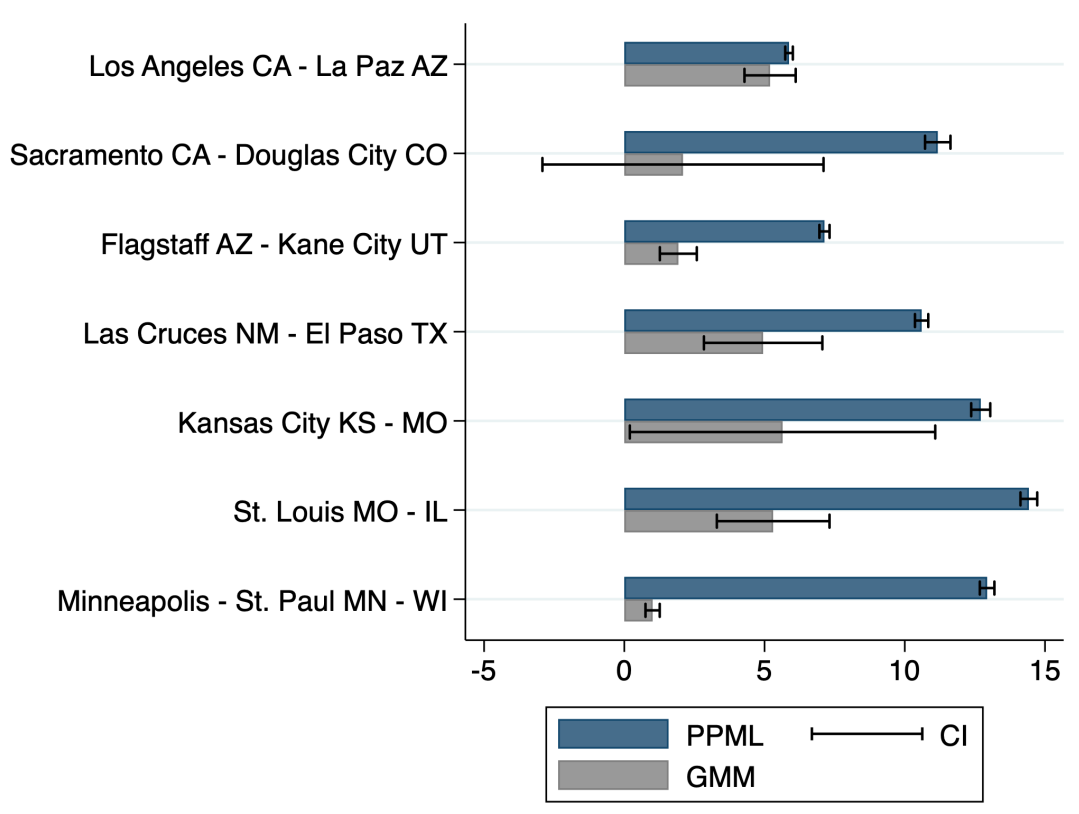

Source: Author's calculations. Observations are 7 commuting zones on state borders with cities considering minimum wage increases. The estimates are obtained from commuting data from LODES described in section 2, and additional data described in Appendix A.1. "PPML" values are maximum likelihood estimates from equation (37). "GMM" values are generalized method of moments estimates from equation (40). Sample goes from 2005 to 2017. 
Figure J.10: Elasticities of low wage searchers $O_{M i}^{\ell}$ and low wage employment probability $\rho_{i}^{\ell}$

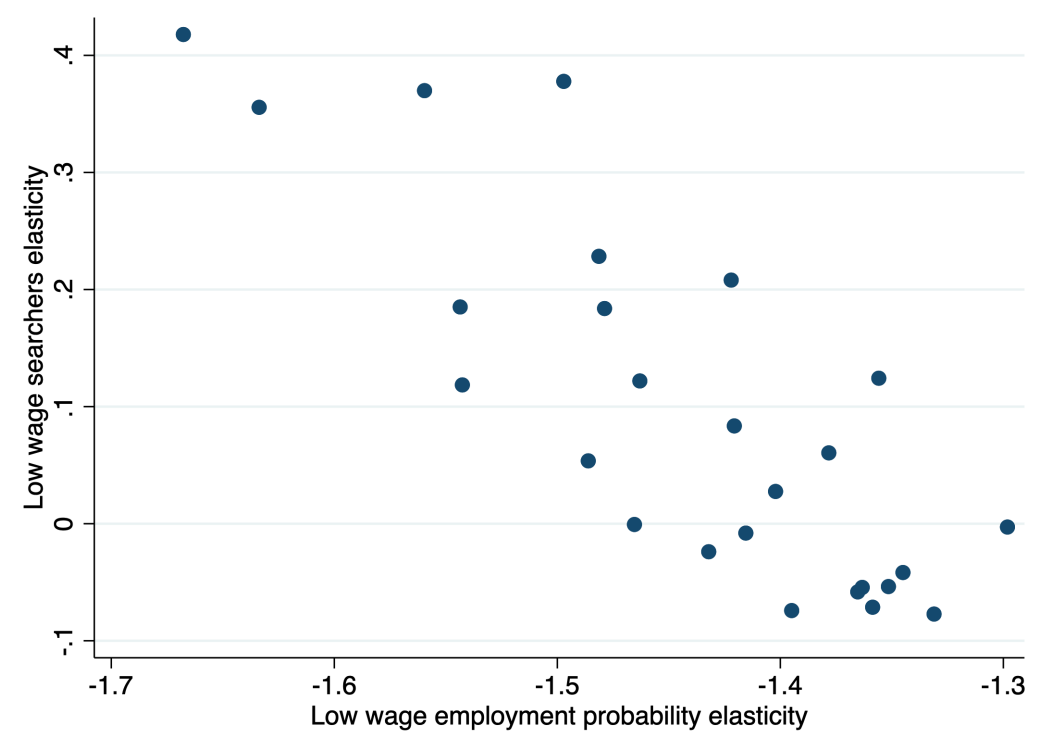

Source: Author's calculations. Observations are 26 counties with cities considering minimum wage increases. Values are elasticities of low wage employment probabilities $\rho^{\ell}$ and low wage searchers $O_{M i}^{\ell}$ to an increase in the minimum wage, calculated from comparing an initial equilibrium to a model counterfactual with a minimum wage increase. In the counterfactuals, minimum wages were increased by $5 \%$.

Figure J.11: Elasticity of mid and high wage employment probabilities $\rho_{i}^{m}$ and $\rho_{i}^{h}$
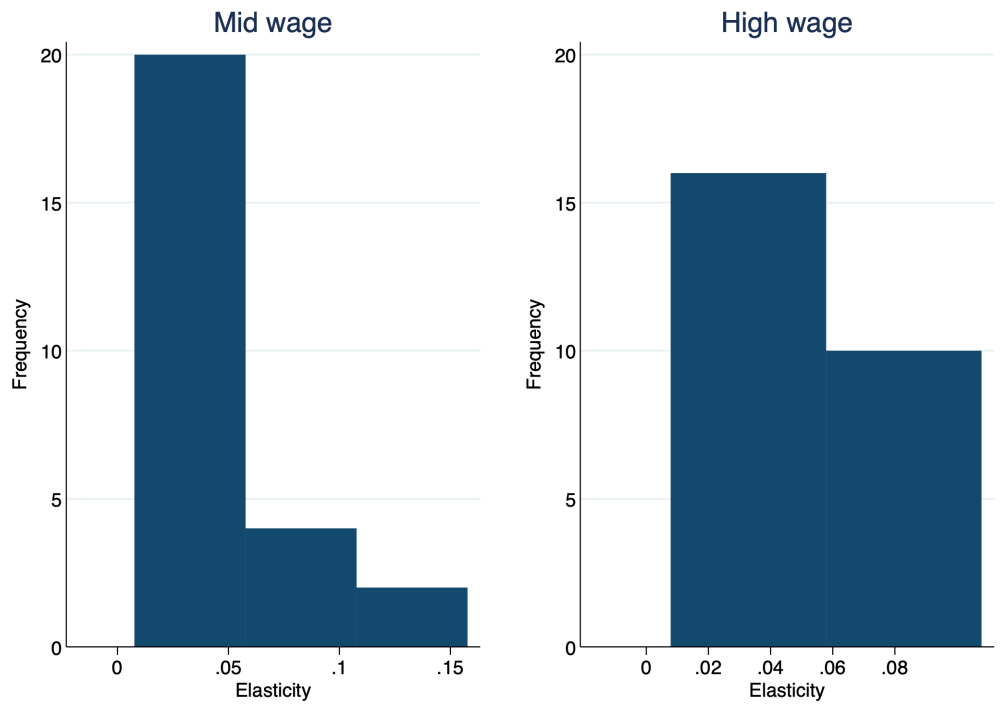

Source: Author's calculations. Observations are 26 counties with cities considering minimum wage increases. Values are elasticities of mid and high wage employment probability $\rho_{i}^{m}$ and $\rho_{i}^{h}$ to an increase in the minimum wage, calculated from comparing an initial equilibrium to a model counterfactual with a minimum wage increase. In the counterfactuals, minimum wages were increased by $5 \%$. 
Table J.5: Average changes in expected utility from a $1 \%$ minimum wage change in counterfactuals

\begin{tabular}{lccc}
\hline \% change in Utility & Search & Employment & Unemployment \\
\hline \multicolumn{1}{c}{ Average across wage groups, weighted by number of residents } \\
Mean & 0.01 & 0.07 & -0.01 \\
Median & 0.02 & 0.04 & -0.01 \\
Range & $(-0.41,0.05)$ & $(-0.01,0.21)$ & $(-0.02,0.02)$ \\
\hline \multicolumn{4}{c}{ Low wage group } \\
Mean & 0.07 & 0.33 & -0.01 \\
Median & 0.04 & 0.21 & -0.01 \\
Range & $(-0.01,0.23)$ & $(0.01,0.97)$ & $(-0.02,0.01)$ \\
\hline & Mid wage group & \\
Mean & -0.08 & -0.01 & -0.01 \\
Median & 0.01 & -0.01 & -0.01 \\
Range & $(-2.37,0.05)$ & $(-0.02,0.02)$ & $(-0.02,0.02)$ \\
\hline & High wage group & \\
Mean & 0.05 & -0.01 & -0.01 \\
Median & 0.01 & -0.01 & -0.01 \\
Range & $(0.00,1.00)$ & $(-0.03,0.01)$ & $(-0.02,0.02)$ \\
\hline
\end{tabular}

Source: Author's calculations. Observations are commuting zones for counties considering minimum wage increases. The average across wage groups, the averages are weighted by the number of residents of each wage group. The expected utility of search comes from equation (25), and the expected utilities of employment and unemployment come from equation (26). 
Table J.6: Average changes in expected utility from a $10 \%$ minimum wage change in counterfactuals

\begin{tabular}{|c|c|c|c|}
\hline$\%$ change in Utility & Search & Employment & Unemployment \\
\hline \multicolumn{4}{|c|}{ All skill levels (weighted) } \\
\hline Mean & 0.11 & 0.81 & -0.08 \\
\hline Median & 0.08 & 0.60 & -0.07 \\
\hline Range & $(-0.21,0.37)$ & $(0.01,2.12)$ & $(-0.20,0.01)$ \\
\hline \multicolumn{4}{|c|}{ Low wage group } \\
\hline Mean & 0.09 & 3.87 & -0.08 \\
\hline Median & 0.13 & 2.95 & -0.09 \\
\hline Range & $(-1.09,0.77)$ & $(0.04,9.85)$ & $(-0.20,0.01)$ \\
\hline \multicolumn{4}{|c|}{ Mid wage group } \\
\hline Mean & 0.04 & -0.07 & -0.07 \\
\hline Median & 0.08 & -0.06 & -0.06 \\
\hline Range & $(-2.16,0.48)$ & $(-0.19,0.01)$ & $(-0.22,0.02)$ \\
\hline \multicolumn{4}{|c|}{ High wage group } \\
\hline Mean & 0.17 & -0.08 & -0.07 \\
\hline Median & 0.13 & -0.08 & -0.07 \\
\hline Range & $(0.01,1.19)$ & $(-0.21,0.00)$ & $(-0.20,0.02)$ \\
\hline
\end{tabular}

Source: Author's calculations. Observations are commuting zones for counties considering minimum wage increases. The average across wage groups, the averages are weighted by the number of residents of each wage group. The expected utility of search comes from equation (25), and the expected utilities of employment and unemployment come from equation (26). 